\title{
Glacial-interglacial productivity in the Polar Frontal Zone, southwest Pacific Ocean
}

\author{
by \\ Melanie Anne Liston
}

\begin{abstract}
A thesis
submitted to Victoria University of Wellington

in partial fulfilment of the requirements for the degree of

Master of Science in Geology
\end{abstract}

School of Geography, Environment and Earth Sciences

Victoria University of Wellington 



\section{Abstract}

The Southern Ocean has a central role in regulating global climate change. Research has shown evidence of changes in biological productivity are coincident with increased iron deposition and rising atmospheric $\mathrm{CO}_{2}$ concentrations. The current data suggests these processes occur homogenously throughout the Southern Ocean, where research largely focuses on changes in biogenic silica as a proxy for upwelling and enhanced opal production. The role of calcium carbonate productivity, however, is rarely discussed, or is referred to in terms of preservation changes associated with shoaling and deepening of the lysocline. This assumption ignores potentially important effects of carbonate productivity and inter-basin complexities on ocean-atmosphere $\mathrm{CO}_{2}$ exchange.

Two gravity cores (TAN1302-96 and TAN1302-97) collected from the southwest Pacific Polar Frontal Zone (PFZ) provide more insight into productivity changes and inter-basin differences across glacial-interglacial timescales. Detailed geochemical analysis, together with $\delta^{18} \mathrm{O}$ stratigraphy and ${ }^{14} \mathrm{C}$ chronology, were used to reconstruct glacial-interglacial changes in terrigenous input and paleoproductivity in the PFZ. Sedimentological and biological analyses provide additional information to support the geochemical observations.

This study highlights two distinct productivity modes (i.e. biogenic silica and calcium carbonate) that vary over glacial-interglacial timescales and with respect to the position of the Polar Front (PF). Key findings include; 1) a systematic series of key biological changes are repeated during glacial Terminations I (TI) and II (TII), the order of which depends on the position relative to the PF; 2) calcium carbonate productivity dominates the early part of the Termination north of the PF, whereas the production of biogenic silica dominates the early Termination south of the PF; 3) following TI and TII, calcium carbonate leads productivity in the early interglacials (i.e. MIS 5e and the Holocene), followed by the production of biogenic silica during the late interglacials, concurrent with declining atmospheric $\mathrm{CO}_{2}$ concentrations. 


\section{Acknowledgments}

I would like to first give thanks to my incredible supervisors Helen Bostock and Gavin Dunbar. The complexity of this work seriously tested me at times, and I doubt I could have completed it without your support. I cannot thank you both enough for your availability and your invaluable insight. Helen, thank you for giving me the opportunity to work on these cores. You have been nothing short of amazing, and I am so grateful for your reassurance and positivity when I needed it the most. And Gavin, thank you for helping me with the XRF and for your enthusiasm for this project. It makes a world of difference, and I am extremely grateful to have worked on something I was very interested in, and to have worked with you both. Thank you for a great year.

A very big thank you must go to Margaret Harper. I am so appreciative of your time spent helping me in the lab and introducing me to the art of identifying diatoms! You were always enthusiastic, and available to help me, and I am so grateful for your ideas and input on my work. I could not have done the diatom work without you.

A special thank you to the staff at NIWA, especially Lisa Northcote, Alan Orpin, Scott Nodder, and Andrew Kingston. You were all so welcoming, and always offered your help with anything, be that lab work, writing, or ideas. Your advice was always hugely appreciated, and I miss working in such a positive, fun environment.

Another special thank you to David Flynn at VUW for introducing me to the wonders of Scanning Electron Microscopy. This was definitely a highlight of my lab work, and I'm very grateful for your time spent teaching me and answering my many questions!

Thank you to my friends for all the little celebrations along the way. Thank you to my office mates, Liesl, Todd, Alan, Lewis, Brent and Jo. I wouldn't have stayed sane without all the laughs and I will miss the great geology chat.

To my chummy. You never failed to make me feel better in times of need and always believed in me when I didn't. Your patience and unwavering support meant the absolute world to me. I know I couldn't have done this without you. Thank you for everything.

Thank you to my family. Ben, Rory, Alasdair, Oliver, Emma, Sam and Vanessa. I hope you pursue something that makes you happy. To Mum and Dad, I will never be able to thank you enough for everything you have done for me. I'm so proud to be your daughter, and I hope this work makes you proud. 


\section{Table of Contents}

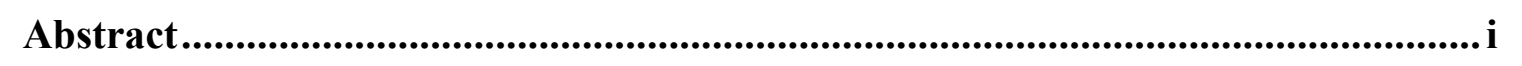

Acknowledgments .............................................................................................ii

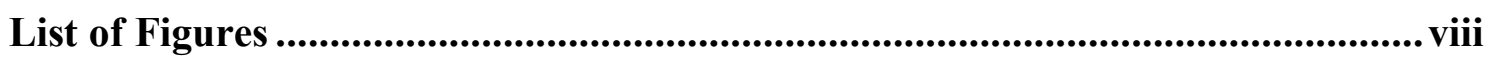

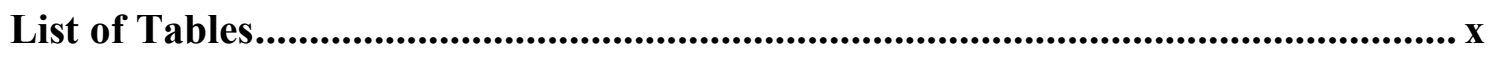

List of Abbreviations ............................................................................................

Chapter 1 Introduction...................................................................................1

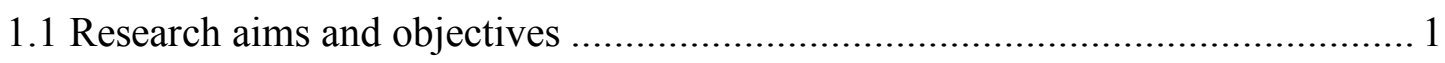

Chapter 2 The Southern Ocean and global climate............................................... 3

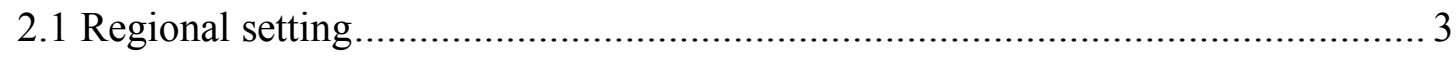

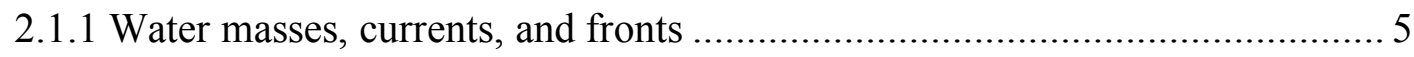

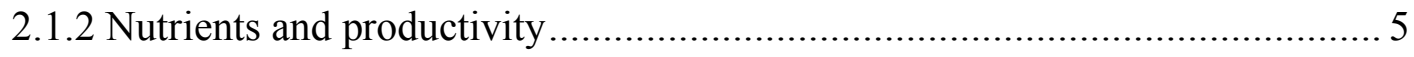

2.1.3 Bathymetry and surrounding geology ............................................ 7

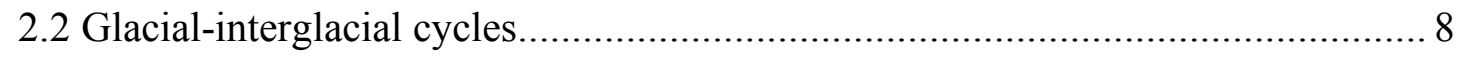

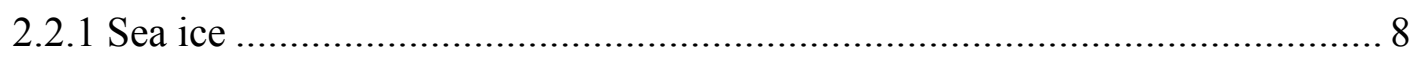

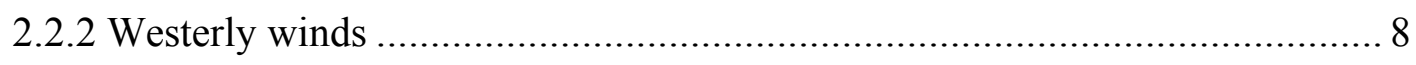

2.2.3 The biological pump and the role of iron .......................................... 9

Chapter 3 Ecology........................................................................................................... 11

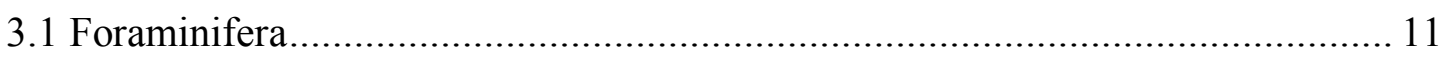

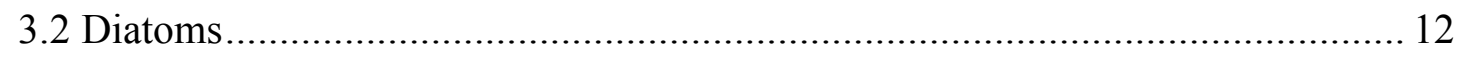

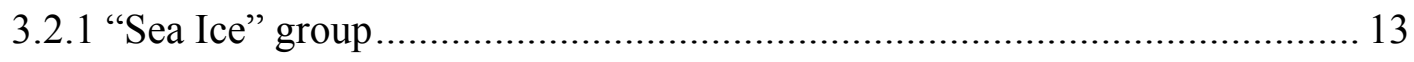

3.2.2 "Polar Open Ocean and Seasonal Ice Tolerant" group .............................. 14

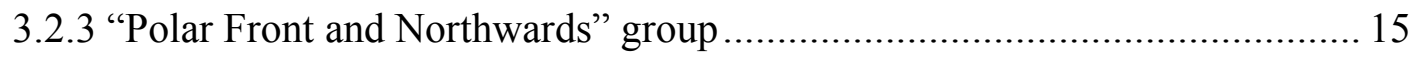

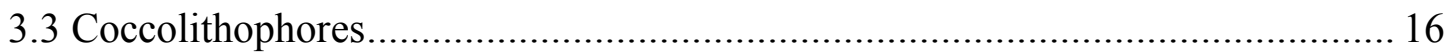




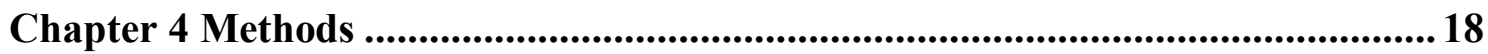

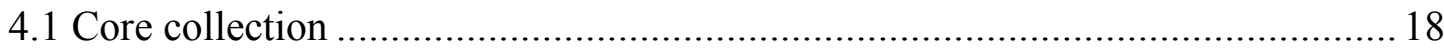

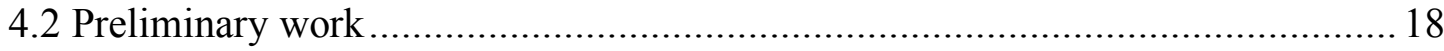

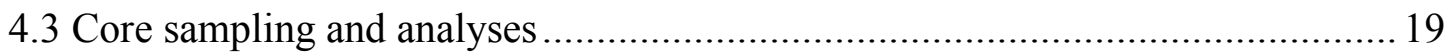

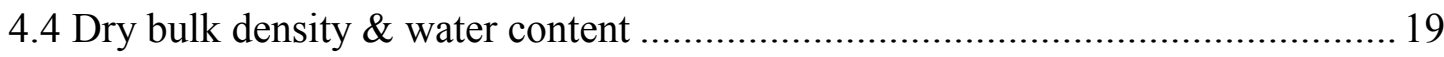

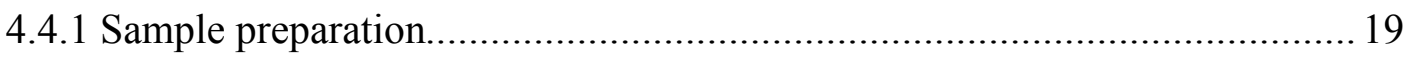

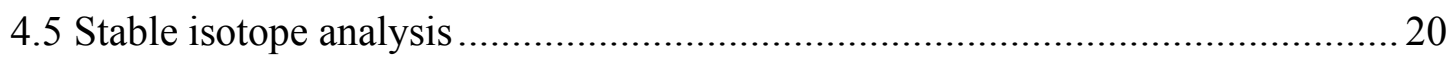

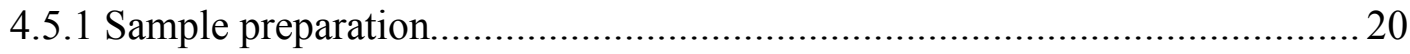

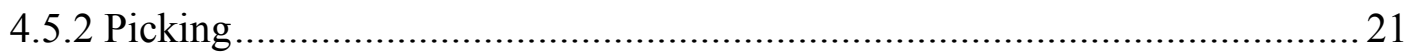

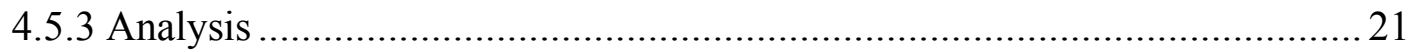

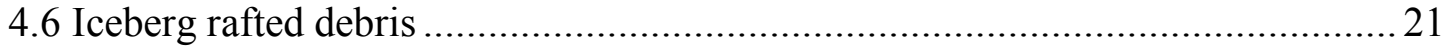

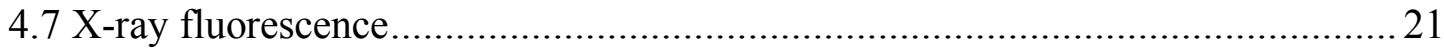

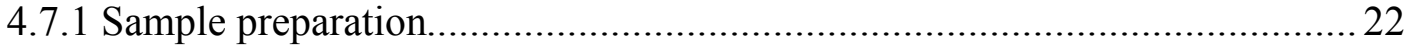

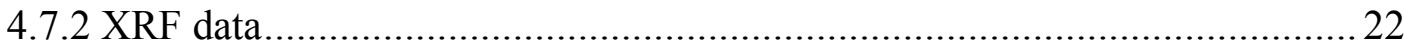

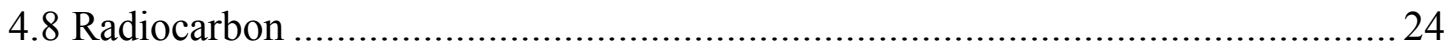

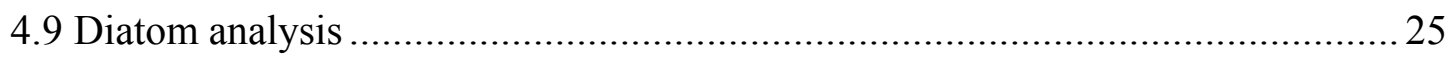

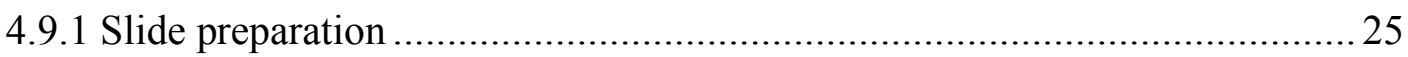

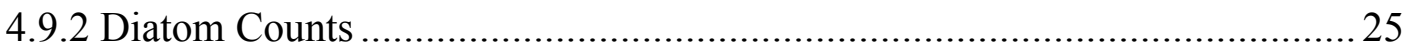

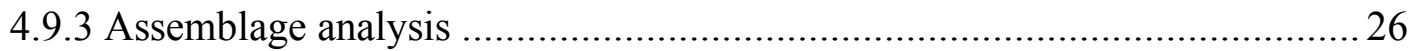

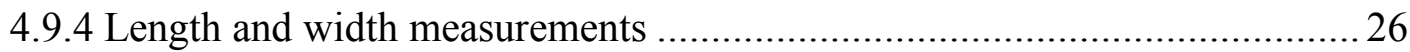

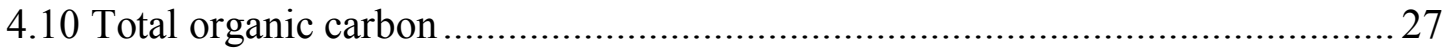

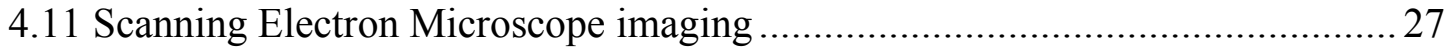

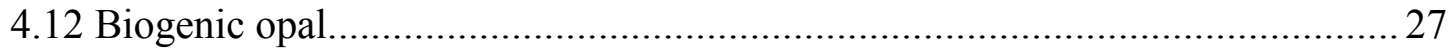

Results ......................................................................................................................... 29

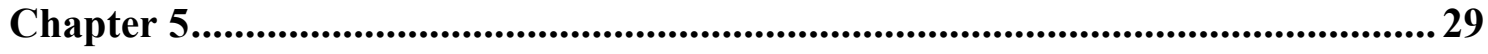

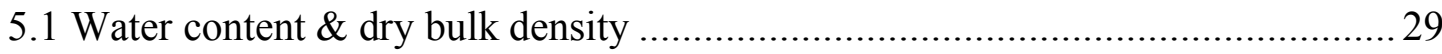

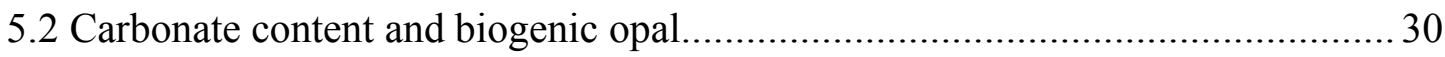

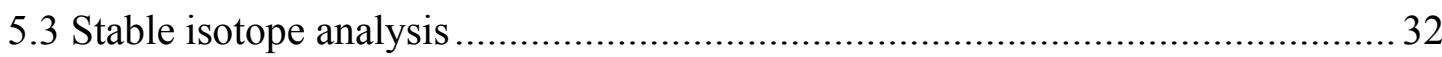




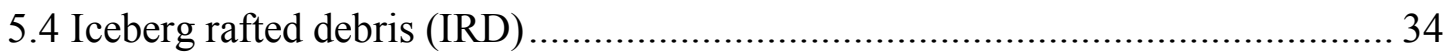

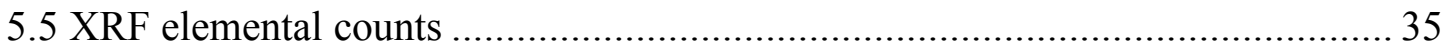

5.5.1 Correlations and principal component analysis .................................... 38

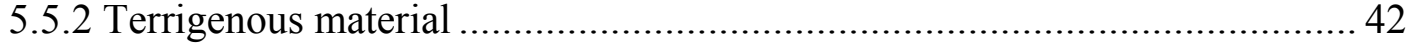

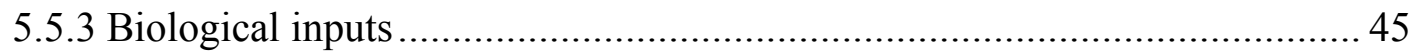

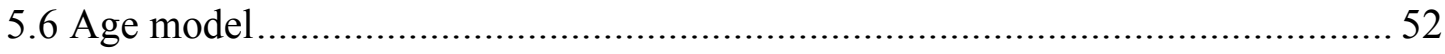

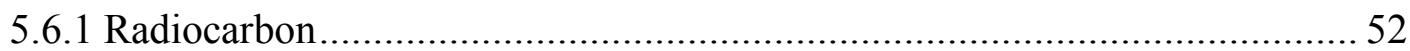

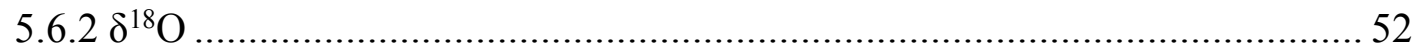

5.7 Linear Sedimentation Rates and Mass Accumulation Rates .............................. 54

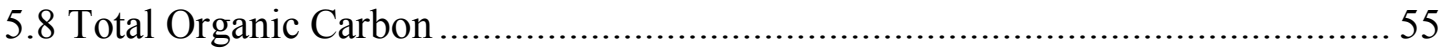

Chapter 6 Discussion ..................................................................................................... 57

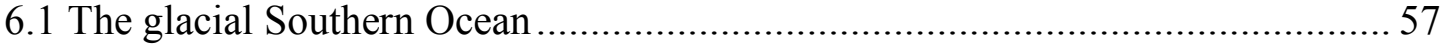

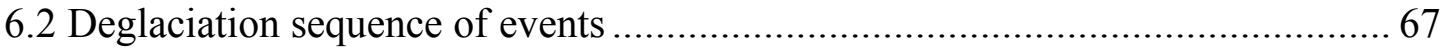

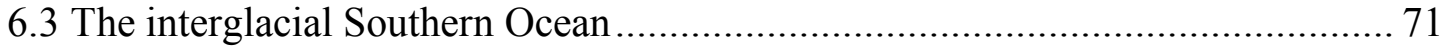

Chapter 7 Conclusions and future work............................................................ 77

Chapter 8 References........................................................................................................ 79

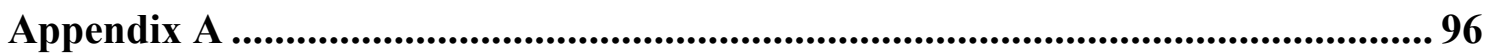

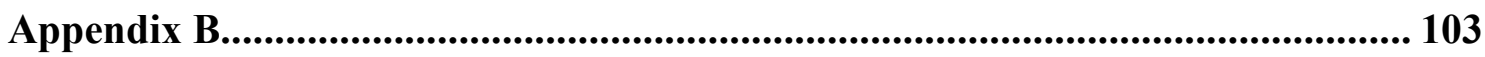

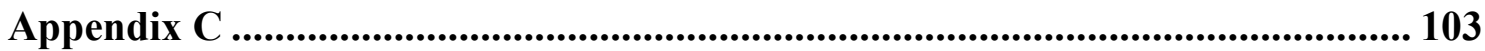




\section{List of Figures}

Figure 2.1. Core locations of TAN1302-96 and TAN1302-97.................................. 4

Figure 2.2. Annual sea surface silicate and nitrate conc from Bostock et al. (2013)......6

Figure 2.3. Latitudinal variability of $\mathrm{CaCO}_{3}$ and biogenic silica from Honjo (2004)..... 7

Figure 2.4. Schematic illustration of the biological pump. From Chisholm (2000)...... 10

Figure 3.1. SEM images of $N$. pachyderma. Images from Kohfeld et al. (1996)........... 12

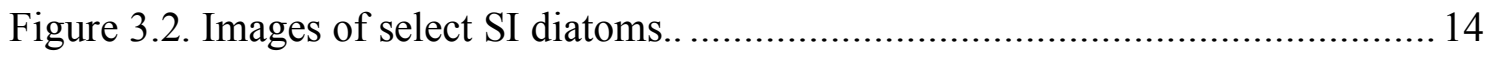

Figure 3.3 Images of select POOSIT group diatoms.......................................... 15

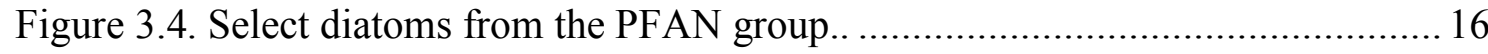

Figure 3.5 Top: coccolith structure of G. oceanica (left) and E. huxleyi (right)........... 17

Figure 4.1. Photographs showing A) the Vanta XRF ............................................... 24

Figure 4.2. Photograph of $F$. kerguelensis individual taken from TAN1302-97 ........... 26

Figure 5.1. Water content (\%) and DBD $\left(\mathrm{g} / \mathrm{cm}^{3}\right)$ along TAN1302-96....................... 29

Figure 5.2. Water content (\%) and DBD $\left(\mathrm{g} / \mathrm{cm}^{3}\right)$ along TAN1302-97 ......................... 30

Figure 5.3. $\mathrm{CaCO}_{3}$ content (weight \%) in blue in TAN1302-96. .............................. 31

Figure 5.4. Biogenic opal (\%) in orange and water content $(\%)$ in grey -96 ................ 31

Figure 5.5. $\mathrm{CaCO}_{3}$ content (weight \%) in blue and opal content (\%) in orange $-96 \ldots . .32$

Figure 5.6. TAN1302-96 isotopes: $\delta^{18} \mathrm{O}(\%)$ in blue and $\delta^{13} \mathrm{C}(\%)$ in orange $-97 \ldots \ldots . .33$

Figure 5.7. TAN1302-97 isotopes: $\delta^{18} \mathrm{O}(\%)$ in blue and $\delta^{13} \mathrm{C}(\%)$ in orange............. 33

Figure 5.8. IRD content in TAN1302-96 at $10 \mathrm{~cm}$ intervals (grains/dry gram)............ 34

Figure 5.9. IRD content in TAN1302-97 at $10 \mathrm{~cm}$ intervals (grains/dry gram)............. 34

Figure 5.10. Cross-correlation between opal and Si concentrations (ppm).................. 36

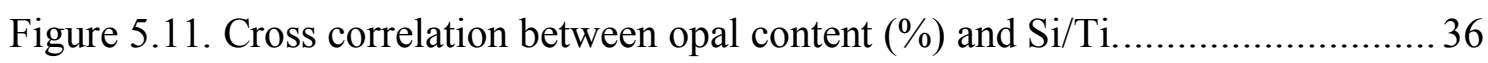

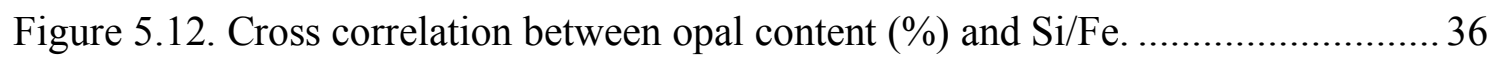

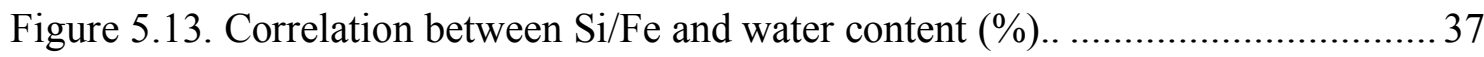

Figure 5.14. PCA with k-means clustering... TAN1302-96 .................................... 38

Figure 5.15. PCA with k-means clustering... TAN1302-97 ..................................... 39

Figure 5.16. Element profiles (ppm) indicative of terrigenous sedimentation $-96 \ldots \ldots . . .43$

Figure 5.17. Element profiles ( $\mathrm{ppm})$ indicative of terrigenous sedimentation $-97 \ldots \ldots . . .44$

Figure 5.18. Elemental concentrations (ppm) and ratios along TAN1302-96 ............. 47

Figure 5.19. Elemental concentrations (ppm) and ratios along TAN1302-97............. 48 


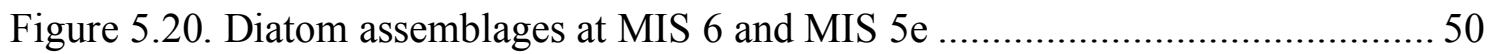

Figure 5.21. SEM images of coccolithophores. ....................................................... 51

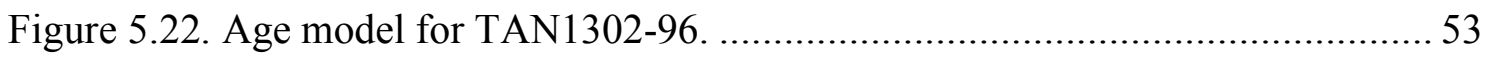

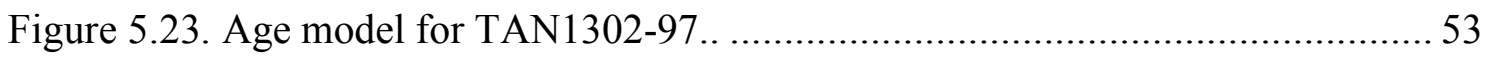

Figure 5.24. $\mathrm{CaCO}_{3} \%$ mass accumulation rates and linear sedimentation rates $-96 \ldots . . .55$

Figure 5.25. $\mathrm{CaCO}_{3} \%$ mass accumulation rates and linear sedimentation rates $-97 \ldots . . .55$

Figure 5.26. TOC (\%) in TAN1302-96 at $10 \mathrm{~cm}$ intervals...................................... 56

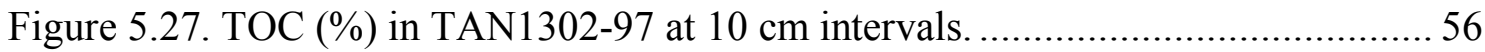

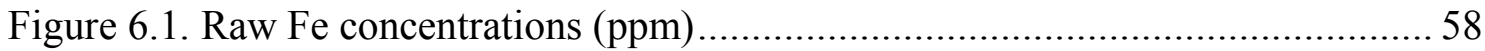

Figure 6.2. Model of dust MAR during the LGM. From Lamy et al. (2014)................ 58

Figure 6.3. Major sources of iron to the Southern Ocean (Boyd and Ellwood, 2010)... 59

Figure 6.4. Fe/Ti records in TAN1302-96 (orange) and TAN1302-97 (red).). ............ 61

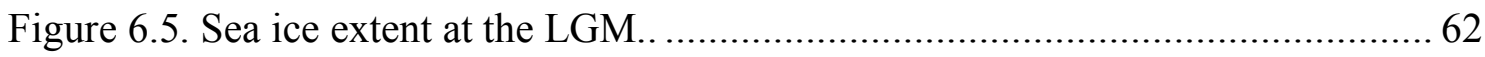

Figure 6.6. Opal productivity of PFZ cores compared to biogenic opal...................... 65

Figure 6.8. Schematic diagram of the glacial Southern Ocean setting......................... 66

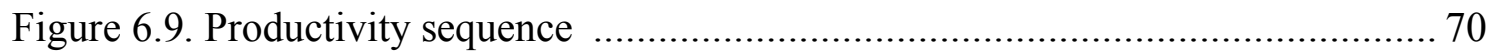

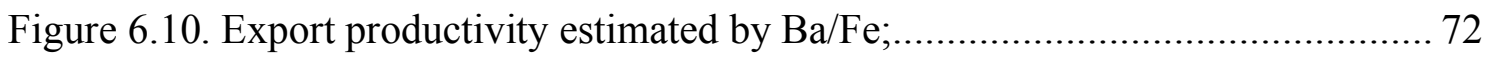

Figure 6.11. Composite productivity record in the PFZ cores.................................. 76 


\section{List of Tables}

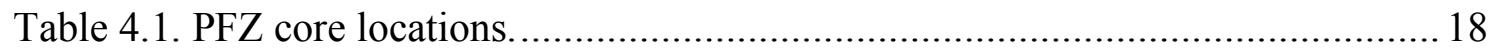

Table 4.2. Weighted standard mixtures made from diatomite spiked with corundum... 23

Table 5.1. Correlation matrix for elemental counts in TAN1302-96........................... 40

Table 5.2. Correlation matrix for elemental counts in TAN1302-97. ........................... 41

Table 5.3. Radiocarbon dates run for TAN1302-96.................................................. 52

Table 5.4. Radiocarbon dates run for TAN1302-97................................................. 52

Table 5.5. Summary of linear sedimentation rates in TAN1302-96 and TAN1302-97. 54 


\section{List of Abbreviations}

ACC - Antarctic Circumpolar Current

AZ - Antarctic Zone

IRD - Iceberg Rafted Debris

LGM - Last Glacial Maximum

LIG - Last Interglacial

MIS - Marine Isotope Stage

PF - Polar Front

PFAN - Polar Front and Northwards

PFZ - Polar Frontal Zone

POOSIT - Polar Open Ocean and Seasonal Ice Tolerant

SAF - Subantarctic Front

SAZ - Subantarctic Zone

SI - Sea Ice

SO - Southern Ocean

SST - Sea Surface Temperature

STF - Subtropical Front

TI - Termination I

TII - Termination II

WSI - Winter Sea Ice 



\section{Chapter 1 Introduction}

Antarctica and the surrounding Southern Ocean (SO) are in a unique position with respect to the global climate system. The thermal gradient between the tropics and Antarctica influences global atmospheric circulation, locally expressed in the Southern Hemisphere as a belt of westerly winds that circle above the SO. The position and strength of these winds regulate upwelling and influence temperature, salinity and nutrient changes on the SO that affect biological productivity. Oceanic productivity has been argued to be an important component in regulating ocean-atmosphere carbon exchange (Sigman and Boyle, 2000; Jaccard et al., 2013; Gottschalk et al., 2016). Despite this, most of the compelling evidence for this relationship has focused on changes in biogenic opal, particularly in the South Atlantic sector of the SO. The TAN1302-96 and -97 cores collected from the southwest Pacific provide a new opportunity to examine the relationship between productivity and atmospheric $\mathrm{CO}_{2}$ in the Pacific sector of the SO. Processes related to oceanic-climate dynamics are often inferred to occur synchronously across all sectors of the SO. Although this simplifies the bigger picture ideas surrounding global ocean-climate dynamics, it overlooks potentially important differences between regions of the SO.

\subsection{Research aims and objectives}

In this study two marine sediment cores from the Polar Frontal Zone (PFZ) were analysed using a combination of sedimentology, paleontology and geochemical methods in order to achieve the following aims:

- To investigate productivity changes over glacial-interglacial timescales in the PFZ, southwest Pacific sector of the SO.

- To reconstruct deglaciation sequences to assess the role of biological productivity, and identify the potential roles of ocean circulation, climate, and iron flux in this region.

- To investigate how the southwest Pacific region of the SO differs from the South Atlantic, with respect to productivity, ocean circulation, and climate-related processes. 
This thesis uses the integration of more traditional geochemical and sedimentological methods, i.e. measuring grainsize, calcium carbonate $\left(\mathrm{CaCO}_{3}\right)$ and opal $\%$, and proxies derived from X-ray Florescence (XRF) to investigate biological and physical changes in the PFZ over glacial-interglacial cycles. Diatom assemblage analyses provide additional insight into key oceanographic and ecological shifts observed across glacial terminations. The data obtained through this research is combined, evaluated and compared with patterns found in other marine records throughout the wider SO, to contribute to the understanding of how the dynamic PFZ region may influence global climate. 


\section{Chapter 2 The Southern Ocean and global climate}

The SO extends from the Antarctic coast $\left(\sim 70^{\circ} \mathrm{S}\right)$ to the Subtropical Front (STF, $\sim 40^{\circ} \mathrm{S}$ ) (Bostock et al., 2013). This region plays an integral part in oceanic connectivity; transporting and redistributing heat, carbon, and nutrients into all the major oceanic basins (Rintoul et al., 2010). In the last two decades, considerable advances have been made in understanding the role of the SO in regards to global climate, although research has increasingly highlighted the complexities in biological, chemical and physical processes amongst the ocean basins (Anderson et al., 2009; Denton et al., 2010; Sigman et al., 2010; Gottschalk et al., 2016). Multiple studies have suggested the SO may play a critical part in regulating glacial-interglacial climate cycles through these key processes (Jaccard et al., 2013; Benz et al., 2016). This conclusion is based on the fact that the SO is one of the largest regions on Earth where direct interaction and exchange exists between the deep ocean and the atmosphere (Anderson et al., 2009).

This chapter will give an overview of the PFZ setting in the southwest Pacific Ocean and will discuss different climate-regulating processes that concern this region. Firstly, the regional setting will be described including the circulation of the region as well as the modern biological conditions and the surrounding geology. Secondly, glacial-interglacial cycles will be described. Key influences regulating these global climate cycles will be outlined, with specific focus on the role of sea ice, the Southern Hemisphere westerly winds, the biological pump and iron (Fe).

\subsection{Regional setting}

The Polar Front (PF) divides the SO into two zones; the Subantarctic Zone (SAZ) to the north and the Antarctic Zone (AZ) to the south (Sigman et al., 2010). Previous studies have suggested that processes contributing to glacial-interglacial $\mathrm{CO}_{2}$ regulation are different between each zone in the South Atlantic (Chase et al., 2003; Jaccard et al., 2013). Oceanographic research has shown that this region is a very complex system of oceanic fronts and eddies (Sokolov and Rintoul, 2007; Sokolov and Rintoul, 2009), commonly defined by changes in sea surface height that demarcate a PFZ, the mean position of which is given as the PF (Sokolov and Rintoul, 2007). In the last two decades, 
detailed investigations into the role of the $\mathrm{SO}$ in global ocean circulation and climate dynamics have revealed increasingly precise estimations of flow velocity, heat and nutrient transportation, and upwelling flux (Sokolov and Rintoul, 2007; Rintoul et al., 2014). Integration of measured data, particularly from satellites, with climate and circulation models has revealed a more complete picture of SO dynamics, and has subsequently reinforced its vital role in modulating global climate (Rintoul et al., 2010).

The TAN1302-96 core is located south of the PF and the TAN1302-97 core is situated slightly north of/directly under the PF (Sokolov et al., 2006) (Figure 2.1).

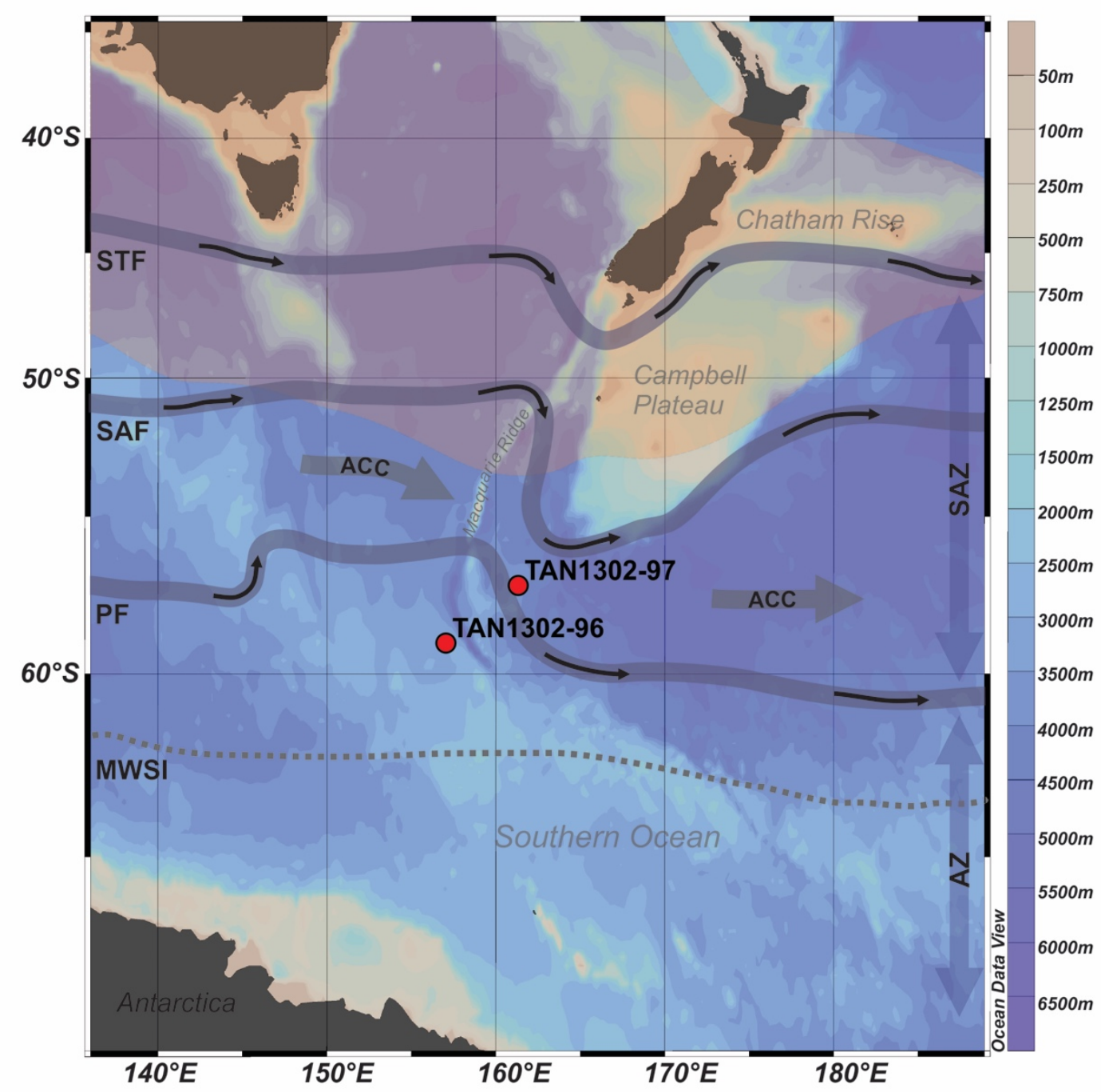

Figure 2.1. Core locations of TAN1302-96 and TAN1302-97 with key water masses and climate-related components important for this study. ACC $=$ Antarctic Circumpolar Current, STF $=$ mean position of the Subtropical Front, $\mathrm{SAF}=$ mean position of the Subantarctic Front, PF = mean position of the Polar Front modified from Sokolov and Rintoul (2009). Arrows indicate flow direction. SAZ = Subantarctic Zone and AZ = Antarctic Zone as divided by the PF from Sigman et al. (2010). MWSI = modern winter sea ice limit modified from Gersonde et al. (2005). Orange region = highest dust concentrations from Australia modified from Lamy et al. (2014). 


\subsubsection{Water masses, currents, and fronts}

The northern boundary of the SO as defined by the Subtropical Front (STF) separates warm (summer sea surface temperatures $14.5-19.5^{\circ} \mathrm{C}$ ), saline, nutrient-poor Subtropical surface water (STW) in the north, from cooler, nutrient-rich Subantarctic water (SAW) in the south (Belkin and Gordon, 1996; Bostock et al., 2013). Located just south of Campbell Plateau and New Zealand, the Subantarctic Front (SAF) marks the northern boundary of the eastward-flowing Antarctic Circumpolar Current (ACC), the Earth's longest and largest current $(\sim 134 \pm 13 \mathrm{~Sv}$, stretching from the seafloor to the surface) (Orsi et al., 1995; Phillips and Rintoul, 2002). Although the frontal structure of the ACC is complex, the majority of flow is focused along the oceanic fronts between 45 and $55^{\circ} \mathrm{S}$, viz. the SAF and the PF (Sokolov and Rintoul, 2007; Bostock et al., 2013). Both the SAF and the PF are composed of multiple branches or jets that extend from the sea surface to the deep ocean, and thus flow is often constrained by bathymetry (Sokolov and Rintoul, 2007; Sokolov and Rintoul, 2009).

Overlooking bathymetric interference, the strength of the ACC is controlled by the Southern Hemisphere westerly winds. Flow velocities weaken with depth; reaching upwards of $50 \mathrm{~cm} / \mathrm{s}$ at the base of the photic zone and decreasing to $<5 \mathrm{~cm} / \mathrm{s}$ near the sea floor (Orsi et al., 1995; Phillips and Rintoul, 2002; Bostock et al., 2013). The Macquarie Ridge in the southwest Pacific acts as a barrier to the ACC, with only a few gaps in the ridge where the ACC fronts are forced through (Sokolov and Rintoul, 2007). Evidence has shown that current speeds through gaps in the Macquarie Ridge can reach up to $50 \mathrm{~cm} / \mathrm{s}$ (Rintoul et al., 2014).

The key surface waters in the PFZ region of the SO are Antarctic Surface waters, which are found south of the PF and extend with 'rather uniform properties' to the margins of Antarctica (Orsi et al. 1995). These waters are cold $\left(<0.5^{\circ} \mathrm{C}\right)$ and relatively fresh (salinity $<34$ ), with high nutrient concentrations as a result of upwelling of Circumpolar Deep Water at the PF (Orsi et al., 1995; Bostock et al., 2013).

\subsubsection{Nutrients and productivity}

The SO is a high nutrient - low chlorophyll area. Upwelling of old, cold Circumpolar Deep Water just south of the PF supplies the surface with high concentrations of nitrate, silicate and phosphate (Figure 2.2), however, these nutrients are poorly utilised by phytoplankton (Bostock et al., 2013; Benz et al., 2016; Wilks et al., 2017). Strong 
grazing pressure, insufficient light and/or iron required for phytoplankton growth have all been suggested as potential reasons for this, though the latter explanation has received the most momentum (Martin, 1990; Mitchell et al., 1991; Minas and Minas, 1992; Boyd et al., 1999; Studer et al., 2015). Iron is an essential micronutrient required for phytoplankton growth. Iron fertilisation experiments in the SO have revealed rapid biological responses to the addition of Fe (Boyd et al., 2007). This elucidates the importance of this micronutrient, believed to be primarily sourced from aeolian dust, for enhancing productivity (Boyd et al., 2000; Fung et al., 2000). Other sources, however, include upwelling of intermediate/deep waters, sea ice melt and iceberg rafted debris (IRD).
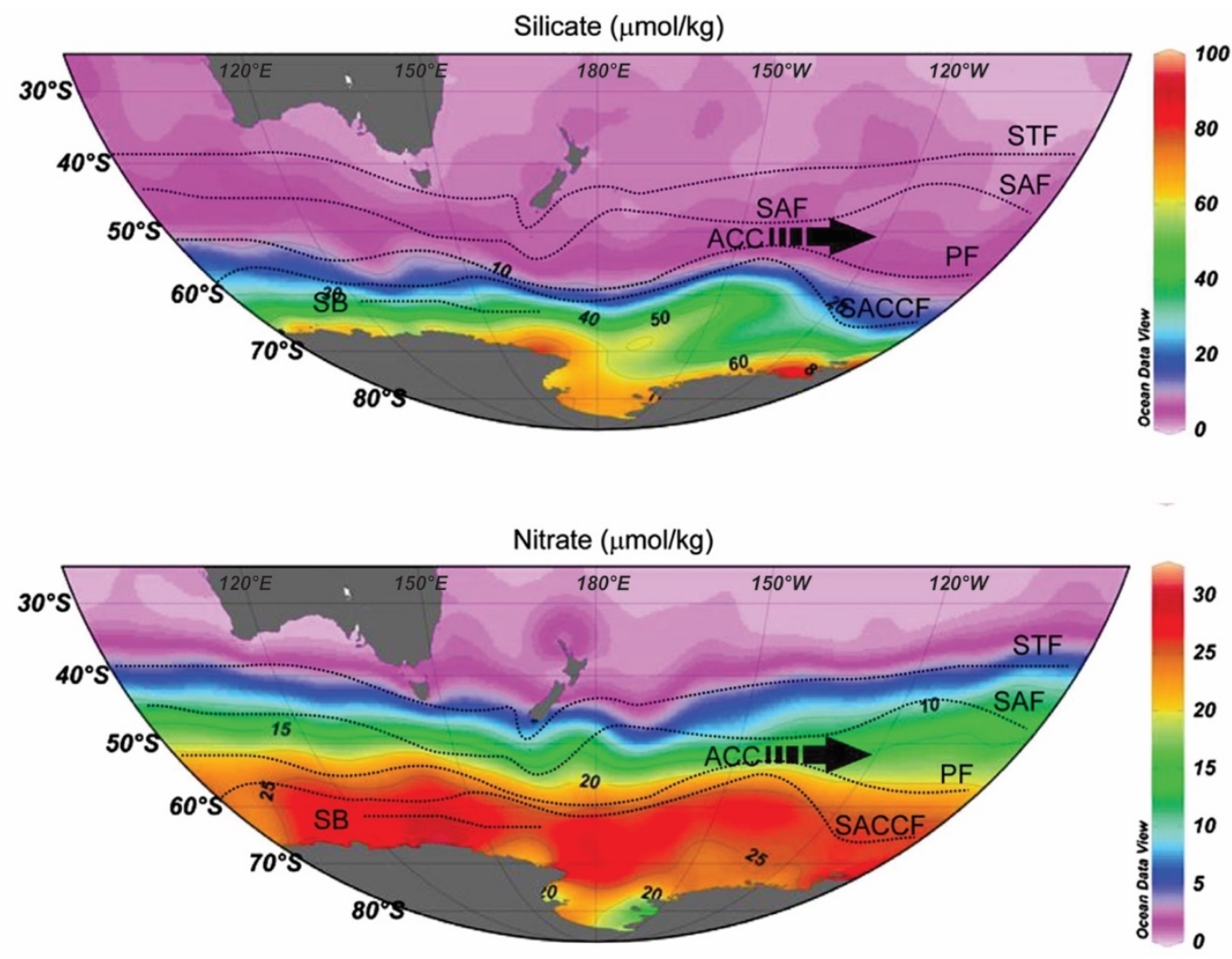

Figure 2.2. Annual sea surface silicate (top) and nitrate (bottom) concentrations from Bostock et al. (2013). Note phosphate concentration shows a similar distribution to nitrate concentrations. STF $=$ Subtropical Front, SAF $=$ Subantarctic Front, PF $=$ Polar Front, SACCF $=$ Southern ACC Front, SB $=$ Southern Boundary, ACC $=$ Antarctic Circumpolar Current.

In addition to forming a key oceanographic barrier, dividing the SO into two zones, the PF is a biogeochemical barrier separating low silica concentrations to the north from high silica concentrations to the south (Bostock et al., 2013). This is also evident from the proportions of total mass flux observed in intermediate waters across SO latitudes (Figure 
2.3) and the underlying sediments, where sedimentation is carbonate-dominated north of the PF and silica-dominated to the south (Honjo, 2004).

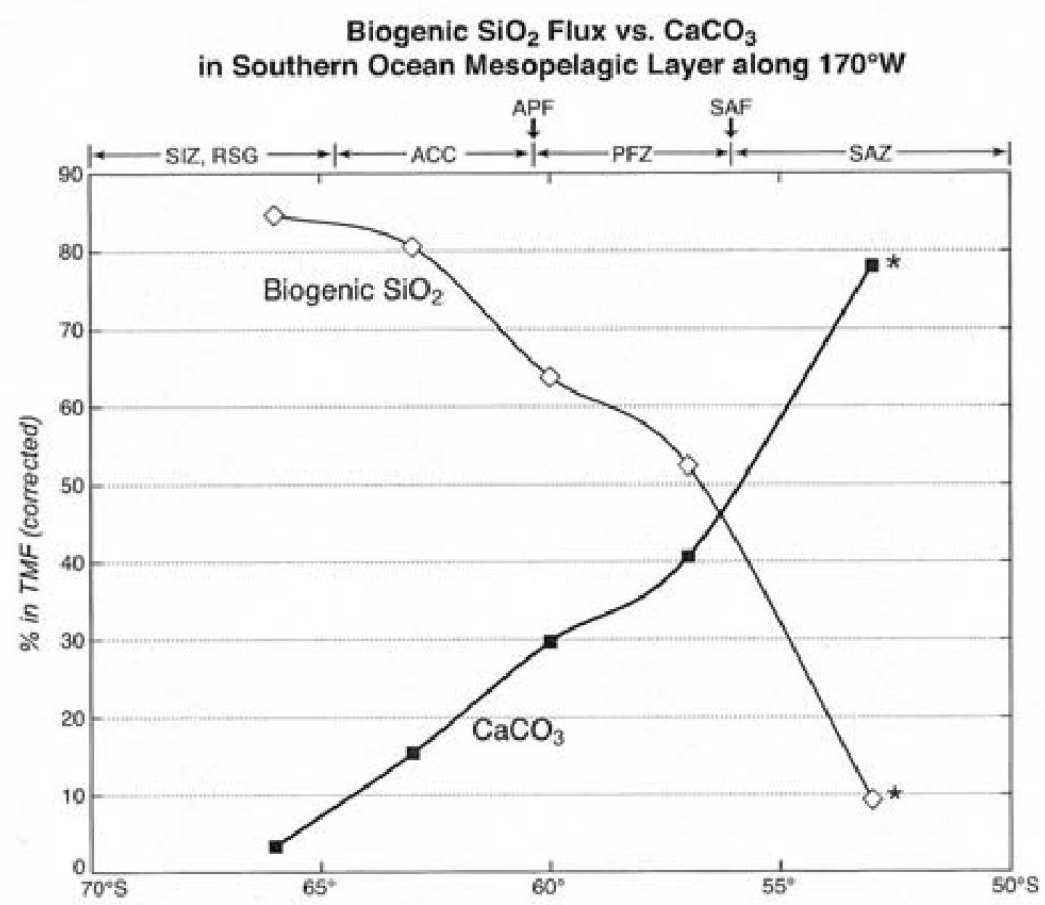

Figure 2.3. Latitudinal variability of calcium carbonate and biogenic silica from Honjo (2004). SIZ = Seasonal Sea Ice Zone, RSG = Ross Sea Gyre, ACC = Antarctic Circumpolar Current, APF = Antarctic Polar Front, PFZ = Polar Frontal Zone, SAF $=$ Subantarctic Front, SAZ $=$ Subantarctic Zone.

\subsubsection{Bathymetry and surrounding geology}

The TAN cores used in this study straddle the Macquarie Ridge; a submarine expression of the Australia-Pacific plate boundary south of New Zealand (Conway et al., 2012). The submarine ridge forms part of a greater ridge complex that is approximately $1,600 \mathrm{~km}$ in length, and varies from $\sim 100 \mathrm{~m}$ to $>1000 \mathrm{~m}$ in depth (Conway et al., 2012). Volcanic rocks on Macquarie Island are predominantly enriched mid-ocean ridge basalts (Varne et al., 2000) and likewise, samples from seamounts on the Macquarie Ridge Complex show that the relict spreading centre is composed of sub-alkaline to alkaline basalts (Conway et al., 2012). The northern PFZ core, TAN1302-97, is located in the Emerald Basin, east of the Macquarie Ridge. Eroded terrigenous material from the Southern Alps can be transported down Solander Trough via turbidity currents to the Emerald Basin during glacial low stands (Carter et al., 1996). Regardless of this, forcing of the ACC through gaps in the Macquarie Ridge and major sediment recycling in the subduction margin create an extremely erosional regime that results in very little sedimentation south of $52^{\circ} \mathrm{S}$ (Carter et al., 1996). 


\subsection{Glacial-interglacial cycles}

The correlation between atmospheric concentrations of $\mathrm{CO}_{2}$, global ice volume and temperature is extremely well documented for the past million years (Sigman et al., 2010). Abrupt changes in these factors from steady-state climate are initially due to changes in orbitally-driven insolation, however, radiative forcing can only account for half of the glacial-interglacial climatic shifts observed (Mackensen, 2004; Tang et al., 2016). Multiple theories exist to explain the additional processes involved in regulating atmospheric $\mathrm{CO}_{2}$, all of which highlight the role of the ocean, and the SO in particular (Mackensen, 2004). The oceans are the largest reservoir of carbon on Earth, containing 60 times more carbon than the atmosphere (Martin, 1990). Carbon from the oceans can be easily exchanged with the atmosphere and thus the oceans are the most likely source of exacerbating insolation-driven changes in atmospheric $\mathrm{CO}_{2}$ over glacial-interglacial timescales. Key theories involve; 1) physical obstruction of $\mathrm{CO}_{2}$ ocean-atmosphere exchange from extensive sea ice, 2) atmospheric circulation changes regulating the rate of upwelling in the SO, and 3) the efficiency of the biological pump and the SO "leak".

\subsubsection{Sea ice}

Low glacial concentrations of atmospheric $\mathrm{CO}_{2}$ have been suggested to result from reduced ventilation of the deep ocean, either as a consequence of perennial Antarctic sea ice cover or a combination of extensive wintertime cover and ice-induced stratification (Stephens and Keeling, 2000). This theory relies on persistent sea ice cover at the high latitudes that would effectively block carbon from escaping the deep ocean. Changes in productivity, nutrient supply or utilisation unrelated to sea ice cover would not be necessary to account for the draw-down of atmospheric $\mathrm{CO}_{2}$, nor would changes in ocean chemistry.

\subsubsection{Westerly winds}

Research has suggested the mean position and strength of the Southern Hemisphere westerly winds can generate a positive feedback on the climate system that forces atmospheric $\mathrm{CO}_{2}$ fluctuations (Toggweiler et al., 2006). The position of the westerly winds is dictated by the phase of the Southern Annular Mode. When the Southern Annular Mode is predominantly positive, the westerly winds accelerate and contract towards Antarctica, whereas a shift to a negative phase is associated with weakening and 
expansion of the Southern Annular Mode and westerly winds over the lower latitudes (see Marshall, 2003 for more detail).

Glacial periods have been associated with an equatorward migration of the westerlies and/or weakening of the winds, slowing the rate of upwelling so that $\mathrm{CO}_{2}$ accumulates in the deep ocean (Toggweiler et al., 2006). Conversely, glacial terminations and interglacials are characterised by a southward shift in the westerly winds, closer to Antarctica. This would increase ventilation of the deep ocean, releasing deeply sequestered carbon into the atmosphere. Increasing atmospheric $\mathrm{CO}_{2}$ would give rise to greater poleward displacement of the winds, creating the positive feedback proposed by Toggweiler et al. (2006).

\subsubsection{The biological pump and the role of iron}

Broecker (1982) first suggested variations in the degree of biological productivity in the oceans was responsible for glacial-interglacial $\mathrm{CO}_{2}$ fluctuations. Biological productivity in the surface waters lowers atmospheric $\mathrm{CO}_{2}$ through photosynthesis, however it is the transferal of organic carbon to the deep ocean, i.e. export production, that increases the oceanic sink of $\mathrm{CO}_{2}$ (Figure 2.4) (see Sigman et al., 2010 for more detail). In the modern ocean, this combination of processes, i.e. the biological pump, operates inefficiently due to poor nutrient and $\mathrm{CO}_{2}$ consumption by phytoplankton. This contributes to the modern $\mathrm{SO}$ "leak" that results in the release of $\mathrm{CO}_{2}$ at the upwelling region south of the PF relative to the draw-down needed in photosynthesis (Sigman et al., 2010; Jaccard et al., 2013). Research in the South Atlantic has shown the export of organic material to the deep ocean was enhanced during glacial periods in the SAZ of the SO, but decreased in the AZ (Jaccard et al., 2013). Coincident Fe deposition from Patagonia, the largest dust source in the Southern Hemisphere, has been associated with improving productivity in the SAZ, rendering the biological pump more efficient, and contributing to declining atmospheric $\mathrm{CO}_{2}$ concentrations (Jaccard et al., 2013; Lamy et al., 2014). 


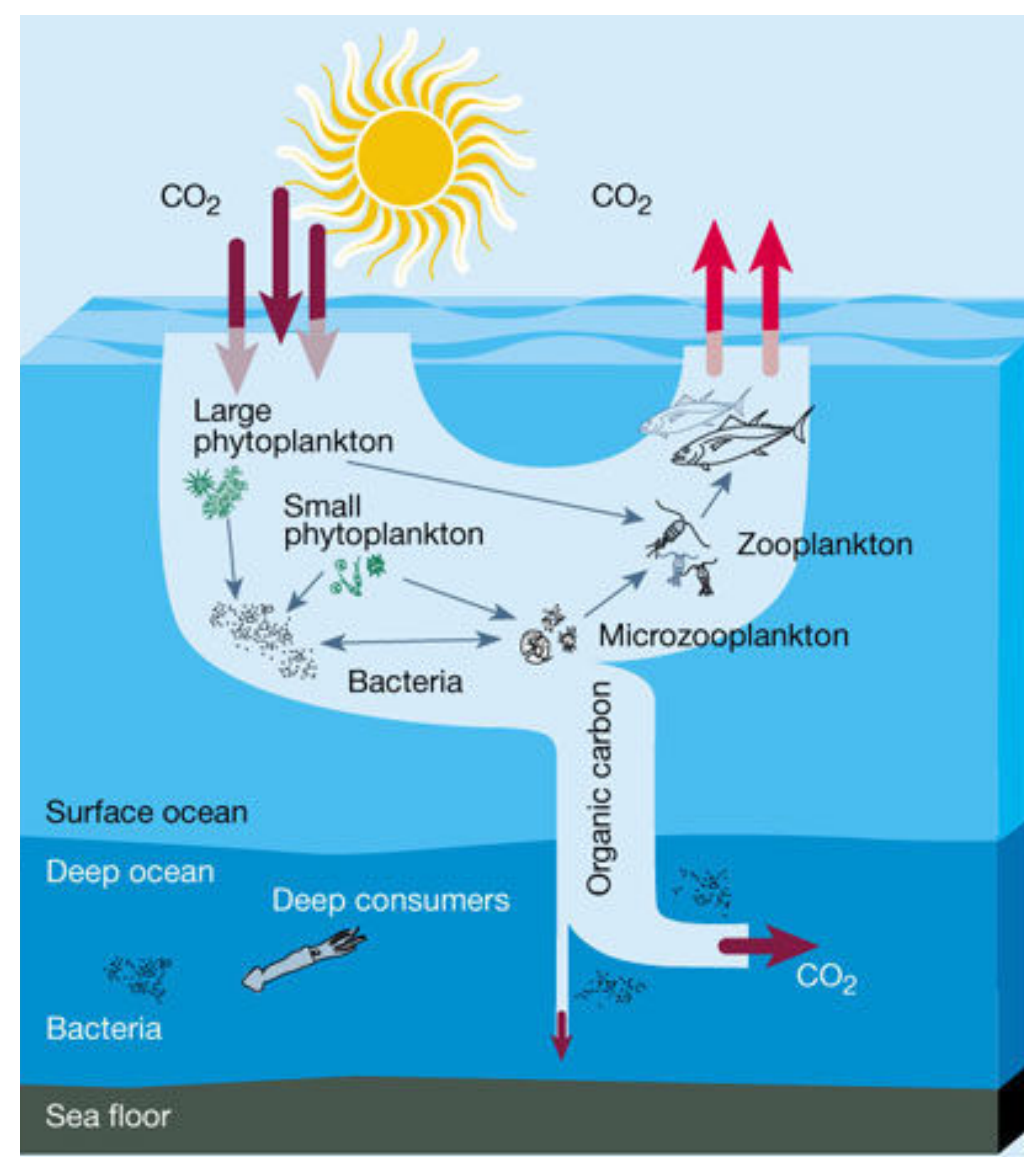

Figure 2.4. Schematic illustration of the biological pump. Phytoplankton use light energy and dissolved nutrients in photosynthesis to covert $\mathrm{CO}_{2}$ to organic carbon. Most of this organic carbon is converted back to $\mathrm{CO}_{2}$ due to consumption and/or dissolution, and is released back into the atmosphere. A small proportion $(<1 \%)$ of organic carbon, however, makes it to the deep ocean and is effectively removed from the carbon cycle for thousands of years. From Chisholm (2000).

Attempts at explaining glacial terminations have concluded a number of factors are required to account for the rapid increase in atmospheric $\mathrm{CO}_{2}$ concentrations and global temperatures (Anderson et al., 2009; Denton et al., 2010). Denton et al. (2010) describe a sequence of events initiated by rising summer insolation in the Northern Hemisphere. Of the most concern to the SO, southward shifts in the westerly winds are responsible for increased upwelling and ventilation of the deep ocean, resulting in rising atmospheric $\mathrm{CO}_{2}$ and warming over Antarctica (Anderson et al., 2009; Denton et al., 2010). The interplay between the atmosphere and the oceans is incredibly complex. This complicates the recognition of a single trigger, be that in the Northern or Southern Hemisphere, that initiates glacial terminations. Though progress has been made in understanding mechanisms behind climate shifts, potential heterogeneity in these processes between ocean basins may have some important implications for understanding future climate responses. 


\section{Chapter 3 Ecology}

This chapter will discuss the marine plankton present in the southwest Pacific PFZ cores. Marine plankton have a vital role in the worlds oceans. Not only do phytoplankton form the base of the food chain, they also have a significant role in regulating glacialinterglacial variability in atmospheric $\mathrm{CO}_{2}$ (Deppeler and Davidson, 2017). Additionally, modern analogues from sediment trap data and core tops can give insights into preferred environmental conditions, and have been used extensively for sea surface temperature (SST) and winter sea ice (WSI) reconstructions (Gersonde and Zielinski, 2000; Armand et al., 2005; Kucera et al., 2005).

\subsection{Foraminifera}

Foraminifera were used in this study for stable isotope analysis to determine an age model for each core. The majority of foraminifera observed in the TAN1302-96 and -97 cores were the planktonic species Neogloboquadrina pachyderma with lesser amounts $(<20 \%)$ of Globigerina bulloides.

N. pachyderma (Ehrenberg, 1861) is a non-spinose, non-symbiotic, left-coiling foraminifera (Figure 3.1) (Hemleben et al., 1989). In the modern ocean, the species dominates polar ocean foraminifera assemblages in both hemispheres, thriving in SSTs between $0-5^{\circ} \mathrm{C}$ with relatively weak surface water stratification (Spindler, 1996; Hilbrecht, 1997; Crundwell et al., 2008). Additionally, the species has been found living within sea ice around Antarctica, where individuals are incorporated into the ice by ice formation processes (Spindler and Dieckmann, 1986; Dieckmann et al., 1991). Because of this, $N$. pachyderma can tolerate a wide range of salinities, however, literature suggests individuals in southern latitudes flourish in waters of relatively low salinities $(\sim 34 \%)$ compared to the much higher salinities associated with sea ice (>50\%) (Spindler, 1996). 


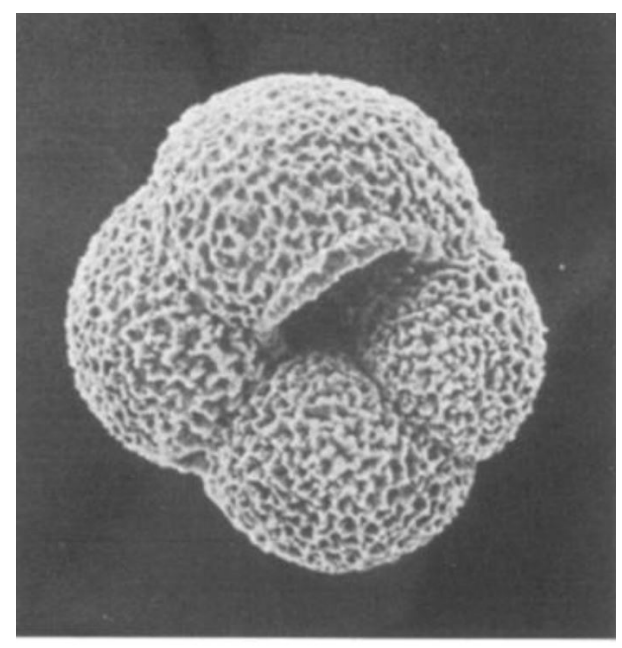

$200 \mathrm{um}$

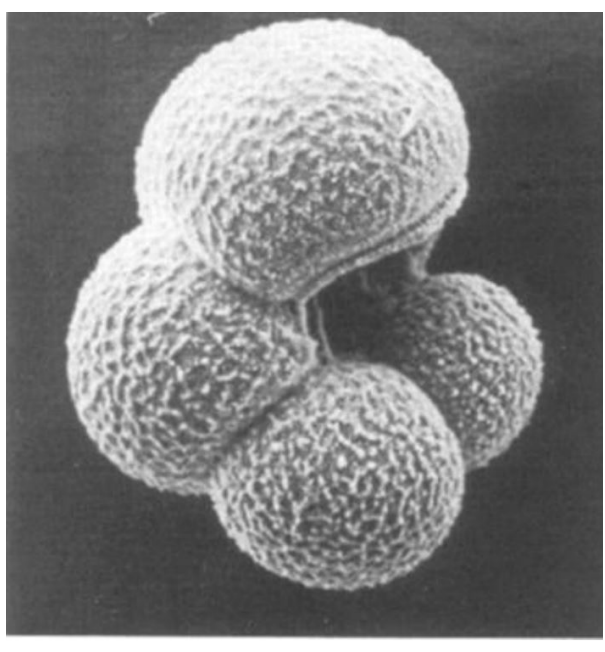

$200 \mathrm{um}$

Figure 3.1. Scanning electron microscope images (200x) of N. pachyderma; encrusted form (left) and non-encrusted form (right). Images from Kohfeld et al. (1996).

G. bulloides (d'Orbigny, 1826) is a spinose, planktic foraminifera present in transitional to polar waters (Hemleben et al., 1989). It occurs in a wide range of SSTs $\left(\sim 2-23^{\circ} \mathrm{C}\right)$, however, maximum densities are present between $9-11^{\circ} \mathrm{C}$ (Tolderlund and Bé, 1971). This species has preference for $<400 \mathrm{~m}$ water depth and is common in regions of enhanced nutrient supply (Hemleben et al., 1989; Neil et al., 2004; Crundwell et al., 2008). For this reason, the relative abundance of G. bulloides has been used as a proxy for upwelling intensity, where nutrient-rich bottom waters are brought to the surface at frontal zones (Conan et al., 2002). Contrary to other spinose planktic foraminifera, high nutrient supply and enhanced productivity are associated with enriched $\delta^{13} \mathrm{C}$ values in $G$. bulloides (Hemleben et al., 1989; Schneider et al., 1994). Current theories for this involve competitive uptake of ${ }^{12} \mathrm{C}$ by phytoplankton during periods of increased primary production, although reasons are still speculated (Neil et al., 2004; Prasanna et al., 2016).

\subsection{Diatoms}

Diatoms are silicifying, photosynthetic algae that contribute up to $75 \%$ of the primary productivity in the $\mathrm{SO}$, thus playing a key role in the global cycling of both silica and carbon (Tréguer et al., 1995; Armand et al., 2005). Due to light requirement for photosynthesis, diatom distributions are limited to the top $200 \mathrm{~m}$ of the water column (Cortese et al., 2012). Additionally, environmental factors, grazing pressure and the availability of macro- and micronutrients influence species abundance, where nutrient 
availability in particular can become growth limiting if concentrations are low (Cortese et al., 2012).

In the SO, species-specific distributions are controlled largely by SST and sea-ice cover (Armand et al., 2005). Analysis of diatom assemblages preserved in marine sediments therefore provides a means to gauge paleoceanographic conditions, particularly for SST reconstructions and sea ice cover estimations (Romero et al., 2005). Detailed research using core-tops has revealed relationships between modern diatom distributions and environmental conditions, such that major taxa can be grouped into zonally-distinct regions (Armand et al., 2005). In this thesis, there was insufficient time to undertake many diatom assemblage counts. Therefore, the diatom analyses will be used to support other sedimentological and geochemical information to inform the paleoceanographic interpretations.

\subsection{1 "Sea Ice" group}

Extant diatom species comprising the "Sea Ice" (SI) group are currently found in oceanic regions south of the PF annually covered by sea ice (Armand et al., 2005). Diatom taxa in this group are most abundant surrounding the coast of Antarctica within the zone of maximum winter, or in some instances, summer sea ice cover; viz. in the Amundsen Sea, the Adélie coastline, Prydz Bay and the Ross Sea (Pichon et al., 1987; Armand et al., 2005; McKay et al., 2012). Species in this group include Actinocyclus actinochilus, Eucampia antarctica, Fragiliariopsis rhombica, F. curta, F. ritscheri and F. separanda (Pichon et al., 1987; Armand et al., 2005). These species have strict SST and sea ice cover preferences, where maximum abundance is observed in regions experiencing $\sim 7-9$ months of sea ice cover per year and SSTs between -1 to $3^{\circ} \mathrm{C}$. Most diatoms in this group have been documented in sea ice (e.g. A. actinochilus), while some prefer melt water conditions (e.g. E. antarctica and F. ritscheri) (Pichon et al., 1987; Armand et al., 2005). 

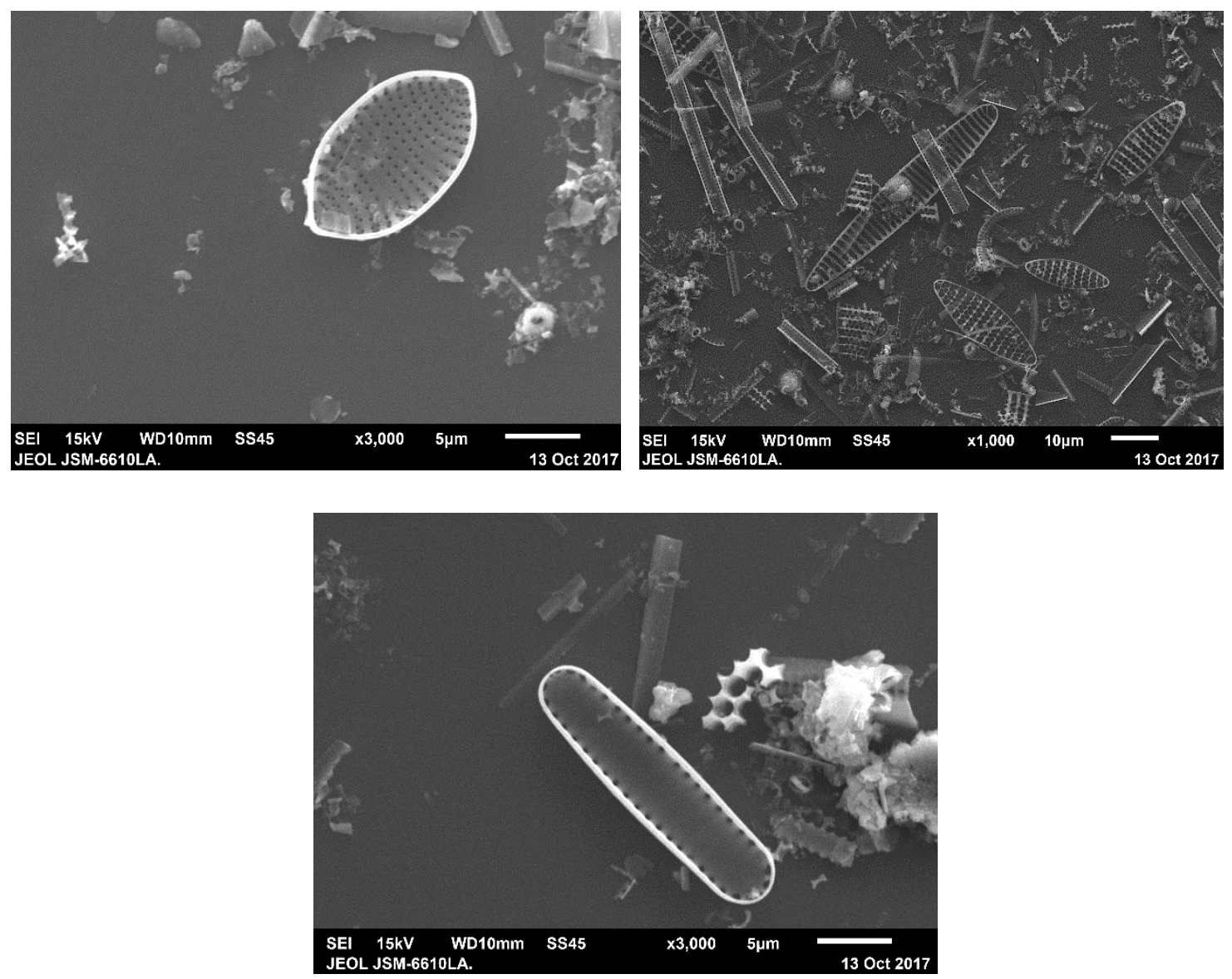

Figure 3.2. Images of select SI diatoms. From top left (clockwise): F. separanda (SEM), F. ritscheri (long centre SEM) and F. curta (SEM).

\subsection{2 "Polar Open Ocean and Seasonal Ice Tolerant" group}

This thesis follows the same species grouping as McKay et al. (2012) for the "Polar Open Ocean and Seasonal Ice Tolerant" (POOSIT) group, who combined the Cool Open Ocean and Pelagic Open Ocean groups from Crosta et al. (2005). Additional species in this group absent from the latter work are included from Pichon et al. (1987). Diatoms in this group have well-established links to open ocean settings, and include Asteromphalus parvulus, Fragilariopsis kerguelensis, Thalassiosira gracilis, T. lentiginosa and Thalassiothrix antarctica. These species occur in a broader SST range than the "sea ice" group, $(\sim 1$ $8^{\circ} \mathrm{C}$ ). However, a common pattern is observed regarding these species distributions, where maximum abundances decrease south of the PF towards areas of prolonged annual sea ice duration (Crosta et al., 2005). This coincides with the "Diatom Ooze Belt;" a band of well-preserved diatomaceous sediment bordered by the SAF and the winter/spring sea ice cover surrounding Antarctica (Burckle and Cirilli, 1987). F. kerguelensis is the dominant component of this sediment, where maximum abundances of the species can make up between $70-83 \%$ of SO diatom assemblages (Crosta et al., 2005). Research has 
also shown that $F$. kerguelensis shows a distinct climatic signature, both in terms of relative abundance and size of individual valves. During glacial periods, though the relative abundance is lower, usually valve areas are larger, and vice versa during interglacials (Crosta et al., 2004; Cortese et al., 2012).
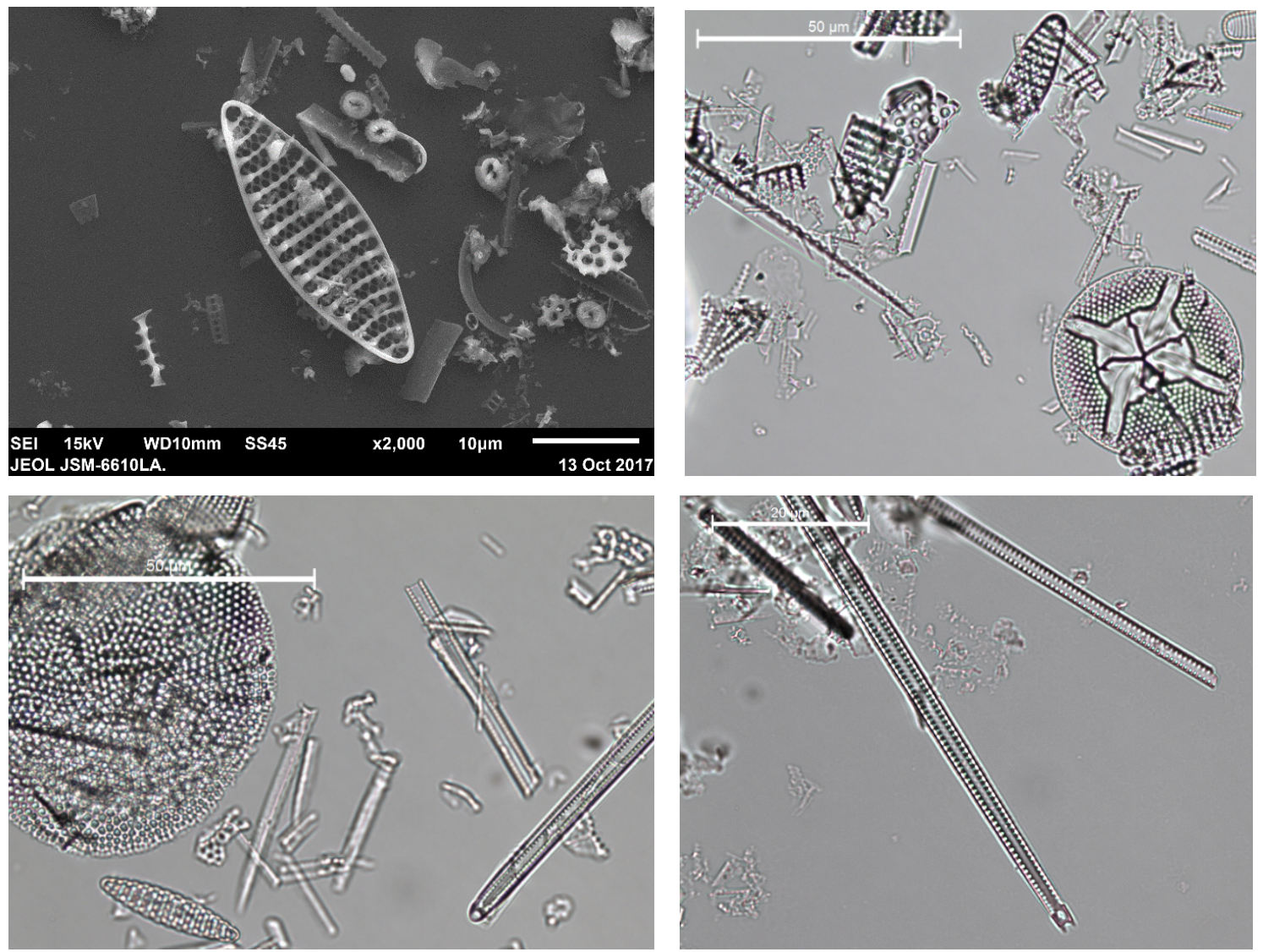

Figure 3.3 Images of select POOSIT group diatoms. From top left (clockwise): F. kerguelensis (SEM), A. parvulus (light microscope), and T. antarctica (both apexes shown) (light microscope).

\subsection{3 "Polar Front and Northwards" group}

Following the methods of McKay et al. (2012), the "Polar Front and Northwards" (PFAN) group is a combination of the extant diatom species in the Warm Open Ocean group from Crosta et al. (2005) and the Subtropical group from Romero et al. (2005). Species in this group include Azpeitia tabularis, Hemidiscus cuneiformis, Thalassionema nitzschioides var. lanceolata, and Thalassiosira oestrupii. These species are generally found north of the SAF, in moderate to warm summer SSTs $\left(\sim 7-15^{\circ} \mathrm{C}\right)$, and have a low tolerance to sea ice presence (Romero et al., 2005). Regardless of the fact some of these species have a wide range of environmental tolerance, clear patterns of decreasing abundance with increasing latitude and sea ice exist, as does a distinct preference for warmer conditions. 

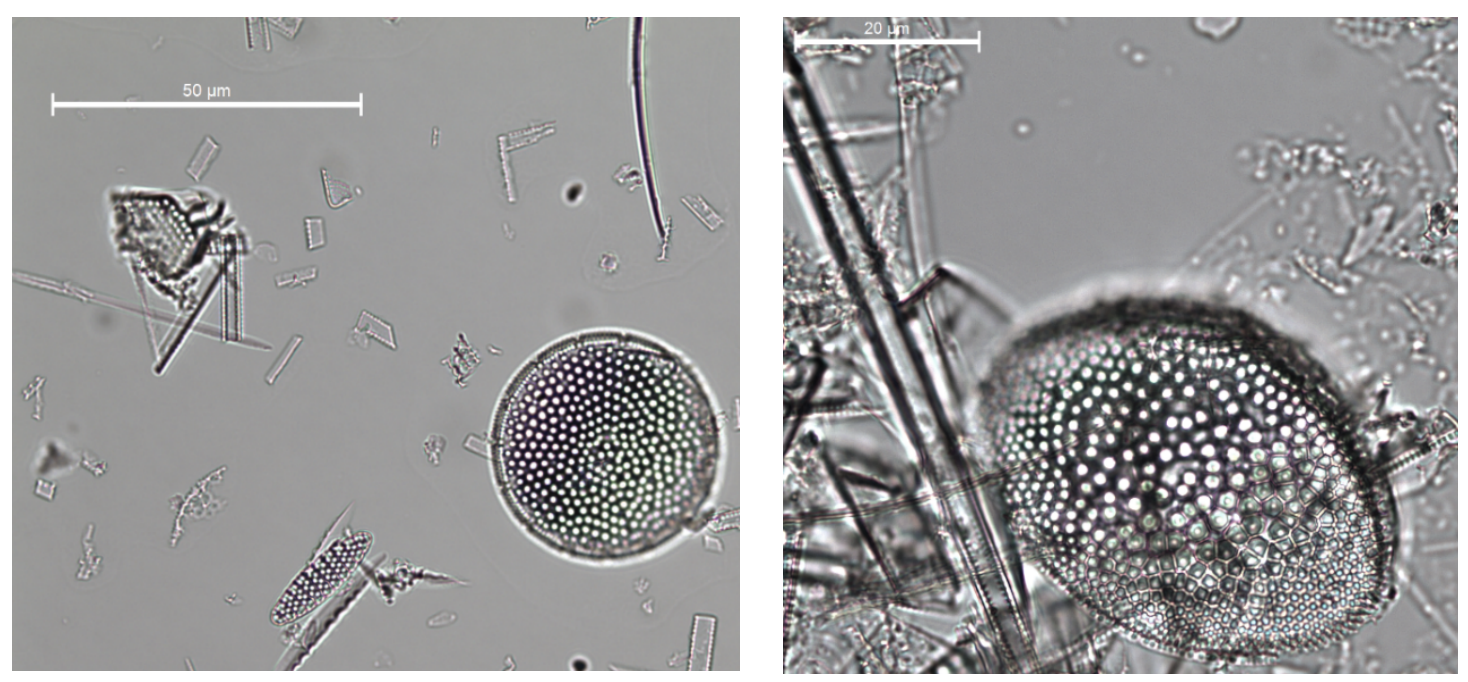

Figure 3.4. Select diatoms from the PFAN group. From left: A. tabularis and H. cuneiformis (light microscope).

\subsection{Coccolithophores}

Coccolithophores are photosynthetic, calcifying phytoplankton that are among the most productive primary producers in the world's oceans (Rost and Riebesell, 2004). For this reason, they are an important component in the marine carbon cycle, both acting as a $\mathrm{CO}_{2}$ sink during photosynthesis and source during calcification processes (Krumhardt et al., 2017). Coccolithophores are widely distributed in the global ocean, though areas with highest calcification rates (or highest particulate inorganic carbon production) are confined to temperate and subpolar regions (Krumhardt et al., 2017). The SO in particular exhibits a permanent band of elevated calcium carbonate concentration just north of the PF during the austral summer; deemed the "Great Calcite Belt" (Balch et al., 2011, 2016; Smith et al., 2017). Coccolithophores are believed to be the major contributor to this phenomenon, dominated almost exclusively by Emiliania huxleyi (Balch, 2018). In this thesis, the presence of coccoliths in the cores was checked in five samples using Scanning Electron Microscopy (SEM). The most common species identified in both TAN1302-96 and -97 were Calcidiscus leptoporus and Gephyrocapsa oceanica, the latter of which is genetically very similar to E.huxleyi (Bendif and Young, 2014; Balch, 2018). 

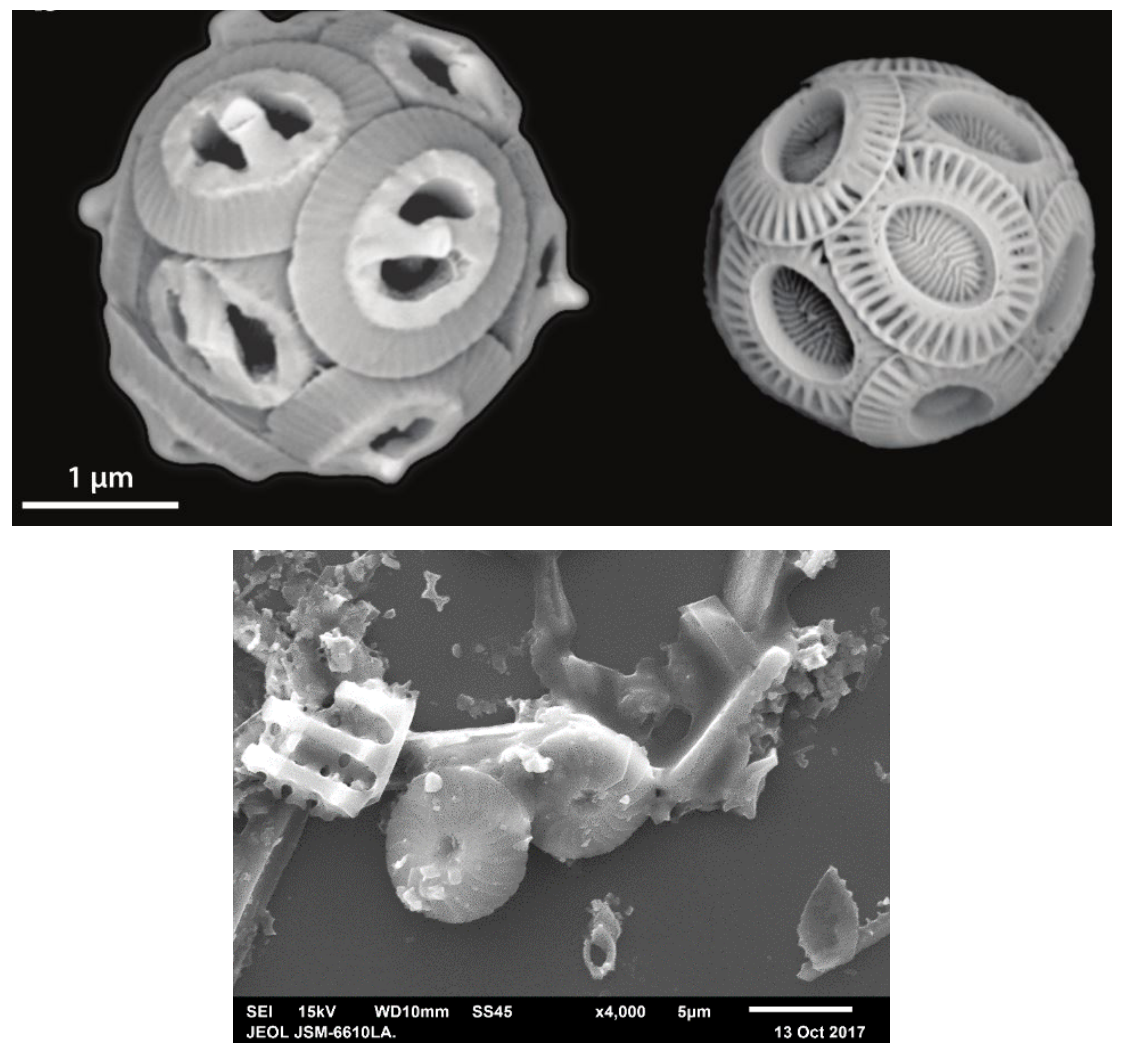

Figure 3.5 Top: coccolith structure of G. oceanica (left) and E. huxleyi (right). Key difference is the presence of a bipartite bridge located in the centre of the placolith in G. oceanica. Image from Balch (2018). Bottom: coccoliths from C. leptoporus (SEM).

G. oceanica is a widely-distributed, bloom-forming coccolithophore, typically found in warm waters (Bendif and Young, 2014). The species are typically found in the top $50 \mathrm{~m}$ of the water column, however, other environmental preferences, such as temperature, are not very well constrained (Rhodes et al., 1995). Recent ocean acidification experiments showed the coccolithophore can adapt to higher $\mathrm{CO}_{2}$ concentrations, although adaptation seems to collapse after exposure over 2,000 generations (Jin and Gao, 2015).

Highest counts of $C$. leptoporus have been recorded in peak interglacials, viz. during the Holocene and Marine Isotope Stage (MIS) 5e, off Campbell Plateau (Wells and Okada, 1997). The coccolithophore has been typically regarded as a warm water species, where abundance of C. leptoporus south of the PF is relatively low (Wells and Okada, 1997). Distribution data of the species in the South Pacific, however, is severely lacking. Recent research has shown that $C$. leptoporus has a requirement for silicate, where Si-limited conditions negatively impacts their ability to calcify (Durak et al., 2016).

Though documentation of modern environmental preferences for both species could be improved, the information currently available will be used to support other data in this thesis. 


\section{Chapter 4 Methods}

\subsection{Core collection}

A gravity corer was used to obtain cores TAN1302-96 and TAN1302-97 in March of 2013 during the return transit of the $R V$ Tangaroa from the Mertz Polynya, East Antarctica. TAN1302-96 is located on the southwestern side of Macquarie Ridge, in the path of the southern PF boundary and TAN1302-97 is situated in the Emerald Basin, to the east of Macquarie Ridge (Table 4.1).

Table 4.1. PFZ core locations.

\begin{tabular}{|c|c|c|c|c|}
\hline Core & Longitude & Latitude & $\begin{array}{c}\text { Water Depth } \\
(\mathbf{m})\end{array}$ & Length (cm) \\
\hline TAN1302-96 & -59.09178 & 157.04998 & 3,099 & 364 \\
\hline TAN1302-97 & -57.28651 & 161.33131 & 3,544 & 480 \\
\hline
\end{tabular}

\subsection{Preliminary work}

Prior to the start of this project some preliminary work had already been undertaken on the cores by Helen Bostock. Preliminary work on TAN1302-96 involved:

- Core was split and a visual core description carried out

- Magnetic susceptibility measured at $2 \mathrm{~cm}$ intervals along the entire core

- Samples sieved at $10 \mathrm{~cm}$ intervals for the top $190 \mathrm{~cm}$ for grain size ( $>63 \mathrm{um}$ )

- Calcium carbonate content (weight \%) measured using the carbonate bomb method every $5 \mathrm{~cm}$ for the top $80 \mathrm{~cm}$, and then at $10 \mathrm{~cm}$ intervals for the remainder of the core

- Oxygen isotopes analysis on the planktonic foraminifera N. pachyderma from the top $120 \mathrm{~cm}$ of the core at $10 \mathrm{~cm}$ resolution

- Radiocarbon dating on N. pachyderma undertaken at two depths; $20 \mathrm{~cm}$ and $50 \mathrm{~cm}$

- Micro-XRF elemental scanning (ITRAX) on the top $185 \mathrm{~cm}$, at $2 \mathrm{~mm}$ resolution 
- Biogenic opal analysis undertaken at Dalhousie University using the one-step method. 19 samples between 4 and $92 \mathrm{~cm}$ depth were analysed

Preliminary work previously undertaken on TAN1302-97 involved:

- Magnetic susceptibility measured at $2 \mathrm{~cm}$ intervals along the entire core

- Samples sieved at $10 \mathrm{~cm}$ intervals for grain size for the top $190 \mathrm{~cm}$

- Calcium carbonate content (weight \%) measured using the carbonate bomb method every $10 \mathrm{~cm}$ for the entire core

- Oxygen isotope analysis on N. pachyderma on the top $190 \mathrm{~cm}$ of the core at $10 \mathrm{~cm}$ resolution

- Radiocarbon dating of N. pachyderma at two depths; $10 \mathrm{~cm}$ and $40 \mathrm{~cm}$

\subsection{Core sampling and analyses}

The working half of the TAN1302-96 and TAN1302-97 cores were utilised for this study, however, previous work on TAN1302-96 (Bostock, unpublished) meant the supplementary samples from the archive half were often needed from the top $2 \mathrm{~m}$. Samples were taken using a $1 \mathrm{~cm}$ wide spatula to obtain $1 \mathrm{~cm}$ thick sample sections, with care taken to avoid sampling the outside of the cores to reduce contamination from disturbed sediment dragged down the inside of the core tube. The collected samples were then used for the analyses listed below.

\subsection{Dry bulk density \& water content}

Dry bulk density measurements are needed along with the linear sedimentation rates (LSR) in order to calculate the mass accumulation rate (MAR) of sediment, viz. calcium carbonate. Due to the positive correlation between organic carbon production and calcium carbonate productivity, MAR of carbonate is often used as a productivity proxy (Brummer and van Eijden, 1992). Water content was also calculated as part of this project to see if this correlated with biogenic opal content, since the former is much easier to measure and diatom-rich sediments retain lots of water.

\subsubsection{Sample preparation}

Samples for the initial dry bulk density analyses of TAN1302-96 and TAN1302-97 were taken every $10 \mathrm{~cm}$ from the working half of the cores. Between 7-10 g of sediment was 
put into $2 \mathrm{~cm} \times 2 \mathrm{~cm} \times 1.5 \mathrm{~cm}=6 \mathrm{~cm}^{3}$ cubes and then weighed (wet weight $=\mathrm{WW}$ ), before being dried at $100^{\circ} \mathrm{C}$ overnight in the oven. Samples were re-weighed when dry $($ dry weight $=\mathrm{DW})$, then dry bulk density $(\mathrm{DBD})$ and water content $(\%)$ were calculated using the equations below. Following this, the dry samples were transferred into a mortar and pestle for crushing and then bagged and labelled for use in further analyses.

1) water content $(\%)=((\mathrm{WW}-\mathrm{DW}) / \mathrm{WW}) * 100$

2) $\mathrm{DBD}=\mathrm{DW} /$ volume of cube

3) Bulk MAR $\left(\mathrm{g} / \mathrm{cm}^{2} / \mathrm{ky}\right)=\operatorname{LSR}(\mathrm{m} / \mathrm{my}) \times \mathrm{DBD}$

4) Carbonate $\mathrm{MAR}=$ bulk MAR $\times\left(\mathrm{CaCO}_{3} \mathrm{wt} \% / 100\right)$

\subsection{Stable isotope analysis}

Although local effects such as salinity and temperature can impact oxygen isotope ratios measured from planktic foraminifera, relative global ice volume changes can be deduced from the isotopic signatures. Oxygen isotopes, expressed as $\delta^{18} \mathrm{O}$, are the ratio of ${ }^{18} \mathrm{O} /{ }^{16} \mathrm{O}$ compared to a standard. The lighter ${ }^{16} \mathrm{O}$ is preferentially evaporated from the surface of the ocean and precipitates as snow to form the ice sheets. This results in an increase in ${ }^{18} \mathrm{O} /{ }^{16} \mathrm{O}$ in the oceans when the ice sheets are large during glacial periods. This isotopic signature denoting glacial and interglacial periods is incorporated into foraminiferal tests. Measuring these ratios from foraminifera helps constrain the chronology of the marine cores when compared with global oxygen isotope reference curves such as LR04 (Lisiecki and Raymo, 2005).

\subsubsection{Sample preparation}

Sub-samples were taken every $10 \mathrm{~cm}$ down both TAN1302-96 and TAN1302-97 from previously wet-bagged samples. These samples were dried overnight in the oven at $50^{\circ} \mathrm{C}$, placed in small pottles and then soaked with $\mathrm{pH}$ buffered distilled water to encourage disaggregation (but not dissolution) for up to 2 hours. The sample was then washed through a $63 \mu \mathrm{m}$ sieve to remove the mud fraction. This $<63 \mu \mathrm{m}$ material was left to dry, bagged, and placed in storage. The $>63 \mu \mathrm{m}$ fraction was transferred onto filter paper and dried overnight at $50^{\circ} \mathrm{C}$. Samples were transferred to vials when dry, and sieved through $355 \mu \mathrm{m}, 250 \mu \mathrm{m}$ and $180 \mu \mathrm{m}$ sieves when used for picking. Individual foraminifera tests were picked from the $180-250 \mu \mathrm{m}$, and $250-355 \mu \mathrm{m}$ fractions. 


\subsubsection{Picking}

Two planktic foraminifera species, N. pachyderma and G. bulloides (where present) were picked under a binocular microscope. $N$. pachyderma were picked from the 180-250 $\mu \mathrm{m}$ fraction following an initial observation that some samples lacked individuals in the 250$355 \mu \mathrm{m}$ fraction. It is typical of this foraminifera species to change position in the water column throughout their life cycle (Hemleben et al., 1989). For this reason, the $180 \mu \mathrm{m}$ sieve was chosen over $150 \mu \mathrm{m}$ as measurements taken from juveniles can have significant effects on $\delta^{18} \mathrm{O}$ values (Jonkers et al., 2013). Approximately 15-20 individuals were picked from the $250-355 \mu \mathrm{m}$ fraction, and 30 individuals were picked from the 180 $250 \mu \mathrm{m}$ fraction.

\subsubsection{Analysis}

Five to six individual $N$. pachyderma from the $180-250 \mu \mathrm{m}$ size fraction were analysed by Andrew Kingston at NIWA for their stable isotopes using Kiel IV individual acid-onsample device and analysed using Finnigan MAT 252 Mass Spectrometer. The precision is $\pm 0.07 \%$ for $\delta^{18} \mathrm{O}$ and $\pm 0.05 \%$ for $\delta^{13} \mathrm{C}$.

\subsection{Iceberg rafted debris}

There have been many debates arguing the environmental interpretation of iceberg rafted debris (IRD) in sediment cores and these are considered in Chapter 6. Regardless of this, the presence of IRD is an important indicator of glaciomarine processes and was visually counted whilst picking foraminifera using the binocular microscope at $10 \mathrm{~cm}$ intervals down the cores, in both the 250-355 $\mu \mathrm{m}$ and 180-250 $\mu \mathrm{m}$ size fractions. Counts were divided by the associated dry weight ( $\mathrm{g}$ ) of the total sample and presented as grains/gram of sediment. See Appendix C for count information.

\subsection{X-ray fluorescence}

Use of X-ray Fluorescence (XRF) scanners in core analysis has increased substantially in the last 20 years (Croudace and Rothwell, 2015). The ability to quickly and nondestructively acquire elemental count data has led to this technique being commonly used in paleoclimate studies, where elemental proxy data can provide valuable information for past climate reconstructions. 


\subsubsection{Sample preparation}

Samples used for XRF analysis were taken from the cores at $2 \mathrm{~cm}$ intervals. XRF data can be highly influenced by sediment properties such as water content, grainsize, bulk density and an excess of organic matter (Croudace and Rothwell, 2015). Whilst the amount of organic matter in both cores is expected to be low $(<2 \%)$, to minimise the effects of variable porosity and grain size, samples were dried at $100^{\circ} \mathrm{C}$ and homogenised by hand grinding with an agate mortar and pestle. Samples were heated to $100^{\circ} \mathrm{C}$ for $>30$ minutes to comply with biosecurity requirements in order to transport the samples to Victoria University of Wellington (VUW) to use the XRF machine. Samples were transported to VUW in labelled bags, and transferred into plastic vials with polypropylene film secured over the opening for subsequent XRF analysis.

\subsubsection{XRF data}

A portable Olympus Vanta M series XRF scanner was used for elemental analysis. The machine was connected to a workstation which enabled remote operation (Figure 4.1). Samples were placed upside down, directly onto the XRF prolene window and the lid closed. Two "methods" were used for analysis. The geochem method utilises 3 beams of 10,15 , and $40 \mathrm{kV}$, run for 30,30 and 60 seconds respectively, to measure light and some trace elements (e.g. $\mathrm{Mg}, \mathrm{Al}, \mathrm{Si}, \mathrm{Ca}, \mathrm{Fe}, \mathrm{K}, \mathrm{S}$ ). The geochem-50 method replaces the 40 $\mathrm{kV}$ beam with a $50 \mathrm{kV}$ beam (run for 30 seconds), and was used to measure Barium specifically. The different beam times were determined from preliminary tests that revealed a longer emission time of the $40 \mathrm{kV}$ beam increased the accuracy of measurements.

The elemental abundance is output in nominal parts per million (ppm), unlike ITRAX and AVATECH instruments that report counts per second (cps). This is determined by an internal calibration pre-set by the factory that assumes the analysed material is loosepacked dry powder. A correction can be made by analysing measured powders of known composition along with the sample material. Diatomaceous material, however, naturally packs into a lower density powder than most lithogenic material. In practice this means that there is less than expected material exposed to the x-ray beams. The effect of this was examined by preparing weighed mixtures of diatomite $\left(\mathrm{SiO}_{2}\right)$ and corundum $\left(\mathrm{Al}_{2} \mathrm{O}_{3}\right)$ (Table 4.2) - representing the elements thought to be of highest abundance in the TAN1302-96 and -97 samples - and comparing measured elemental abundance against 
the expected value. Analysis of UGSS/GSJ samples shows an almost 1:1 relationship (1:0.99) between expected and measured abundance for Al. The spiked diatomite mixtures, however, reveal a highly linear relationship $\left(r^{2}=0.98\right)$, but the gradient is much less (1:0.6). This effectively means the instrument is under reporting the abundance of Al because of the low density of the diatomite sample material. For this reason, changes in relative abundance down core will be focused on rather than absolute element abundance.

Table 4.2. Weighted standard mixtures made from diatomite from Middlemarch, Otago, spiked with corundum.

\begin{tabular}{|c|c|c|}
\hline Sample & Diatomite weight $(\mathbf{g})$ & Corundum weight $(\mathbf{g})$ \\
\hline $26 \%$ Diatomite & 0.33 & 0.954 \\
\hline $54 \%$ Diatomite & 0.67 & 0.569 \\
\hline $77 \%$ Diatomite & 0.805 & 0.237 \\
\hline $100 \%$ Diatomite & 1.014 & 0 \\
\hline
\end{tabular}

XRF data were output into excel spreadsheets, where elemental data were selected and used if concentrations were above detection limits and where correlations were significant. Initial data analysis involved plotting the elemental count data against traditionally measured data, including; calcium carbonate content, biogenic opal content, previously collected ITRAX data, water content and IRD content. This was to validate the XRF measurements, and ultimately confirmed the use of XRF data for elemental analysis.

Principal Component Analysis (PCA) was performed on logged elemental data to investigate multivariate relationships within the dataset. Kmeans clustering was then used to highlight key groups. Visual inspection of plots for $n=2 \ldots 10$ ( $n$ being the number of clusters) was used to infer the number of clusters suitable to group the data.

The PCA performed in this thesis has been utilised to highlight elements that vary either dependently or independently. The nature of the data ( $\mathrm{ppm})$, however, means that a change in one value affects the other values, and is commonly known as the mathematical closure problem. In attempt to resolve this issue, a log transformation was used prior to the PCA to standardize the data, i.e. scale the variability, and not all elements have been used in the analysis (i.e. sum $\neq 1,000,000$ ) (Borcard et al., 2011). It should be noted that the problem may not be completely corrected, although for the purpose of this thesis, the 
results obtained are unlikely to significantly compromise the conclusions from the analysis.
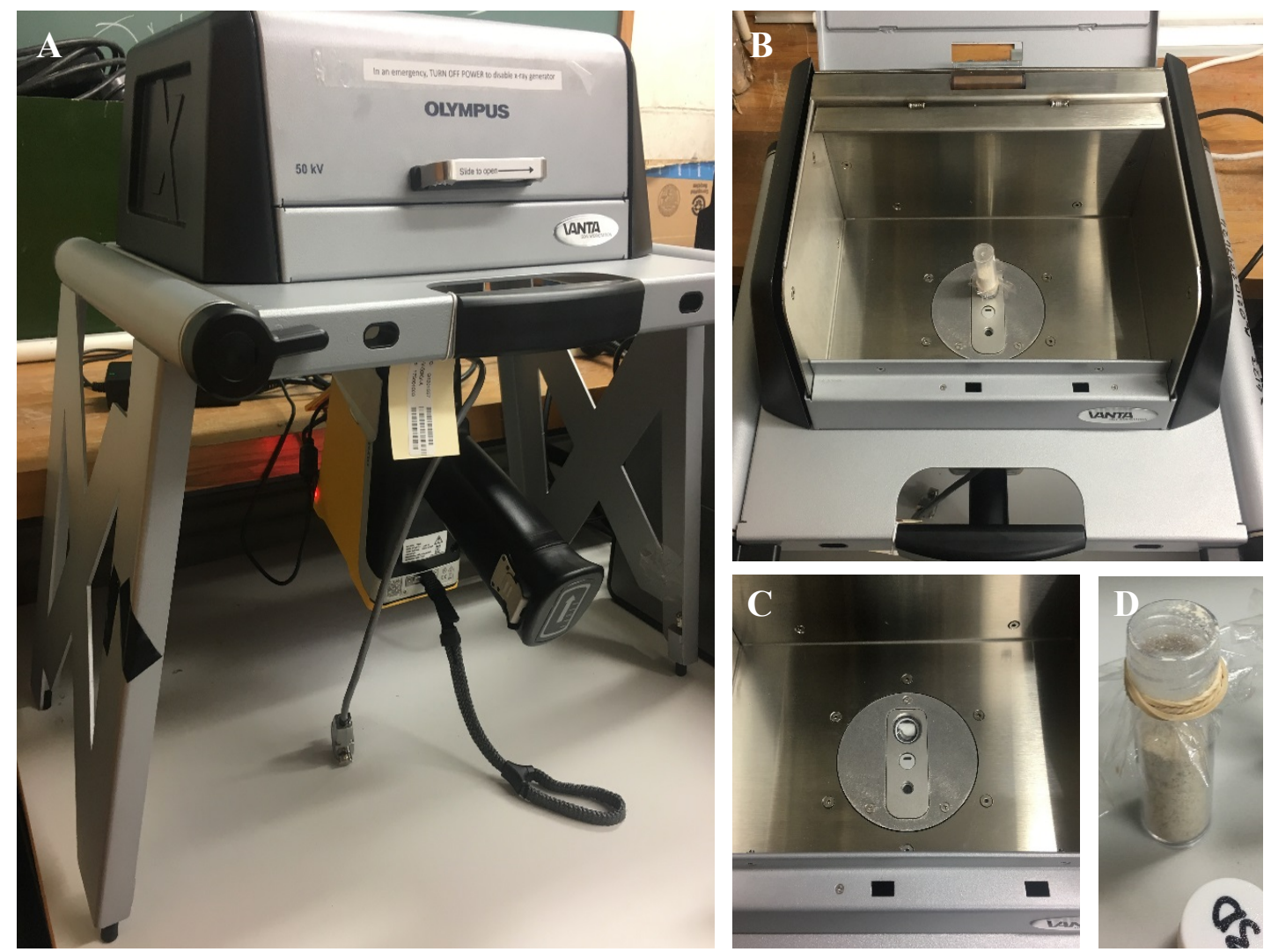

Figure 4.1. Photographs showing A) the Vanta XRF employed in the work station, B) a sample loaded into the lead-based chamber atop the work station, $\mathrm{C}$ ) the $\mathrm{XRF}$ is attached to the work station with a circular connector that attaches to the work-mount, D) the sample is analysed in plastic vials with a thin polypropylene film secured tautly at the opening with a rubber band. Samples are placed upside down, directly onto the XRF lens to

\subsection{Radiocarbon}

Two additional radiocarbon dates were obtained to better constrain the ages of the cores. Using XRF and carbonate data, the sample depths were selected from calcium carbonate peaks that were believed to be in the age range of the ${ }^{14} \mathrm{C}$ method, i.e. $<50 \mathrm{ka}$. A mixed assemblage of planktonic foraminifera, primarily N. pachyderma and G. bulloides, were picked for a total sample weight of $\sim 4 \mathrm{mg}$ of carbonate. The ${ }^{14} \mathrm{C}$ samples were processed and analysed using Accelerator Mass Spectrometry at the GNS Rafter laboratory. 


\subsection{Diatom analysis}

\subsubsection{Slide preparation}

Previously collected wet sediment samples were subsampled at $10 \mathrm{~cm}$ intervals for diatom analysis. Between $0.5 \mathrm{~g}$ and $1 \mathrm{~g}$ of material was transferred from zip-lock bags into plastic vials for ease of preparation and transport. Samples were treated with ethanol before being transported to VUW to comply with Ministry for Primary Industries biosecurity regulations. The ethanol was evaporated off before the dried samples were used for constructing slides.

Slide preparation followed similar methods to those outlined by Hasle and Fryxell (1970) and Clarke et al. (2005). Between 0.02-0.1g of sediment from the above subsamples (variation due to opal concentrations) was placed in a $50 \mathrm{~mL}$ vial which was topped up with $40 \mathrm{~mL}$ of filtered water to create the required dilution for effective analysis. The solution was shaken manually, and then mixed using a vortex mechanical stirrer for no longer than 10 seconds to assist disaggregation of sediment. After a 30 second period of settling, $0.25 \mathrm{~mL}$ of solution was transferred to a coverslip with a disposable pipette, dried, and attached to a microscope slide using naphrax, a high refractive index mountant commonly used for diatom slide preparation.

\subsubsection{Diatom Counts}

Diatom counts were performed on samples known to bracket a glacial termination (identified from $\delta^{18} \mathrm{O}$ data) in order to assess changes in abundance and community structure during a period of rapid warming. The termination of MIS 6 into MIS 5e i.e. TII, was selected for slide analysis. Samples identified were: $270-271 \mathrm{~cm}$ and $320-321 \mathrm{~cm}$ from TAN1302-96, and 210-211 cm and 230-231 cm TAN1302-97.

Three hundred individuals were counted using a transect method from each slide under 100X magnification. For pennate diatoms, an individual was counted as "one" if the majority $(>70 \%)$ or the whole specimen was intact, or as "one half" if a fragment included an apex. Centric diatoms were counted as "one" if the majority $(>70 \%)$ of the valve was present. 


\subsubsection{Assemblage analysis}

Diatom assemblages were formed by grouping the raw counts of individual species into their respective environmental groups (Section 3.2). The assemblage information was plotted as percentage bar graphs, including the three key environmental groups and an "other" category. Analysis involved comparing the key species present between samples, and how the relative proportions varied.

\subsubsection{Length and width measurements}

It has been shown in the South Atlantic region of the SO that the valve area of $F$. kerguelensis changes significantly across glacial terminations, whereby individuals are typically larger during glacial periods (Cortese et al., 2012). This is thought to be related to increased iron availability during windier glacial conditions (Shukla et al., 2013). The relationship between valve area and glacial-interglacial cycles in other regions of the SO however, appears to be more complex (Shukla et al., 2013). In an attempt to contribute to resolving some of these complexities within the southwest Pacific, the length and width of 50 random F. kerguelensis individuals were measured from each sample (Figure 4.2). An average valve area was then calculated, and box and whisker plots were constructed to show the degree of difference between samples.

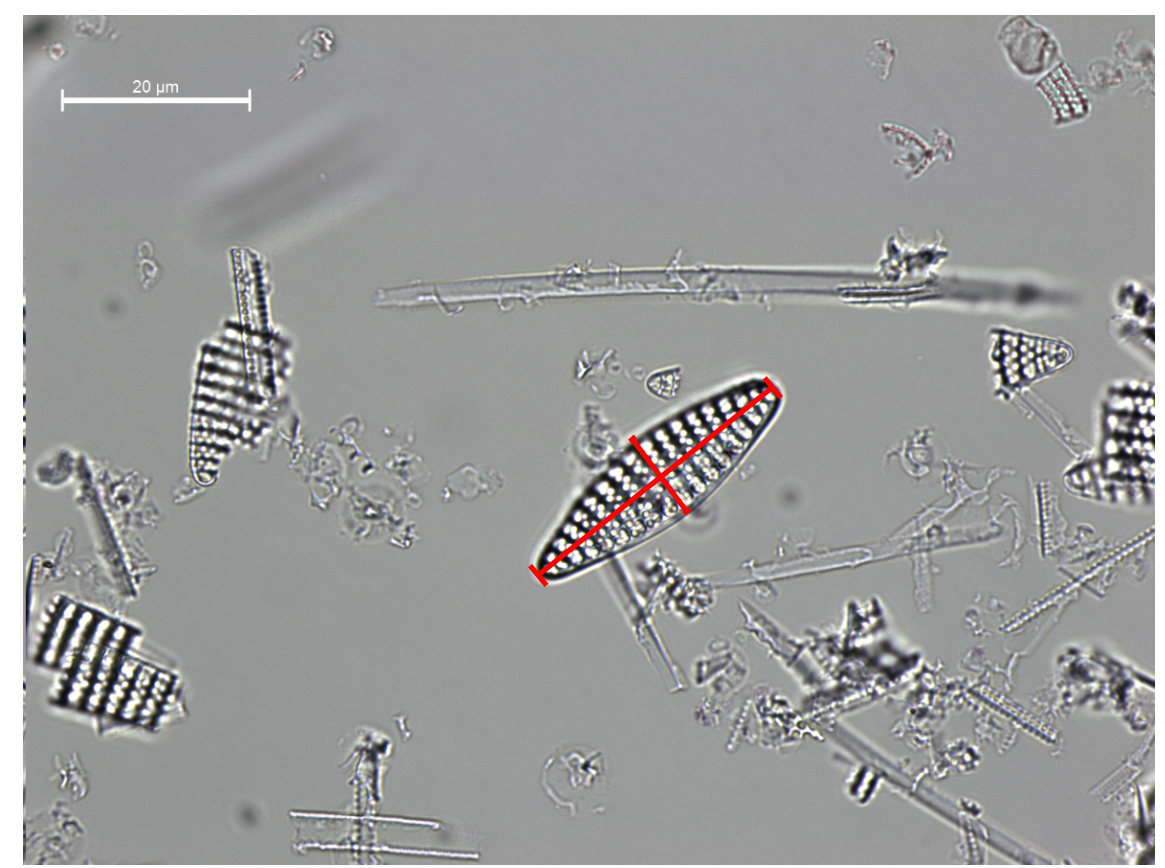

Figure 4.2. Photographof $F$. kerguelensis individual (middle) taken from TAN1302-97 at 210-211 cm depth. Measured axes highlighted in red. 


\subsection{Total organic carbon}

Samples used for dry bulk density (DBD) were used to calculate total organic carbon (TOC) $\%$ at $10 \mathrm{~cm}$ intervals. These samples had been previously dried at $100^{\circ} \mathrm{C}$ and had been stored in labelled zip-lock bags to prevent moisture from re-entering the material. Approximately $1 \mathrm{~g}$ of dried sample was weighed and transferred into aluminium dishes, before being placed in the furnace at $400^{\circ} \mathrm{C}$ for 2 hours. Once combusted, samples were reweighed and TOC \% was calculated using the following equations:

1) $\%$ water weight $=($ wet weight - dry weight $/$ wet weight $) * 100$

2) Salt weight $(\mathrm{g})=$ water weight*0.0346

3) Salt 1 correction for dry sediment $(\mathrm{g})=$ dry weight - salt weight

4) Salt 2 correction for combusted sediment $(\mathrm{g})=$ combusted weight - salt weight

5) $\% \mathrm{TOC}=(($ salt 1 -salt 2$) /$ salt 1$) * 100$

\subsection{Scanning Electron Microscope imaging}

Samples used for Scanning Electron Microscope (SEM) imaging were chosen from calcium peaks observed in the XRF data in order to determine and identify nannoplankton present within these periods. Two samples were chosen from TAN1302-96; $180-181 \mathrm{~cm}$ and $290-291 \mathrm{~cm}$, and three were selected from TAN1302-97; 210-211 cm, $250-251 \mathrm{~cm}$ and $310-311 \mathrm{~cm}$. A suspension was created using $0.01 \mathrm{~g}$ of dry sediment and $10 \mathrm{~mL}$ of filtered water, and mixed using an ultrasonic water bath. Where further dilution was necessary, $\sim 1 \mathrm{~mL}$ of suspension was taken from the solution and more filtered water was added. Carbon tape was attached to SEM stubs, and a silicon wafer was placed on top of the carbon tape. A glass pipette was used to transfer a drop of the diluted sediment onto the silicon wafer. The stubs were left to dry in a vacuum overnight, before being carbon coated for observation in a JEOL JSM-6610LA low vacuum electron microscope housed in the Electron Microscope Facility at VUW.

\subsection{Biogenic opal}

Additional biogenic opal analyses were performed on samples from TAN1302-96 and TAN1302-97 at the University of Tasmania by sequential alkaline leaching (DeMaster, 1981; Mortlock and Froelich, 1989). The results from Tasmania were obtained using the 
five-step method, compared to the one-step method used at Dalhousie University. Samples selected for the additional opal analysis were chosen from peaks and troughs observed in $\mathrm{Si} / \mathrm{Fe}$ ratios derived from XRF in attempt to minimise the impact of silicon hosted in lithogenic material. Ten samples were selected from TAN1302-96 and twelve were picked from TAN1302-97 (See Appendix C for opal data). 


\section{Chapter 5 Results}

\subsection{Water content \& dry bulk density}

TAN1302-96

Water content averages at $72.6 \%$ in TAN1302-96, and ranges from $79.4 \%$ at $100 \mathrm{~cm}$ to $65.9 \%$ at $320 \mathrm{~cm}$. Three significant peaks (>77\%) occur at 100, 220 and $310 \mathrm{~cm}$. Dry bulk density (DBD) variations in TAN1302-96 show that the material in the core is of relatively low density, ranging from $0.22-0.42 \mathrm{~g} / \mathrm{cm}^{3}$ and averaging $0.31 \mathrm{~g} / \mathrm{cm}^{3}$. Four distinct peaks are observed in the DBD data at 110, 180, 290 and $320 \mathrm{~cm}$ (Figure 5.1). These peaks coincide with significant drops in the water content of the core.

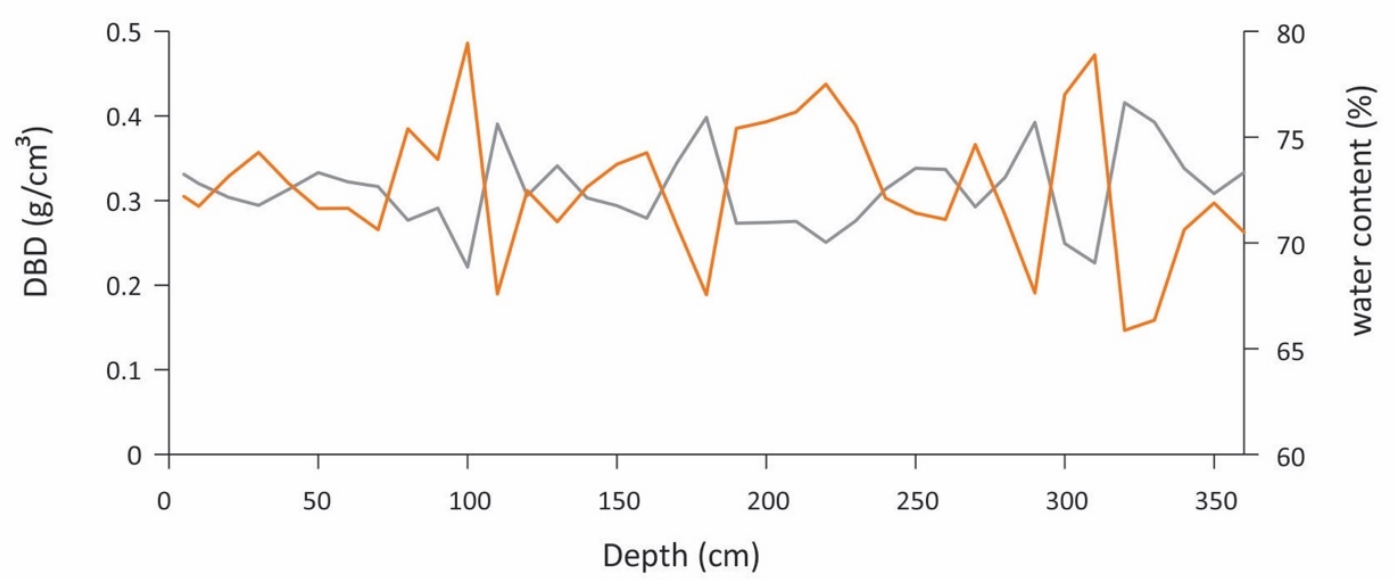

Figure 5.1. Water content $(\%)$ and dry bulk density $(\mathrm{DBD})\left(\mathrm{g} / \mathrm{cm}^{3}\right)$ at $10 \mathrm{~cm}$ intervals along TAN1302-96. DBD in grey and water content in orange.

\section{TAN1302-97}

Water content remains relatively high throughout TAN1302-97, but does vary by 20\%; reaching $78.0 \%$ at $289 \mathrm{~cm}$ and dropping to $57.8 \%$ at $309 \mathrm{~cm}$. The water content in the core drops abruptly at 48,229, 249 and $309 \mathrm{~cm}$, which occur concurrently with peaks in DBD (Figure 5.2). DBD data are very similar to the results from TAN1302-96 (0.24 $0.56 \mathrm{~g} / \mathrm{cm}^{3}$ ), and averages at $0.34 \mathrm{~g} / \mathrm{cm}^{3}$. 


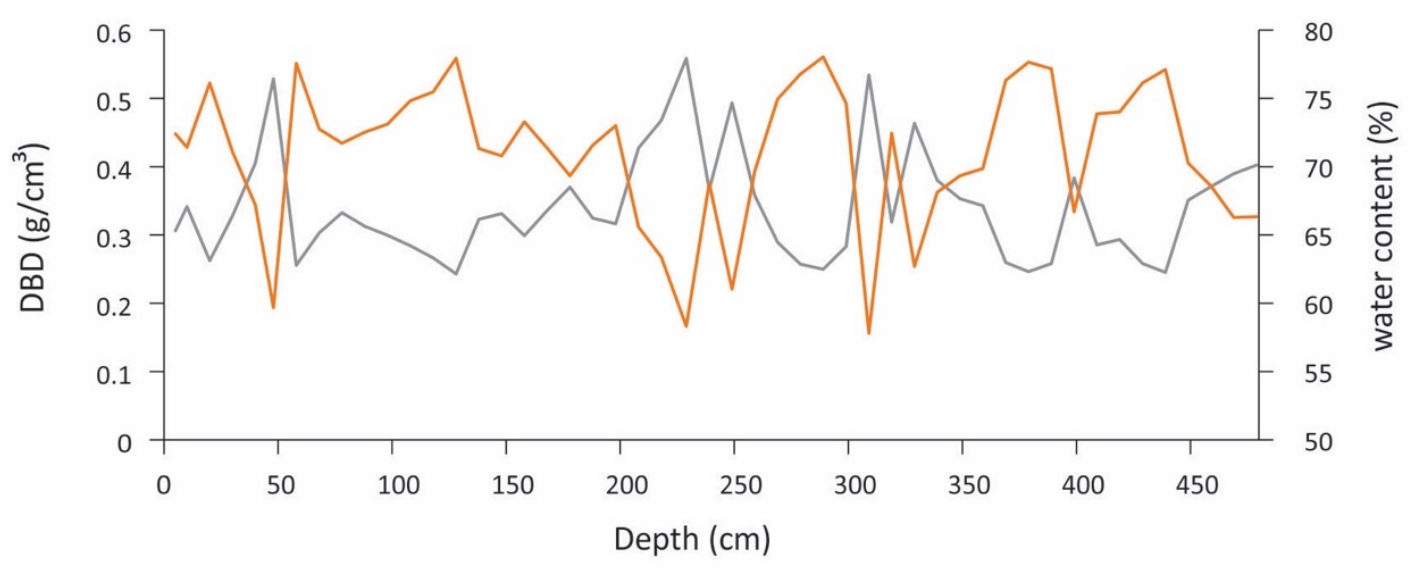

Figure 5.2. Water content $(\%)$ and $\mathrm{DBD}\left(\mathrm{g} / \mathrm{cm}^{3}\right)$ at $10 \mathrm{~cm}$ intervals along TAN1302-97. DBD in grey and water content in orange.

\subsection{Carbonate content and biogenic opal}

\section{TAN1302-96}

TAN1302-96 contains low to moderate levels of carbonate, ranging from $1.52-47.8 \%$. One large peak ( $48 \%)$ can be seen at $290 \mathrm{~cm}$, with smaller peaks apparent at 65,170 and $260 \mathrm{~cm}$, ranging between $21-25 \%$ (Figure 5.3).

The opal content in the upper section of TAN1302-96 remains relatively high, ranging from $57.4-78.6 \%$. A general anticorrelation between $\%$ opal and $\mathrm{CaCO}_{3} \%$ can be observed from the measured data (Figure 5.3), however, this relationship is much clearer $\left(\mathrm{r}^{2}>-0.94\right)$ in the XRF-derived elemental data (see Sections 5.5.1 and 5.5.3).

There is no clear relationship between the opal content and the water content of this core (Figure 5.4). Positive correlations were expected, however, whereby the water content of the cores could be used as a proxy to estimate the amount of biogenic opal (See Appendix A for cross correlations). The upper $40 \mathrm{~cm}$ of the top one meter section loosely follow the same trend, although this covariance is poorly constrained throughout the remaining 60 $\mathrm{cm}$. 


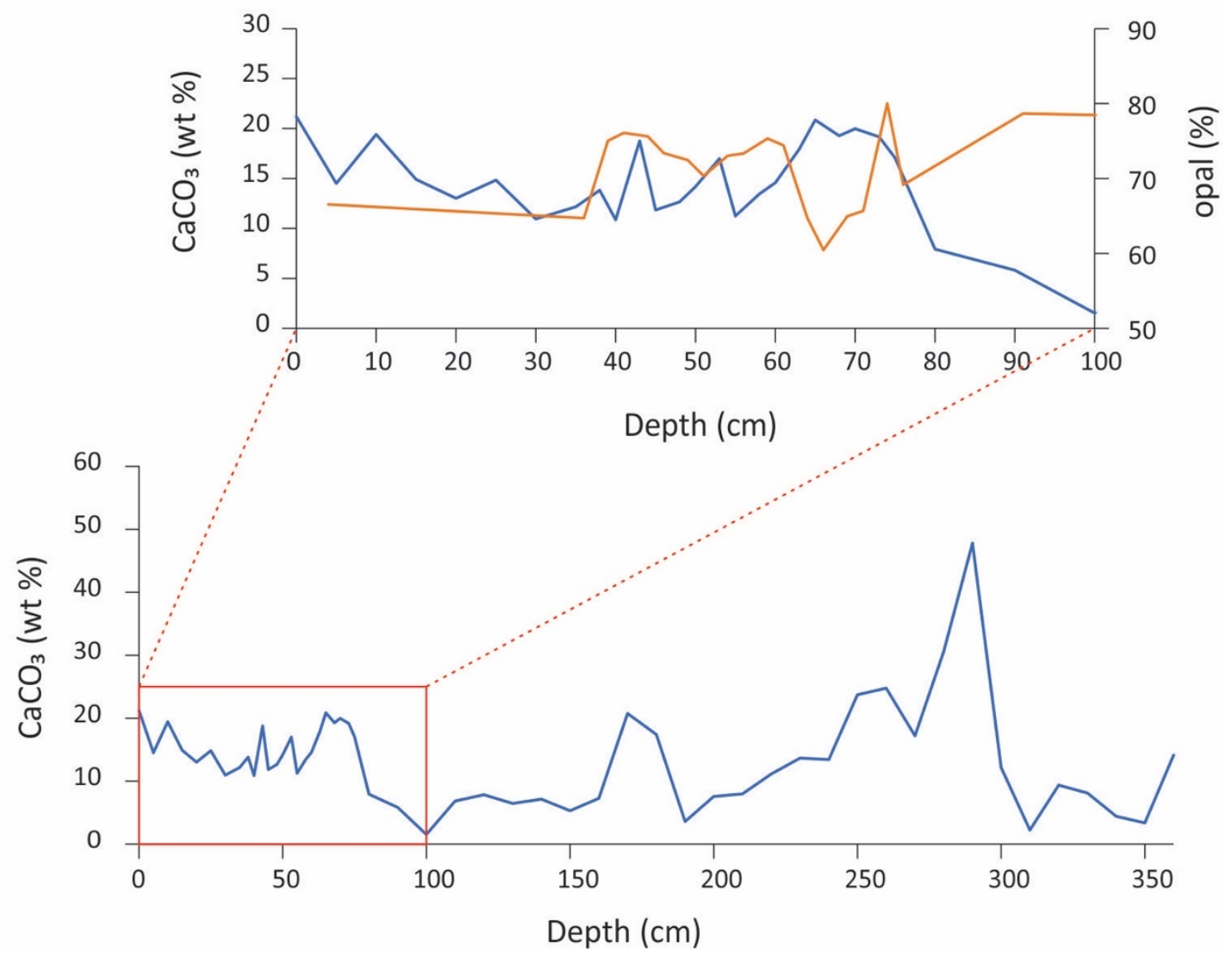

Figure 5.3. $\mathrm{CaCO}_{3}$ content (weight \%) in blue in TAN1302-96. Red box indicates section of the core analysed in detail for opal content at Dalhousie University. Inset graph is $\mathrm{CaCO}_{3}$ content (wt \%) in blue versus opal content (\%) in orange. Data provided by Helen Bostock.

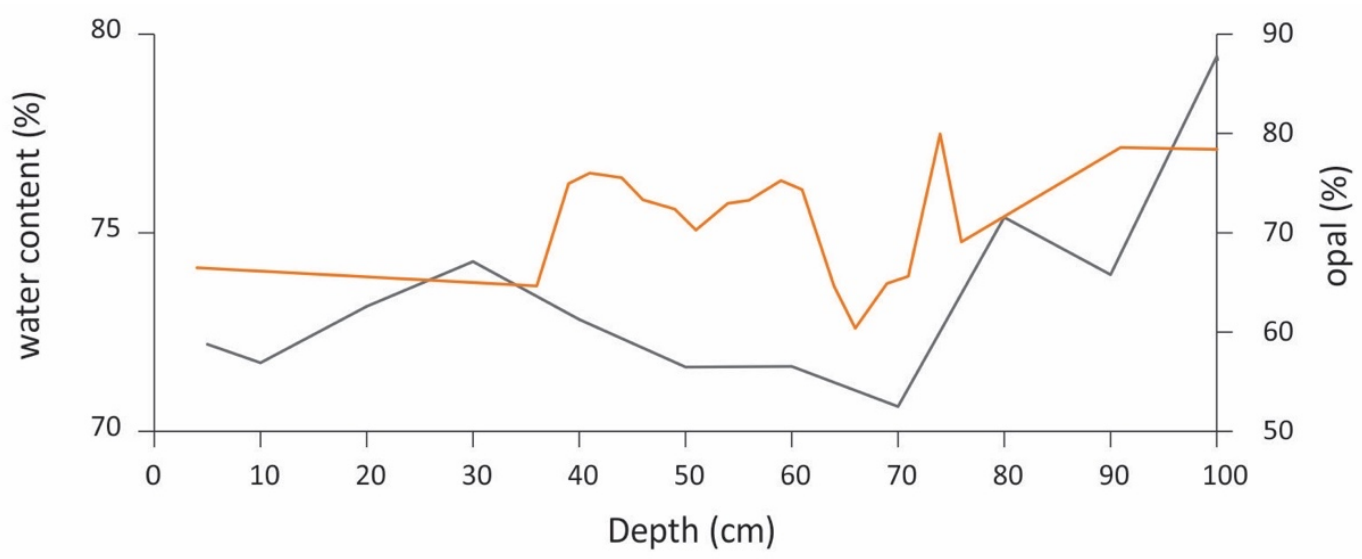

Figure 5.4. Biogenic opal (\%) in orange and water content (\%) in grey in the upper section of TAN1302-96. Biogenic opal data provided by Helen Bostock. 
TAN1302-97

$\mathrm{CaCO}_{3}$ content in TAN1302-97 varies significantly throughout the core, ranging from $6.49-61.7 \%$. Although there appears to be no apparent trend in $\mathrm{CaCO}_{3}$ throughout the core, significant peaks occur at 40,210, 250, 310 and $340 \mathrm{~cm}$ in a saw-tooth pattern (Figure 5.5).

Similarly to TAN1302-96, an overall anticorrelation between $\mathrm{CaCO}_{3}$ and opal \% can be observed in the measured data in the -97 core (Figure 5.5). Opal content in this core averages at $26.5 \%$, with three large peaks at 60,116 and $378 \mathrm{~cm}$ (ranging from 38.1 $46.9 \%)$.

Cross correlations between opal \% and water content revealed poor relationships in the TAN1302-96 opal data, however, a moderately strong, positive, exponential relationship can be observed in the -97 data $\left(r^{2}=0.51\right.$; See Appendix A) .

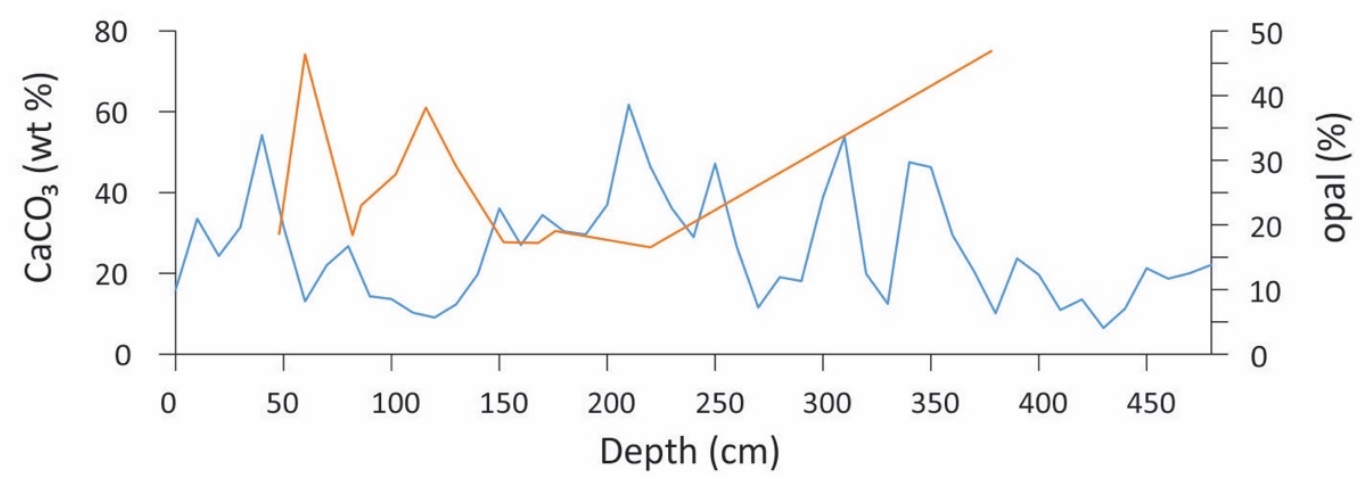

Figure 5.5. $\mathrm{CaCO}_{3}$ content (weight \%) in blue and opal content (\%) in orange in TAN1302-97. Data provided by Helen Bostock.

\subsection{Stable isotope analysis}

The $\delta^{18} \mathrm{O}$ signatures derived from planktic $N$. pachyderma show the clear saw-tooth pattern associated with glacial-interglacial climate cycles as recognised from Lisiecki \& Raymo's (2005) global benthic stack LR04 (Figure 5.6 and Figure 5.7). $\delta^{18} \mathrm{O}$ values range from $2.90-4.71 \%$ in TAN1302-96, and from $2.32-4.44 \%$ in TAN1302-97. Comparatively, the $\delta^{13} \mathrm{C}$ signatures generally reflect the variations observed in the $\delta^{18} \mathrm{O}$ record. These changes are not as profound, where values range from $-0.12-1.22 \%$ in TAN1302-96 and from $0.12-2.32 \%$ in TAN1302-97. 


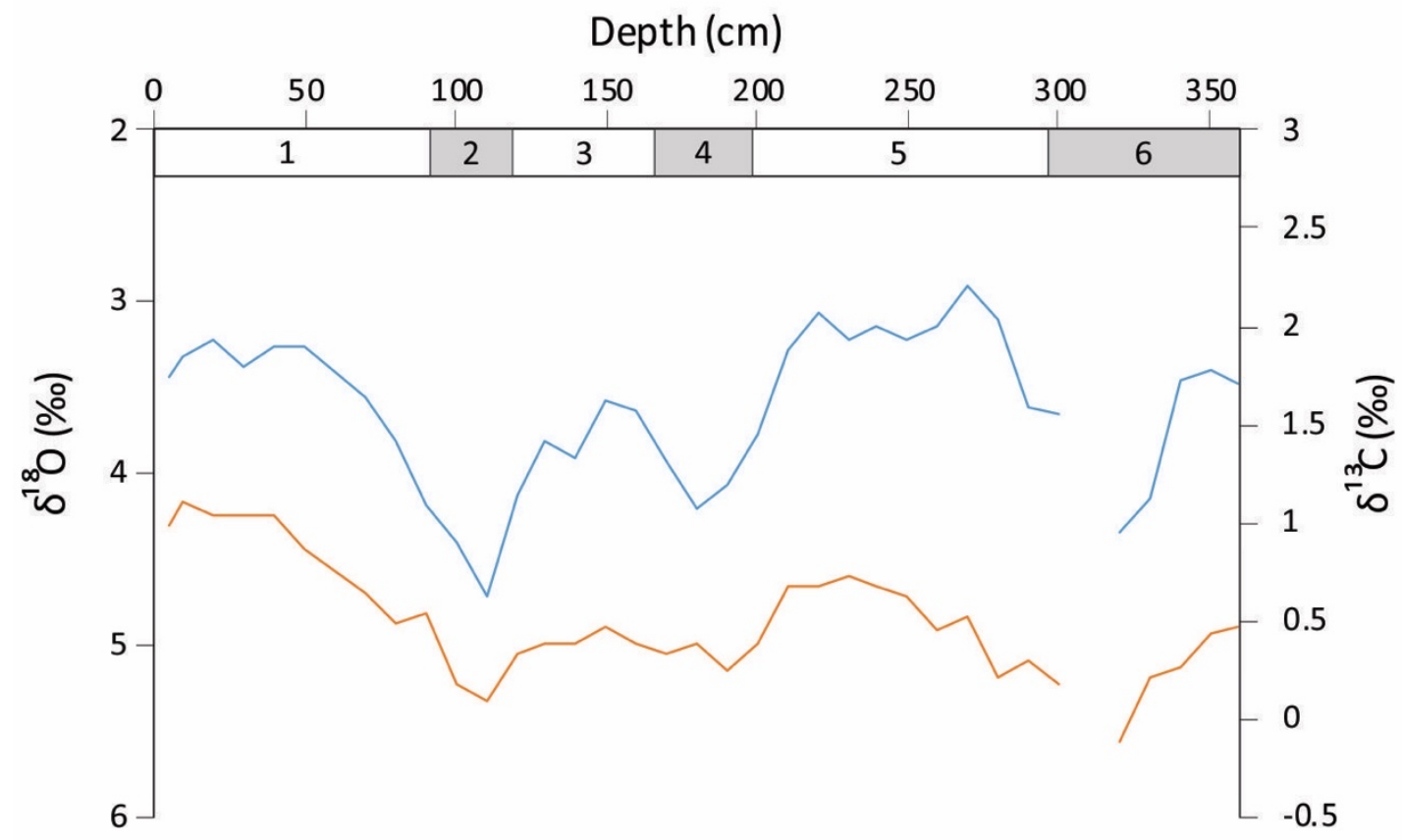

Figure 5.6. TAN1302-96 isotopes: $\delta^{18} \mathrm{O}(\%)$ in blue and $\delta^{13} \mathrm{C}(\%)$ in orange. Records derived from $N$. pachyderma in TAN1302-96. Value missing at $310 \mathrm{~cm}$ due to insufficient sample present. Estimations of Marine Isotope Stages (MIS) based on $\delta^{18} \mathrm{O}$ record indicated in top bar. Shaded bars denote glacial stages.

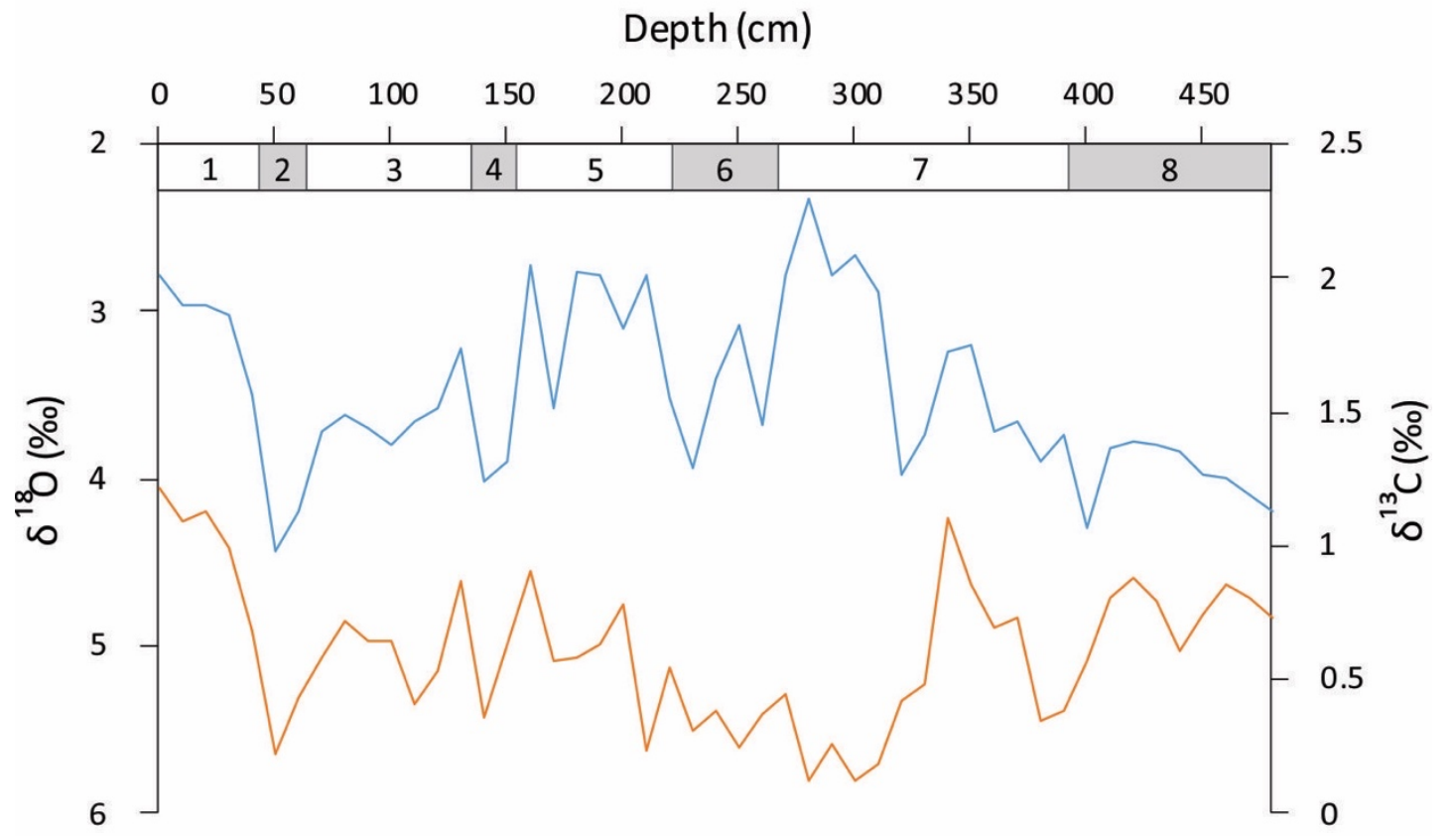

Figure 5.7. TAN1302-97 isotopes: $\delta^{18} \mathrm{O}(\%)$ in blue and $\delta^{13} \mathrm{C}(\%)$ in orange. Records derived from $N$. pachyderma in TAN1302-97. Estimations of Marine Isotope Stages (MIS) based on $\delta^{18} \mathrm{O}$ record indicated in top bar. Shaded bars denote glacial stages. 


\subsection{Iceberg rafted debris (IRD)}

\section{TAN1302-96}

IRD grains observed under the microscope in the $>180$ um fraction were typically quartz or small rock fragments. Two distinct IRD peaks can be observed in TAN1302-96; one at 110 and the other at $330 \mathrm{~cm}$, with a smaller peak at $180 \mathrm{~cm}$ (Figure 5.8).

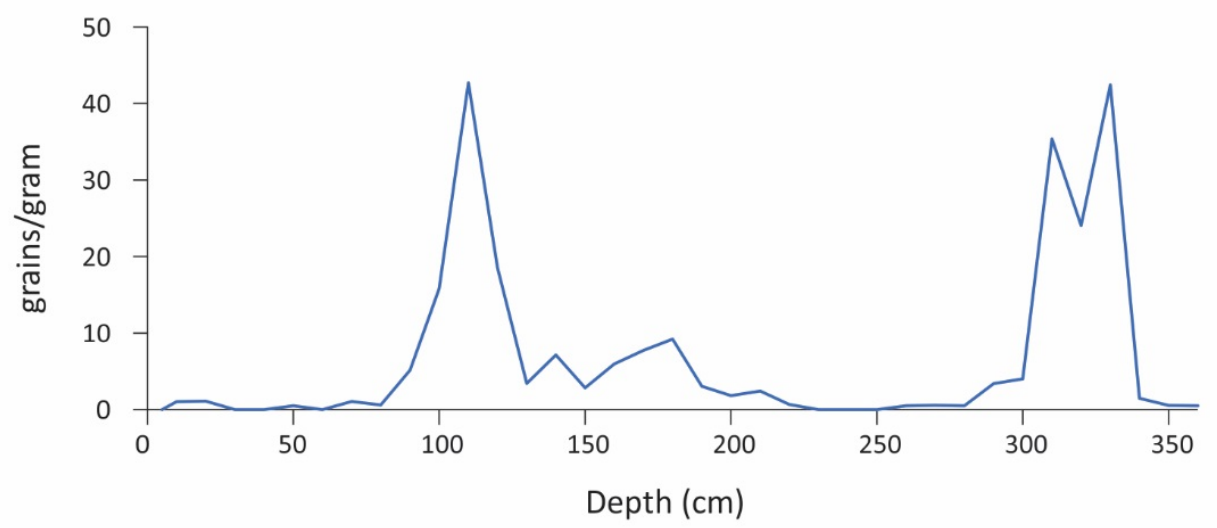

Figure 5.8. IRD content in TAN1302-96 at $10 \mathrm{~cm}$ intervals (grains/dry gram).

TAN1302-97

Similarly to TAN1302-96, the data in TAN1302-97 show clear periods of increased IRD, specifically at 50,230, 330 and $400 \mathrm{~cm}$, with smaller peaks at 260, 190, and $80 \mathrm{~cm}$ (Figure 5.9).

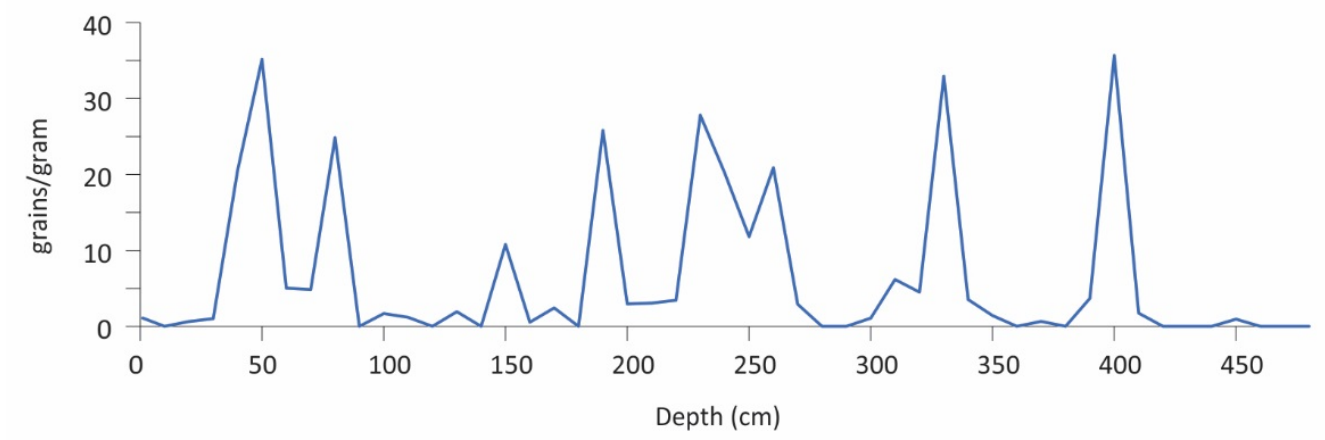

Figure 5.9. IRD content in TAN1302-97 at $10 \mathrm{~cm}$ intervals (grains/dry gram). 


\subsection{XRF elemental counts}

To test the validity of the XRF elemental data, Ca concentrations were compared to $\mathrm{CaCO}_{3} \%$ in both TAN1302-96 and -97. In both cores, Ca counts from XRF correlate strongly with $\mathrm{CaCO}_{3} \%$, (TAN1302-96: $\mathrm{r}^{2}=0.83$; TAN1302-97: $\mathrm{r}^{2}=0.92$ ) giving high confidence that the XRF provides a good relative measure of the amount of calcium carbonate in the cores (See Appendix A).

Additionally, the $\mathrm{Si}, \mathrm{Si} / \mathrm{Ti}$ and $\mathrm{Si} / \mathrm{Fe}$ ratios were compared to the opal data in the TAN cores (Figure 5.10, Figure 5.11, and Figure 5.12). In contrast to $\mathrm{Ca}$, the opal data and the biogenic silica proxies show different relationships between the TAN cores. Moderate to strong linear correlations exist in TAN1302-97 between opal and the silica proxies, the strongest $\left(\mathrm{r}^{2}=0.73\right)$ of which being between opal \% and $\mathrm{Si} / \mathrm{Fe}$ (Figure 5.12) When comparing the opal data in TAN1302-96, two distinct groups are evident; one high in opal and the other with lower amounts of opal (See Appendix A for combined TAN-96 opal data).

The group with higher opal content, in most cases, has better linear correlations with the biogenic silica proxies $\left(r^{2}<0.43\right)$ compared to the other opal group which has very poor linear relationships $\left(\mathrm{r}^{2}<0.11\right)$. Reconciling the poor correlation between these datasets is beyond the scope of this thesis, however, two possibilities would warrant further investigation. The first is that since $\mathrm{Si}$ is hosted in both biogenic silica and lithogenic material and the two sources are not differentiated by XRF, there is a significantly greater flux of non-biogenic silica to TAN1302-96 compared to -97 that is not being adequately normalised by dividing Si by Fe. This might occur where there are large changes in the composition/provenance of lithogenic material over time. A second possibility involves the lab methodologies used, given that the two groups also represent the two opal datasets collected from Dalhousie University and the University of Tasmania. Typically, the 5step method (used at Tasmania) gives a better relationship (DeMaster, 1981; Mortlock and Froelich, 1989), although it is still much poorer compared to the -97 data. It therefore may be that the alkali leaching process is not extracting Si proportional to the to the abundance of biogenic silica. Alternatively, it may be some combination of the two possibilities outlined. 


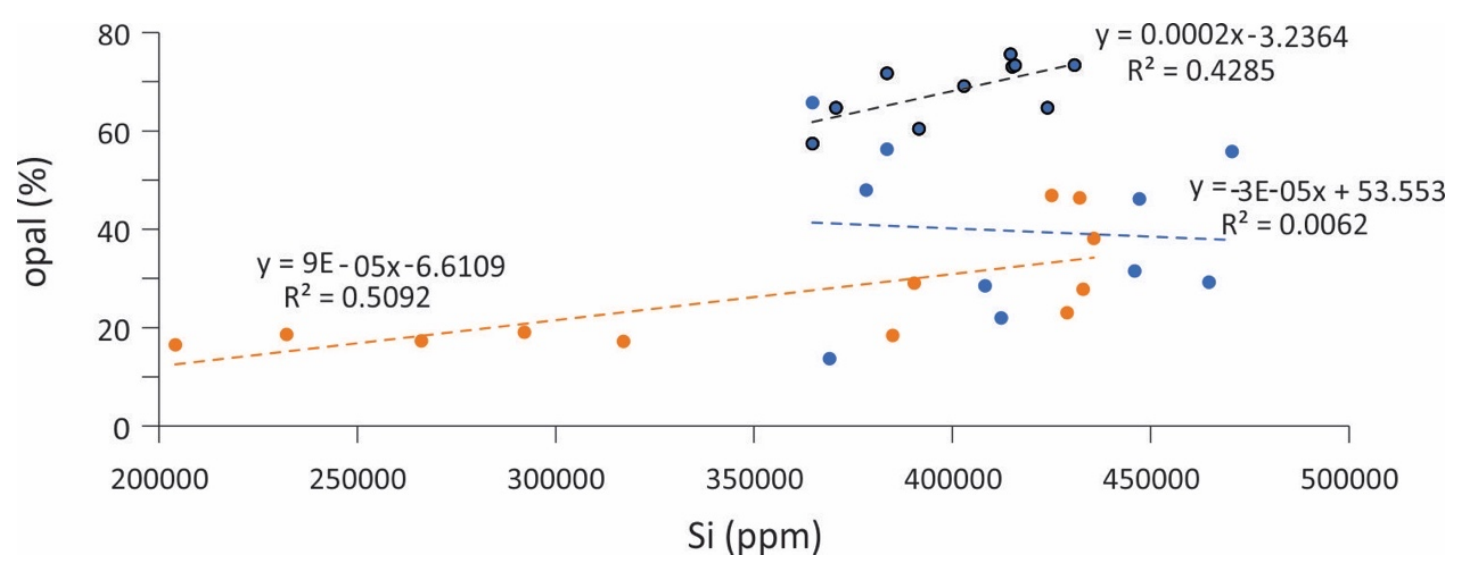

Figure 5.10. Cross-correlation between opal \% and Si concentrations (ppm) measured from XRF in TAN1302-96 $\left(\mathrm{r}^{2}<\right.$ $0.01)$ in blue, and in TAN1302-97 $\left(r^{2}=0.51\right)$ in orange. Dalhousie opal data points $\left(r^{2}=0.43\right)$ outlined in black.

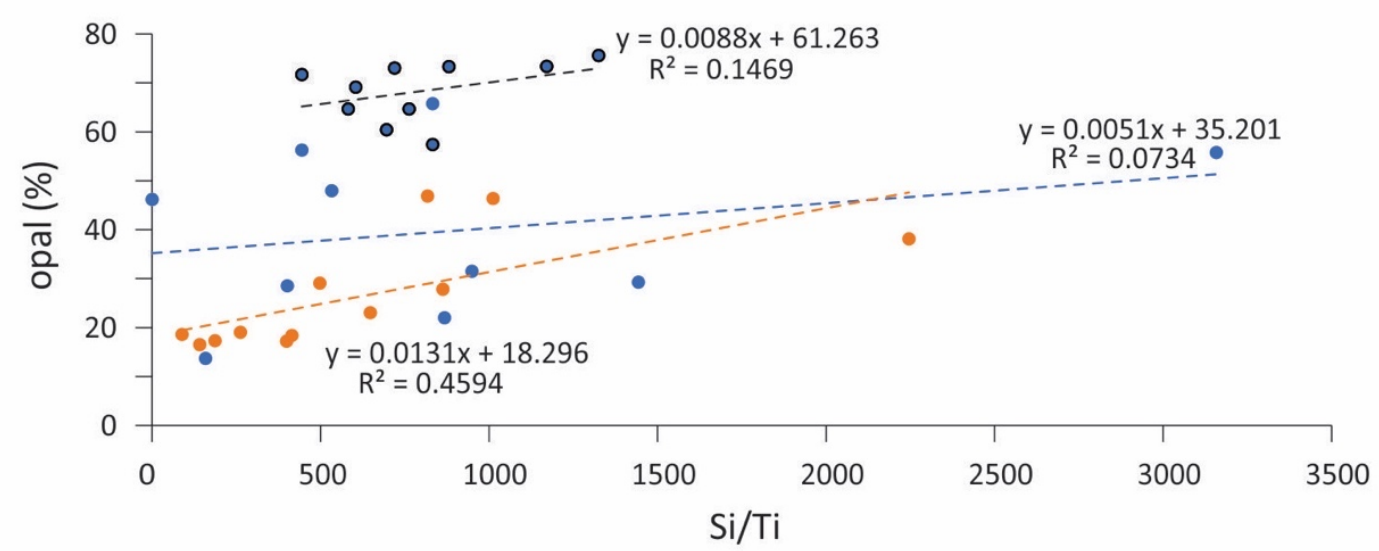

Figure 5.11. Cross correlation between opal \% and Si/Ti. TAN1302-96 in blue and TAN1302-97 in orange. Correlation is stronger in TAN1302-97 $\left(\mathrm{r}^{2}=0.46\right)$ compared to TAN1302-96 $\left(\mathrm{r}^{2}=0.07\right)$. Dalhousie opal data $\left(\mathrm{r}^{2}=0.15\right)$ outlined in black.

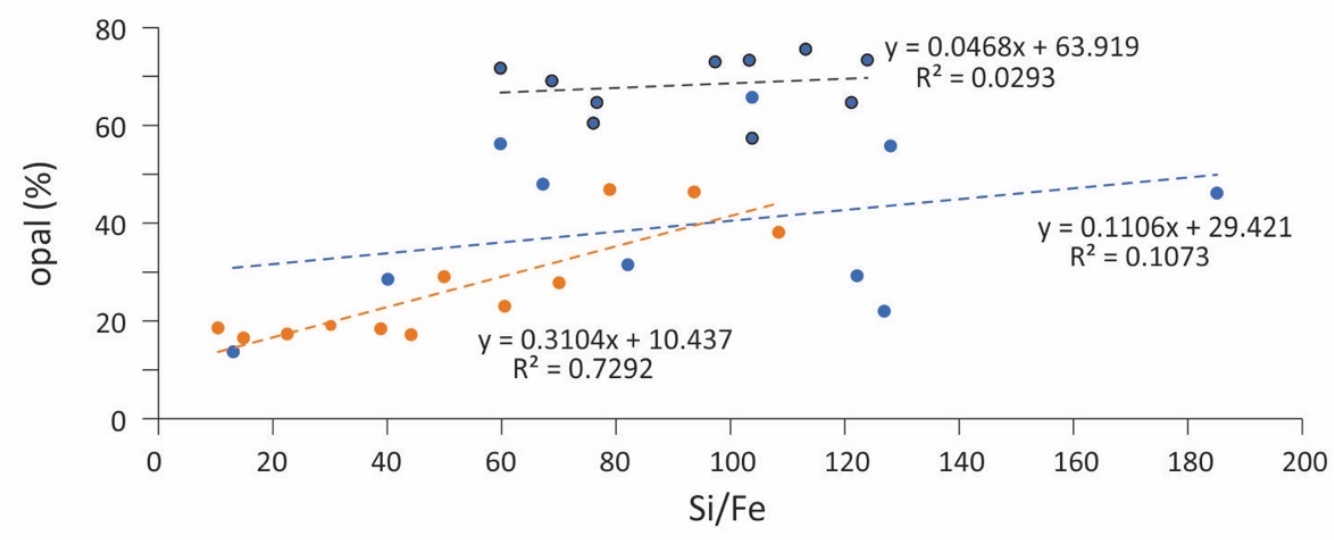

Figure 5.12. Cross correlation between opal \% and Si/Fe. TAN1302-96 in blue and TAN1302-97 in orange. Correlation is stronger in TAN1302-97 $\left(\mathrm{r}^{2}=0.73\right)$ compared to TAN1302-96 $\left(\mathrm{r}^{2}=0.11\right)$. Dalhousie opal data $\left(\mathrm{r}^{2}=0.03\right)$ outlined in black. 
In comparing the $\mathrm{Si}$ concentrations to the water content of the cores, moderately strong positive relationships are observed (TAN1302-96: $r^{2}=0.45$; TAN1302-97: $r^{2}=0.69$ ). Furthermore, similar moderately strong exponential relationships are also noted in both cores (TAN1302-96: $\mathrm{r}^{2}=0.48$; TAN1302-97: $\mathrm{r}^{2}=0.63$ ) between the water content and $\mathrm{Si} / \mathrm{Fe}$ ratios (Figure 5.13).

Under non-linear regressions, the correlations between $\mathrm{Si} / \mathrm{Fe}$ and opal improve considerably for the TAN-96 Tasmania data $\left(\mathrm{r}^{2}=0.34\right)$, as well as for the -97 data $\left(\mathrm{r}^{2}=\right.$ 0.78) (See Appendix A). Given moderate-strong relationships exist between opal, $\mathrm{Si} / \mathrm{Fe}$, and the water content across the cores, $\mathrm{Si} / \mathrm{Fe}$ is used as the primary proxy for biogenic silica in this study. Although this is not ideal for TAN1302-96, $\mathrm{Si} / \mathrm{Fe}$ is the best approximation for biogenic silica in this thesis as a result of apparent inconsistencies in lab methodology and for attempting to normalise the seemingly greater input of nonbiogenic silica to the southern PFZ core site.

The decision to use $\mathrm{Fe}$ over $\mathrm{Ti}$ was due to lower concentrations of $\mathrm{Ti}$ (sometimes 0 ) relative to $\mathrm{Fe}$ (Figure 5.16 and Figure 5.17).

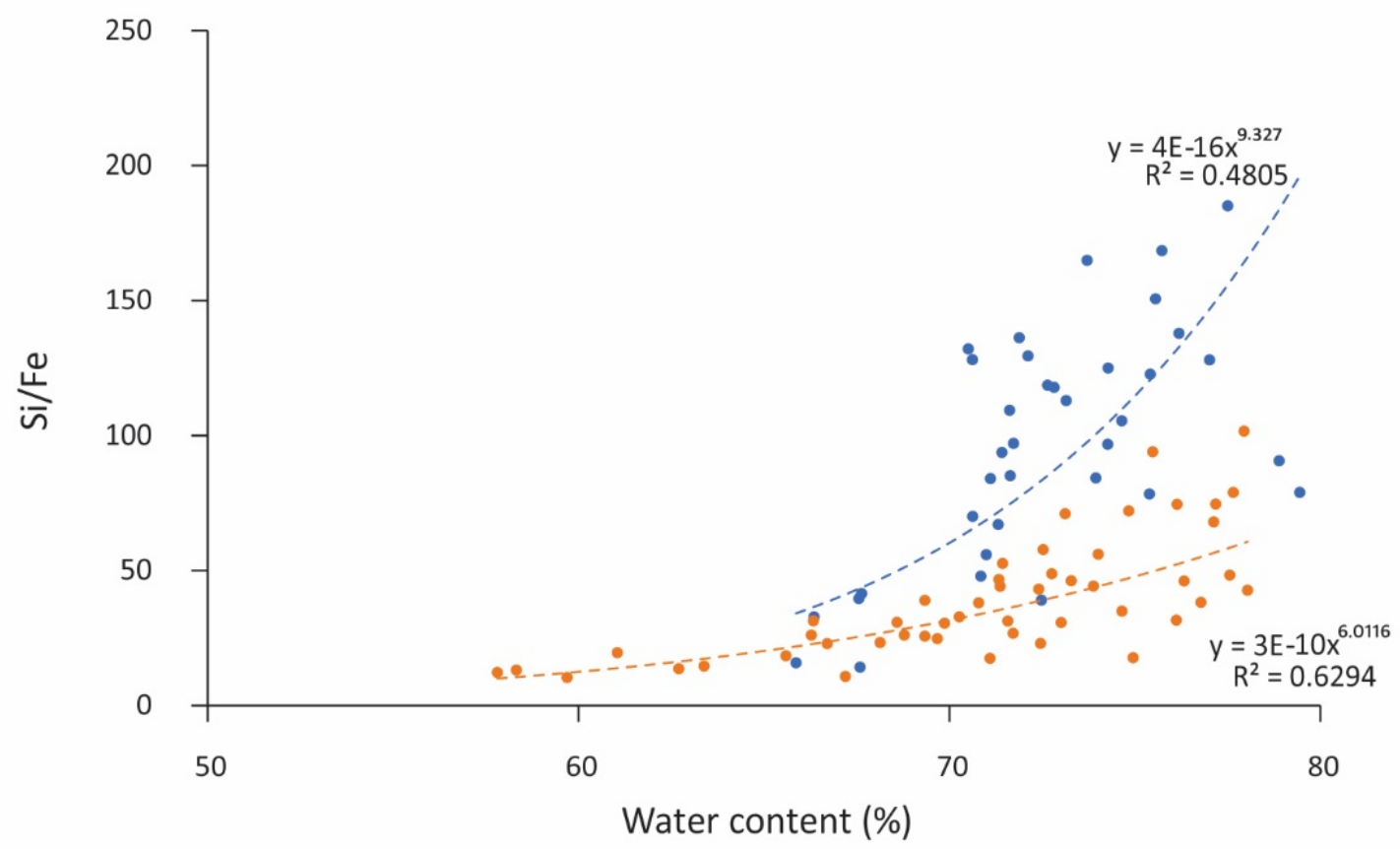

Figure 5.13. Correlation between $\mathrm{Si} / \mathrm{Fe}$ and water content (\%). TAN1302-96 in blue, and TAN1302-97 in orange. Correlation is stronger in TAN1302-97 $\left(r^{2}=0.63\right)$ than TAN1302-96 $\left(r^{2}=0.48\right)$. 


\subsubsection{Correlations and principal component analysis}

Correlation matrices were produced using elements that were significantly above detection limits (Table 5.1 and Table 5.2). Elements that were strongly correlated fall into three distinct groups; $\mathrm{Fe}, \mathrm{Ti}, \mathrm{Al}, \mathrm{K}$ and $\mathrm{Zr}$ - a reflection of the input of terrigenous material; $\mathrm{Ca}$ and $\mathrm{Sr}$ - reflecting calcifying organisms, i.e. foraminifera and coccolithophores; and $\mathrm{Si}$ - related to biogenic silica i.e. diatoms. This was confirmed from PCA and kmeans clustering, which highlighted 3-4 key groups of elements (Figure 5.14 and Figure 5.15).

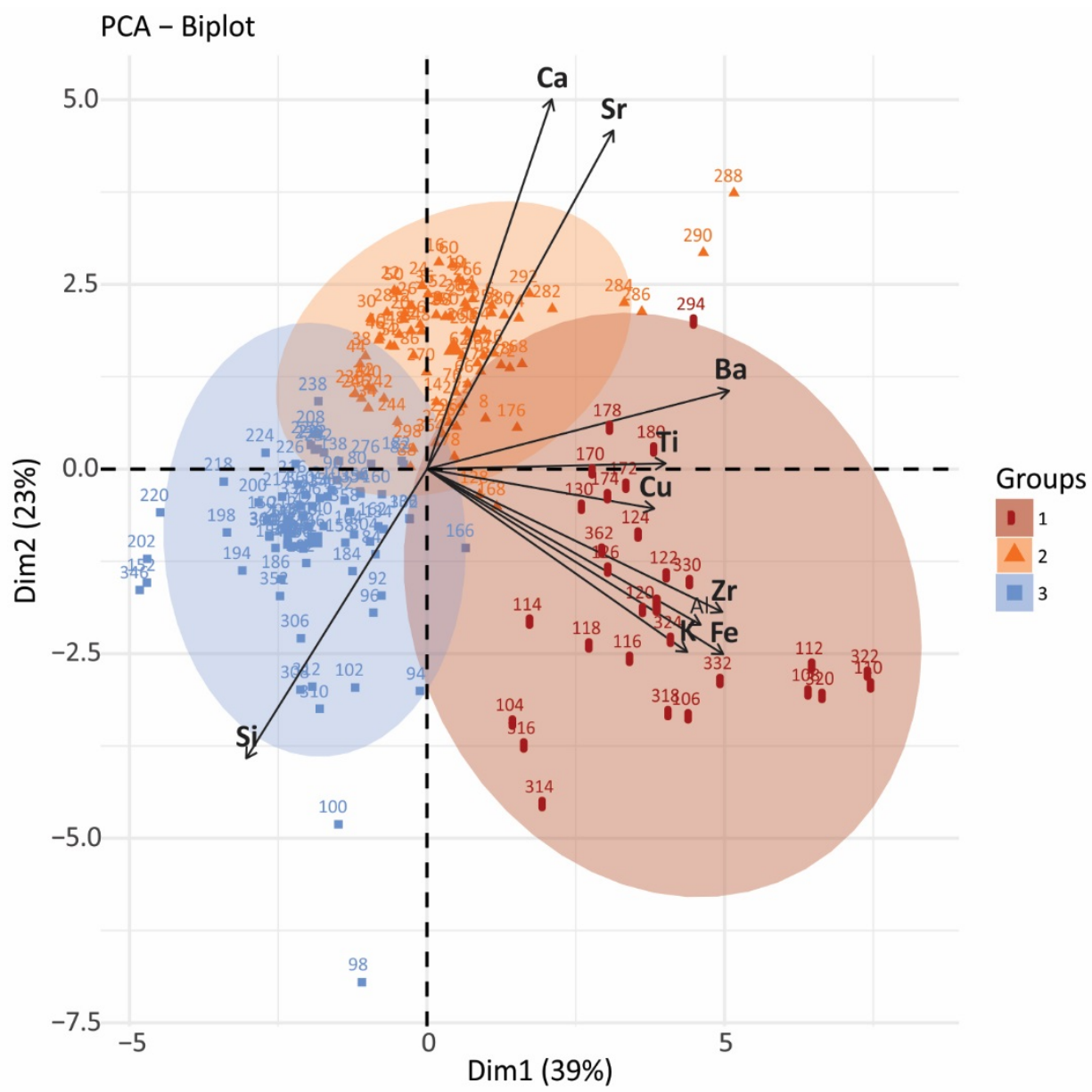

Figure 5.14. PCA with k-means clustering on depth samples obtained from XRF scanning on TAN1302-96. 


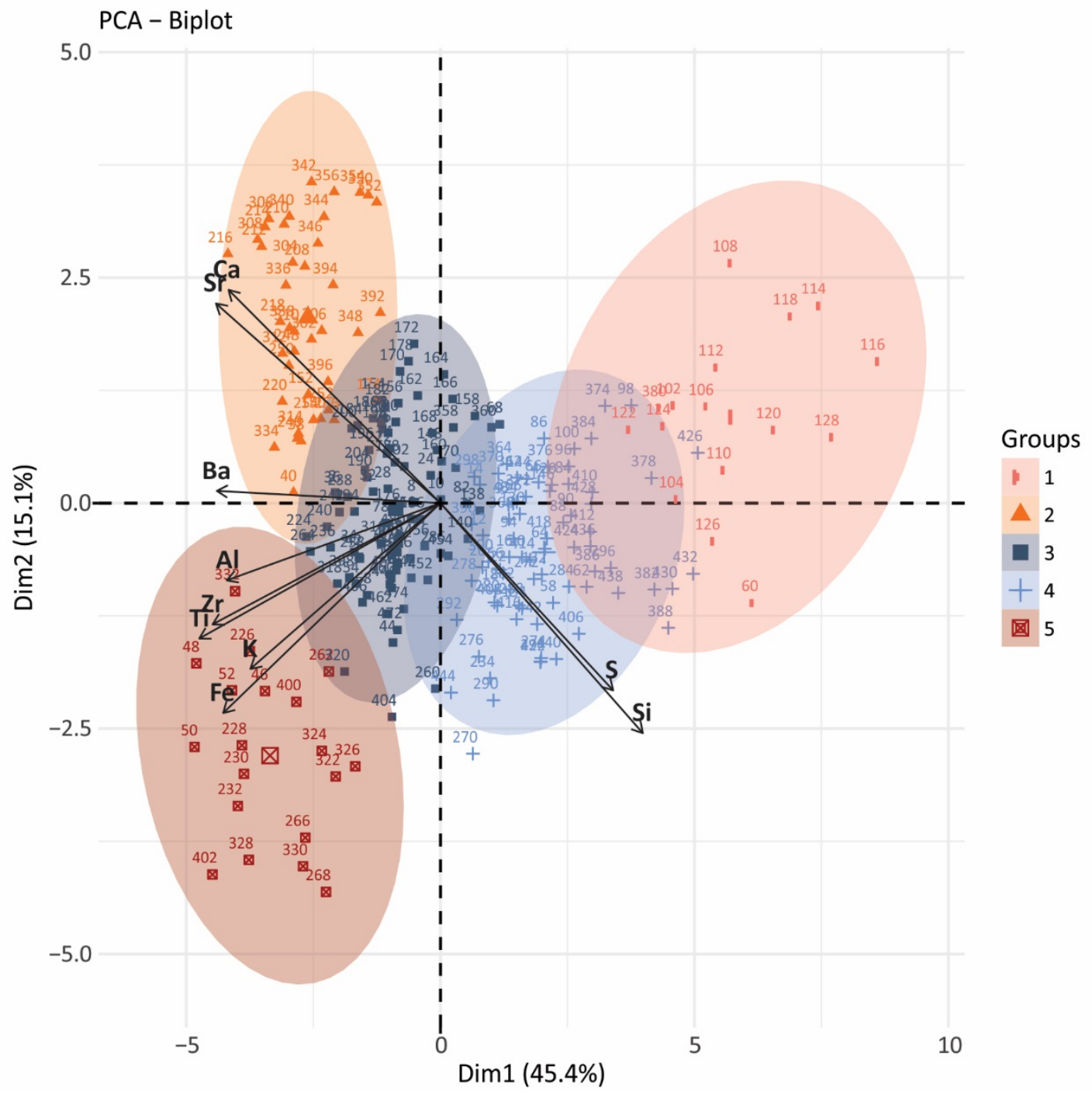

Figure 5.15. PCA with k-means clustering on depth samples obtained from XRF scanning on TAN1302-97. 
Table 5.1. Correlation matrix for elemental counts in TAN1302-96. Strong correlations are highlighted.

\begin{tabular}{|c|c|c|c|c|c|c|c|c|c|c|c|c|c|c|}
\hline Element & $\mathrm{Al}$ & $\mathrm{Si}$ & $\mathrm{Ca}$ & $\mathrm{Ti}$ & $\mathrm{Mn}$ & $\mathrm{Fe}$ & $\mathrm{Cu}$ & $\mathrm{Zn}$ & $\mathrm{Rb}$ & $\mathrm{Sr}$ & $\mathrm{Ba}$ & $S$ & $\mathrm{~K}$ & $\mathrm{Zr}$ \\
\hline $\mathrm{Al}$ & 1 & -0.1323 & -0.0827 & 0.8341 & -0.0687 & 0.9166 & 0.4265 & 0.2467 & 0.6313 & 0.0095 & -0.0254 & 0.1328 & 0.9773 & 0.8954 \\
\hline Si & -0.1323 & 1 & -0.9361 & -0.2715 & 0.1590 & -0.0972 & -0.1877 & 0.2306 & -0.1740 & -0.9285 & -0.1860 & 0.3428 & -0.0960 & -0.1923 \\
\hline $\mathrm{Ca}$ & -0.0827 & -0.9361 & 1 & 0.1156 & -0.2032 & -0.0965 & 0.0822 & -0.4010 & 0.0803 & 0.9792 & 0.2004 & -0.3793 & -0.1179 & 0.0231 \\
\hline $\mathrm{Ti}$ & 0.8341 & -0.2715 & 0.1156 & 1 & -0.0431 & 0.9421 & 0.5843 & 0.1008 & 0.5984 & 0.2373 & -0.0695 & 0.1103 & 0.8718 & 0.9126 \\
\hline $\mathrm{Mn}$ & -0.0687 & 0.1590 & -0.2032 & -0.0431 & 1 & -0.0271 & 0.6409 & 0.5687 & -0.2146 & -0.1641 & 0.0478 & 0.1615 & -0.0194 & -0.0647 \\
\hline $\mathrm{Fe}$ & 0.9166 & -0.0972 & -0.0965 & 0.9421 & -0.0271 & 1 & 0.5254 & 0.2550 & 0.6489 & 0.0250 & -0.1157 & 0.1346 & 0.9455 & 0.9577 \\
\hline $\mathrm{Cu}$ & 0.4265 & -0.1877 & 0.0822 & 0.5843 & 0.6409 & 0.5254 & 1 & 0.3395 & 0.1146 & 0.1893 & 0.0804 & 0.0270 & 0.4726 & 0.5155 \\
\hline $\mathrm{Zn}$ & 0.2467 & 0.2306 & -0.4010 & 0.1008 & 0.5687 & 0.2550 & 0.3395 & 1 & 0.0745 & -0.3901 & -0.0923 & 0.1193 & 0.2833 & 0.1872 \\
\hline $\mathrm{Rb}$ & 0.6313 & -0.1740 & 0.0803 & 0.5984 & -0.2146 & 0.6489 & 0.1146 & 0.0745 & 1 & 0.1226 & 0.1740 & -0.0280 & 0.6558 & 0.6317 \\
\hline $\mathrm{Sr}$ & 0.0095 & -0.9285 & 0.9792 & 0.2373 & -0.1641 & 0.0250 & 0.1893 & -0.3901 & 0.1226 & 1 & 0.1649 & -0.3511 & -0.0187 & 0.1493 \\
\hline $\mathrm{Ba}$ & -0.0254 & -0.1860 & 0.2004 & -0.0695 & 0.0478 & -0.1157 & 0.0804 & -0.0923 & 0.1740 & 0.1649 & 1 & -0.3471 & -0.0248 & -0.1262 \\
\hline$S$ & 0.1328 & 0.3428 & -0.3793 & 0.1103 & 0.1615 & 0.1346 & 0.0270 & 0.1193 & -0.0280 & -0.3511 & -0.3471 & 1 & 0.1716 & 0.0427 \\
\hline $\mathrm{K}$ & 0.9773 & -0.0960 & -0.1179 & 0.8718 & -0.0194 & 0.9455 & 0.4726 & 0.2833 & 0.6558 & -0.0187 & -0.0248 & 0.1716 & 1 & 0.9003 \\
\hline $\mathrm{Zr}$ & 0.8954 & -0.1923 & 0.0231 & 0.9126 & -0.0647 & 0.9577 & 0.5155 & 0.1872 & 0.6317 & 0.1493 & -0.1262 & 0.0427 & 0.9003 & 1 \\
\hline
\end{tabular}


Table 5.2. Correlation matrix for elemental counts in TAN1302-97. Strong correlations are highlighted.

\begin{tabular}{|c|c|c|c|c|c|c|c|c|c|c|c|c|c|c|}
\hline Elements & $\mathrm{Al}$ & $\mathrm{Si}$ & $\mathrm{Ca}$ & $\mathrm{Ti}$ & $\mathrm{Mn}$ & $\mathrm{Fe}$ & $\mathrm{Cu}$ & $\mathrm{Zn}$ & $\mathrm{Rb}$ & $\mathrm{Sr}$ & $\mathrm{Ba}$ & $S$ & $\mathrm{~K}$ & $\mathrm{Zr}$ \\
\hline $\mathrm{Al}$ & 1 & -0.5468 & 0.3899 & 0.9464 & 0.0442 & 0.9328 & 0.3377 & 0.1012 & 0.4268 & 0.4563 & 0.5975 & -0.4756 & 0.9358 & 0.9225 \\
\hline $\mathrm{Si}$ & -0.5468 & 1 & -0.9685 & -0.4965 & 0.0250 & -0.3565 & -0.1604 & 0.2305 & 0.0437 & -0.9737 & -0.6093 & 0.6103 & -0.3346 & -0.4654 \\
\hline $\mathrm{Ca}$ & 0.3899 & -0.9685 & 1 & 0.3461 & -0.0353 & 0.1877 & 0.1101 & -0.3669 & -0.1332 & 0.9908 & 0.5623 & -0.5694 & 0.1627 & 0.3140 \\
\hline $\mathrm{Ti}$ & 0.9464 & -0.4965 & 0.3461 & 1 & 0.0138 & 0.9625 & 0.4036 & 0.0869 & 0.4285 & 0.4084 & 0.7133 & -0.4830 & 0.9333 & 0.9221 \\
\hline $\mathrm{Mn}$ & 0.0442 & 0.0250 & -0.0353 & 0.0138 & 1 & 0.0327 & 0.5043 & 0.2335 & -0.2994 & -0.0248 & -0.1466 & 0.2733 & 0.0140 & 0.0065 \\
\hline $\mathrm{Fe}$ & 0.9328 & -0.3565 & 0.1877 & 0.9625 & 0.0327 & 1 & 0.3977 & 0.1929 & 0.5131 & 0.2555 & 0.5806 & -0.3987 & 0.9583 & 0.9175 \\
\hline $\mathrm{Cu}$ & 0.3377 & -0.1604 & 0.1101 & 0.4036 & 0.5043 & 0.3977 & 1 & 0.1988 & -0.0997 & 0.1348 & 0.3374 & -0.1238 & 0.3148 & 0.3443 \\
\hline $\mathrm{Zn}$ & 0.1012 & 0.2305 & -0.3669 & 0.0869 & 0.2335 & 0.1929 & 0.1988 & 1 & 0.1003 & -0.3653 & -0.2332 & 0.1705 & 0.1852 & 0.0806 \\
\hline $\mathrm{Rb}$ & 0.4268 & 0.0437 & -0.1332 & 0.4285 & -0.2994 & 0.5131 & -0.0997 & 0.1003 & 1 & -0.1193 & 0.1961 & -0.0002 & 0.5512 & 0.4191 \\
\hline $\mathrm{Sr}$ & 0.4563 & -0.9737 & 0.9908 & 0.4084 & -0.0248 & 0.2555 & 0.1348 & -0.3653 & -0.1193 & 1 & 0.6009 & -0.6050 & 0.2341 & 0.3859 \\
\hline $\mathrm{Ba}$ & 0.5975 & -0.6093 & 0.5623 & 0.7133 & -0.1466 & 0.5806 & 0.3374 & -0.2332 & 0.1961 & 0.6009 & 1 & -0.5705 & 0.5822 & 0.5625 \\
\hline$S$ & -0.4756 & 0.6103 & -0.5694 & -0.4830 & 0.2733 & -0.3987 & -0.1238 & 0.1705 & -0.0002 & -0.6050 & -0.5705 & 1 & -0.3514 & -0.4680 \\
\hline $\mathrm{K}$ & 0.9358 & -0.3346 & 0.1627 & 0.9333 & 0.0140 & 0.9583 & 0.3148 & 0.1852 & 0.5512 & 0.2341 & 0.5822 & -0.3514 & 1 & 0.8913 \\
\hline $\mathrm{Zr}$ & 0.9225 & -0.4654 & 0.3140 & 0.9221 & 0.0065 & 0.9175 & 0.3443 & 0.0806 & 0.4191 & 0.3859 & 0.5625 & -0.4680 & 0.8913 & 1 \\
\hline
\end{tabular}




\subsubsection{Terrigenous material}

There are many elements used in literature that reflect inputs of terrigenous sediment, including Fe, Ti, K, Al and Si (Croudace and Rothwell, 2015). These elements are often used to normalise biogenic elements that can also be lithogenic in origin, such as $\mathrm{Si}$ and Ca.

TAN1302-96

All well-established terrigenous proxies are strongly correlated in TAN1302-96, where $\mathrm{r}^{2}$ $>0.83$. The most abundant terrigenous element in the core is Fe followed by Al, with highest concentrations reaching $\sim 30,000$ and $15,000 \mathrm{ppm}$ respectively. The top meter of the core is dominated by low concentrations of terrigenous material, before a large spike occurs at $110 \mathrm{~cm}$ (Figure 5.16). Concentrations return to low levels for most of TAN1302-96, with the exception of a small peak beginning at $170 \mathrm{~cm}$ and a second significant peak near the end of the core, at $322 \mathrm{~cm}$. The Fe/Ca ratio peaks slightly before this, at $98 \mathrm{~cm}(\mathrm{Fe} / \mathrm{Ca}>4)$, and the other significant peak observed in the elemental records at $322 \mathrm{~cm}$ is significantly less defined in the Fe/Ca record $(\sim 0.5)$. The elemental peaks in this core are bimodal, and peaks occur synchronously with peaks observed in both the IRD and $\delta^{18} \mathrm{O}(\%)$ records.

\section{TAN1302-97}

TAN1302-97 shows very strong correlations between the terrigenous elements, ranging from $0.89-0.96$. There are five significant peaks in the core, the first at $50 \mathrm{~cm}$, followed by 226, 266, 328 and $402 \mathrm{~cm}$ (Figure 5.17). Again, Fe has the highest concentrations within this supply of terrigenous material, with peaks reaching $\sim 25,000 \mathrm{ppm}$, and lower levels ranging from $\sim 5,000-10,000 \mathrm{ppm}$. Fluctuations in the $\mathrm{Fe} / \mathrm{Ca}$ ratio in this core are more consistent with the other elemental records (i.e. Fe, Ti, K, Al, Zr) both in timing and in magnitude with the exception of a smaller first peak ( $\mathrm{Fe} / \mathrm{Ca} \sim 1.7$ at $50 \mathrm{~cm})$. Similarly to the -96 core, the significant peaks in terrigenous material occur simultaneously with the IRD and $\delta^{18} \mathrm{O}(\%)$ records, however, all elemental profiles don't pick up the small IRD peak observed at $190 \mathrm{~cm}$ (Figure 5.9). 


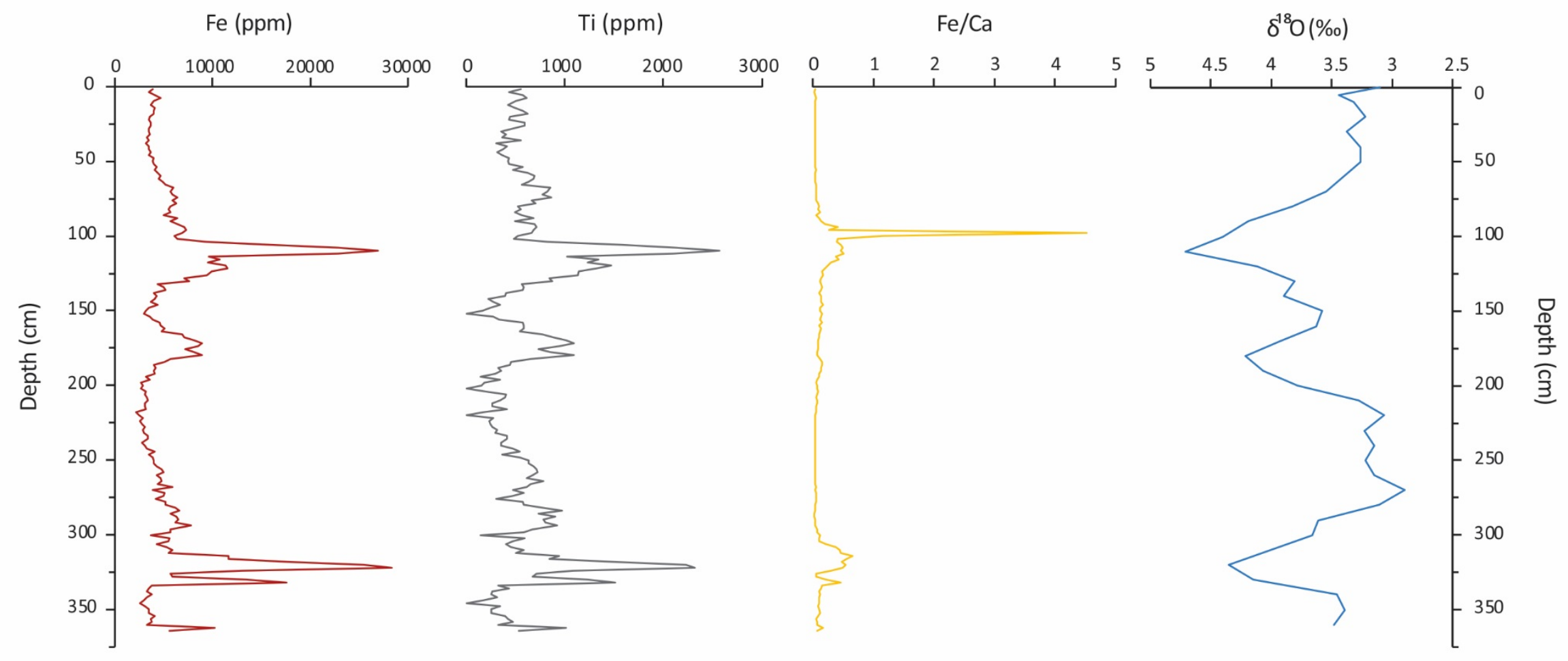

Figure 5.16. Element profiles (ppm) indicative of terrigenous sedimentation obtained through XRF scanning along TAN1302-96 (at $2 \mathrm{~cm}$ scale) and $\delta^{18} \mathrm{O}(\%)$ in blue. Fe (red) and Ti (grey) are highly correlated $\left(\mathrm{r}^{2}=0.94\right)$. Fe/Ca (yellow) records changes in $\mathrm{Fe}$ with respect to $\mathrm{Ca}$ (i.e. biological material). Al, $\mathrm{K}$, $\mathrm{Zr}$ elemental profiles not shown but are very similar to those of Fe and Ti. 


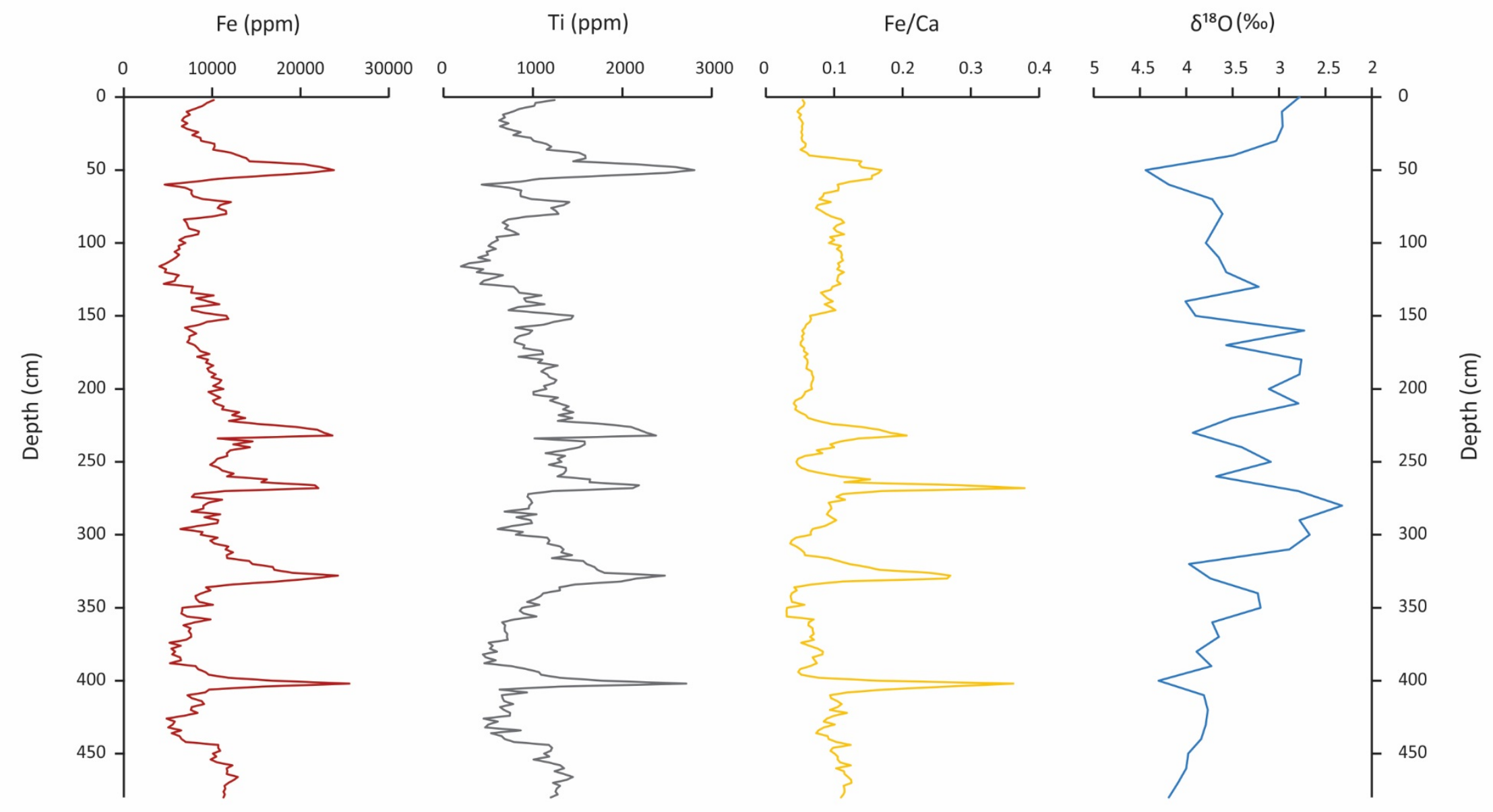

Figure 5.17. Element profiles (ppm) indicative of terrigenous sedimentation obtained through XRF scanning along TAN1302-97 (at $2 \mathrm{~cm}$ scale) and $\delta^{18} \mathrm{O}(\%)$ in blue. Fe (red) and Ti (grey) are highly correlated $\left(r^{2}=0.96\right)$. Fe/Ca (yellow) records changes in Fe with respect to $\mathrm{Ca}$ (i.e. biological material). $\mathrm{Al}, \mathrm{K}, \mathrm{Zr}$ elemental profiles not shown but are very similar to those of $\mathrm{Fe}$ and $\mathrm{Ti}$. 


\subsubsection{Biological inputs}

$\underline{\mathrm{XRF}}$

Two distinct biological components were identified in Principal Component Analyses (Figure 5.14 and Figure 5.15), those being $\mathrm{Si}$ and $\mathrm{Ca}\left(\mathrm{r}^{2}>-0.94\right)$. Ratios of $\mathrm{Si} / \mathrm{Fe}, \mathrm{Si} / \mathrm{Ti}$, and $\mathrm{Si} / \mathrm{Al}$ are commonly used proxies for biogenic opal (Agnihotri et al., 2008; Dickson et al., 2010). Similarly, $\mathrm{Ca} / \mathrm{Fe}$ has been used to track relative changes in biogenic carbonate versus lithogenic sedimentation (Croudace and Rothwell, 2015). Comparing the $\mathrm{Ca}$ concentrations measured from XRF with $\mathrm{CaCO}_{3} \%$ yields strong positive linear relationships $\left(\mathrm{r}^{2}>0.85-\right.$ see Appendix A) compared to the relationships observed between $\mathrm{CaCO}_{3} \%$ and $\mathrm{Ca} / \mathrm{Fe}, \mathrm{Ca} / \mathrm{Ti}$ and $\mathrm{Ca} / \mathrm{Al}\left(\mathrm{r}^{2}<0.55\right.$ in TAN1302-96 and $\mathrm{r}^{2}<0.49$ in -97). $\mathrm{Ba} / \mathrm{Fe}$ has been extensively used in paleoclimatology as a proxy for documenting changes in export productivity (Jaccard et al., 2013; Studer et al., 2015). The Ba/Fe ratio in the TAN cores appears to record changes in both Si-based biological input and changes in biogenic carbonate (Figure 5.18 and Figure 5.19).

\section{TAN1302-96}

The amount of $\mathrm{Ca}$ in TAN1302-96 varies from $\sim 1,500-230,000 \mathrm{ppm}$ (Figure 5.18). The top $70 \mathrm{~cm}$ shows little variation around $\sim 100,000 \mathrm{ppm}$, however, this drops to $\sim 1,500$ ppm at $98 \mathrm{~cm}$. The data show small peaks at $178 \mathrm{~cm}$ and $326 \mathrm{~cm}(\sim 110,000 \mathrm{ppm}$ and 100,000 ppm respectively), and a significantly large peak at $288 \mathrm{~cm}$, which is the highest concentration of $\mathrm{Ca}$ in the core. The same trend is observed in $\mathrm{Ca} / \mathrm{Fe}$, however the smaller peak at $178 \mathrm{~cm}$ is less defined.

Elemental analysis shows $\mathrm{Si}$ is the dominant material in the PFZ cores (average $\sim 43 \mathrm{wt}$ $\%$ in TAN1302-96). Concentrations vary from $\sim 225,000-545,000 \mathrm{ppm}$, at 288 and 312 $\mathrm{cm}$, respectively. Significant peaks in $\mathrm{Si}$ are more defined in $\mathrm{Si} / \mathrm{Fe}$, where the input of $\mathrm{Si}$ relative to the input of terrigenous material is highest $(\mathrm{Si} / \mathrm{Fe}>150)$ at 152,218 and 346 $\mathrm{cm}$. Likewise, the troughs in the Si record at 110, 180, 288 and $332 \mathrm{~cm}$ are more pronounced in $\mathrm{Si} / \mathrm{Fe}(\mathrm{Si} / \mathrm{Fe} \sim 14-40)$.

The amount of $\mathrm{Ba}$ relative to Fe remains relatively high throughout the core $(\mathrm{Ba} / \mathrm{Fe} \sim$ $0.25)$, however, distinct troughs are apparent at 110 and $318 \mathrm{~cm}(\mathrm{Ba} / \mathrm{Fe}<0.08)$. This coincides with troughs in $\mathrm{Si} / \mathrm{Fe}$, low $\mathrm{Ca}$, and peaks in $\delta^{18} \mathrm{O}(\%)$. 
TAN1302-97

The concentration of $\mathrm{Ca}$ in TAN1302-97 varies from $\sim 35,000-290,000 \mathrm{ppm}$, and is on average 2 times higher than TAN1302-96. Significant peaks are observed at 216, 250, 306,340 and $394 \mathrm{~cm}(>195,000 \mathrm{ppm})$. Similarly to the upper section of the -96 core, after a relatively stable upper $40 \mathrm{~cm}$, the Ca concentration drops to $45,000 \mathrm{ppm}$ at $60 \mathrm{~cm}$. Again, the $\mathrm{Ca} / \mathrm{Fe}$ record is very similar to the $\mathrm{Ca}$ concentration.

The amount of $\mathrm{Si}$ in the -97 core is $10 \%$ lower than -96 , however, Si still makes up a significant amount of the core material compared to other elements. The Si record generally shows more variation than TAN1302-96, $(\sim 125,000-470,000 \mathrm{ppm})$. This variability is more pronounced in the $\mathrm{Si} / \mathrm{Fe}$ record, with significant peaks above 75 at 60 , 116,382 and $426 \mathrm{~cm}$.

The $\mathrm{Ba} / \mathrm{Fe}$ profile in TAN1202-97 on average is less than half that observed in TAN130296 , averaging around 0.12 . A significant peak in $\mathrm{Ba} / \mathrm{Fe}$ occurs simultaneously with $\mathrm{Ca}$ at $354 \mathrm{~cm}$, however, typically peaks in $\mathrm{Ca}$ are associated with troughs in $\mathrm{Ba} / \mathrm{Fe}$ and $\mathrm{Si} / \mathrm{Fe}$. Similarly to TAN1302-96, significant troughs in $\mathrm{Ba} / \mathrm{Fe}(<0.06$ at 50, 226, 266, 330 and $402 \mathrm{~cm})$ are coincident with peaks in $\delta^{18} \mathrm{O}(\%)$. 

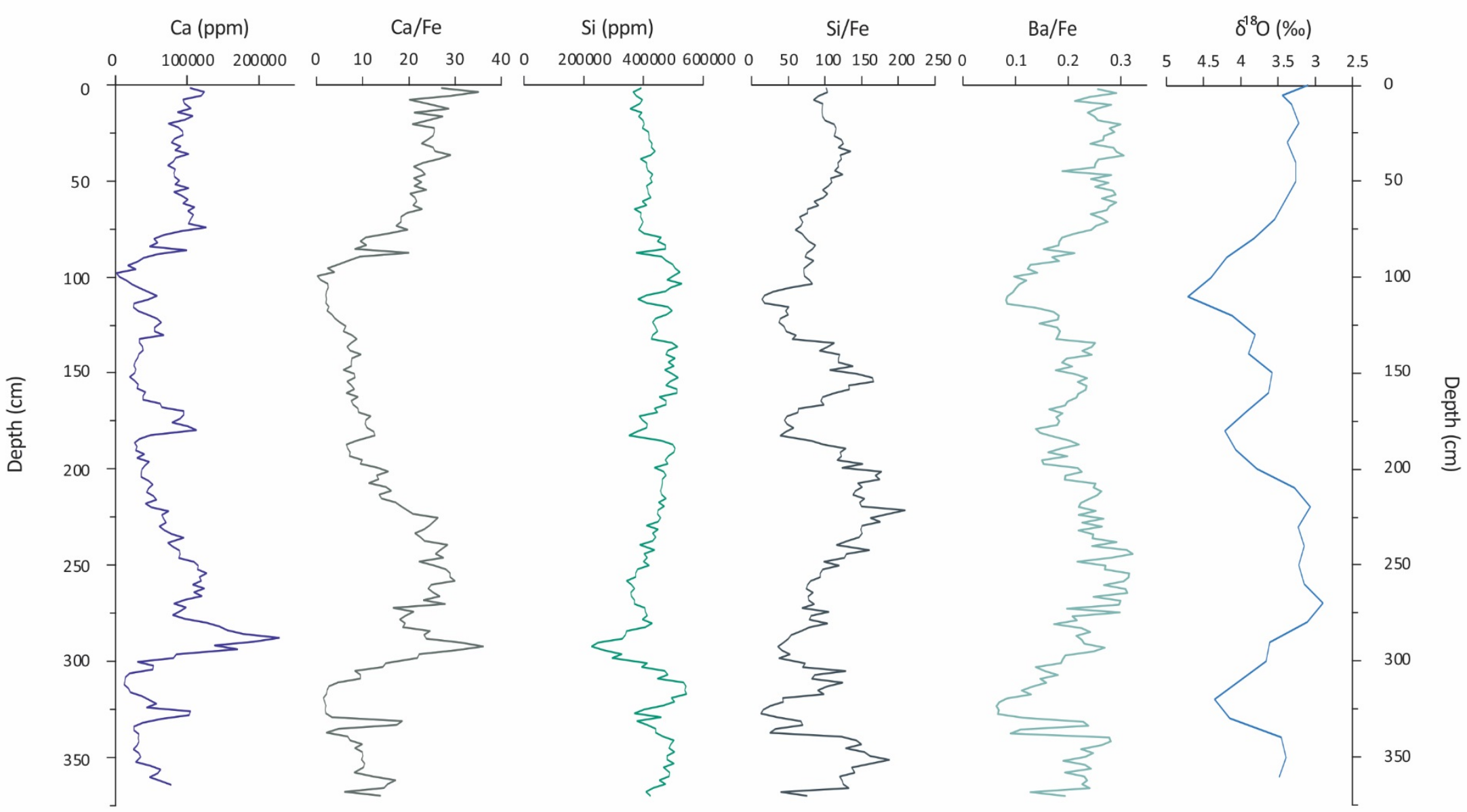

Figure 5.18. Elemental concentrations (ppm) and ratios along TAN1302-96 obtained from XRF scanning (at $2 \mathrm{~cm}$ scale) and $\delta^{18} \mathrm{O}(\%)$ in blue. Ratios are commonly used proxies for biogenic silica ( $\mathrm{Si} / \mathrm{Fe}$ - dark grey) and export productivity $(\mathrm{Ba} / \mathrm{Fe}$ - light green). These profiles represent key biological inputs, i.e. Ca in purple and $\mathrm{Si}$ in green, determined by high correlation coefficients and Principal Component Analysis. 


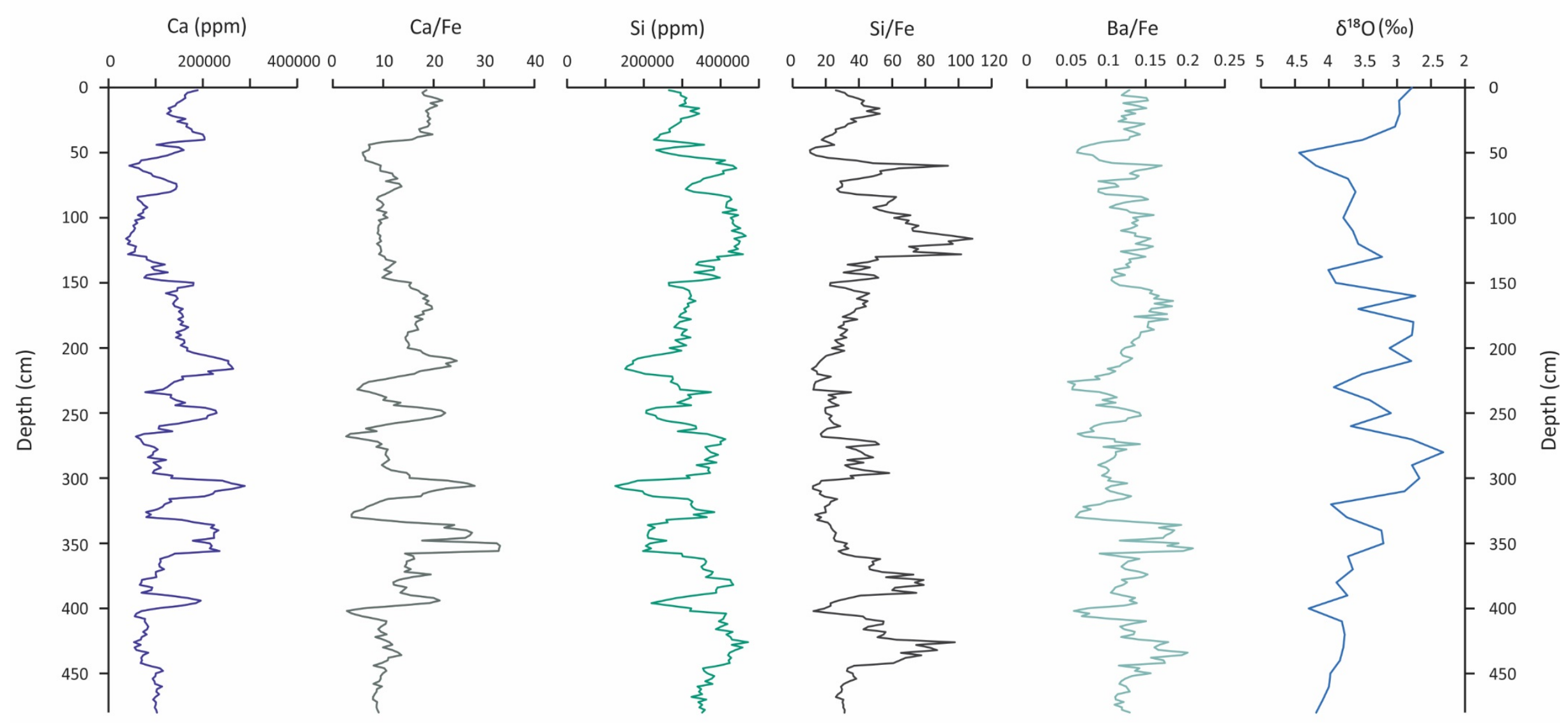

Figure 5.19. Elemental concentrations (ppm) and ratios along TAN1302-97 obtained from XRF scanning (at $2 \mathrm{~cm}$ scale) and $\delta^{18} \mathrm{O}$ (\%) in blue. Ratios are commonly used proxies for biogenic silica ( $\mathrm{Si} / \mathrm{Fe}$ - dark grey) and export productivity ( $\mathrm{Ba} / \mathrm{Fe}$ - light green). These profiles represent key biological inputs, i.e. Ca in purple and $\mathrm{Si}$ in green, determined by high correlation coefficients and Principal Component Analysis. 


\section{$\underline{\text { Diatom assemblage analysis }}$}

TAN1302-96

At $270 \mathrm{~cm}$, over $75 \%$ of the entire assemblage is F. kerguelensis, where the Polar Open Ocean and Seasonal Ice Tolerant (POOSIT) group comprises $\sim 88 \%$ of the diatoms at this time (Figure 5.20). The proportion of Sea Ice (SI) diatoms is $8 \%$, composed of $F$. separanda and $F$. ritscheri ( 5 and $\sim 3 \%$ respectively). In comparing the assemblage at 320 $\mathrm{cm}$ to $270 \mathrm{~cm}$, the relative proportion of SI diatoms is approximately double. This is concomitant with a decrease in the abundance of POOSIT diatoms ( $77 \%)$ and a similar proportion of Polar Front and Northwards (PFAN) diatoms to the proportion observed at $270 \mathrm{~cm}(\sim 3-4 \%)$.

\section{TAN1302-97}

In contrast to TAN-96, the amount of SI diatoms at $210 \mathrm{~cm}$ is insignificant $(\sim 1 \%)$ (Figure 5.20). The POOSIT group makes up $91 \%$ of the diatoms at this time, where the majority $(\sim 72 \%)$ of all diatoms present is F. kerguelensis. The proportion of SI diatoms at $230 \mathrm{~cm}$ is 9 times that observed at $210 \mathrm{~cm}$, where similarly to TAN-96, the relative abundance of POOSIT diatoms decreases by $\sim 8 \%$. Interestingly, the proportion of PFAN diatoms increases from $2-6 \%$ between 210 and $230 \mathrm{~cm}$ respectively.

In comparing the length and valve areas of $F$. kerguelensis between the two samples selected, no significant difference is observed in TAN1302-96 or TAN1302-97 (see Appendix A). 
TAN1302-96

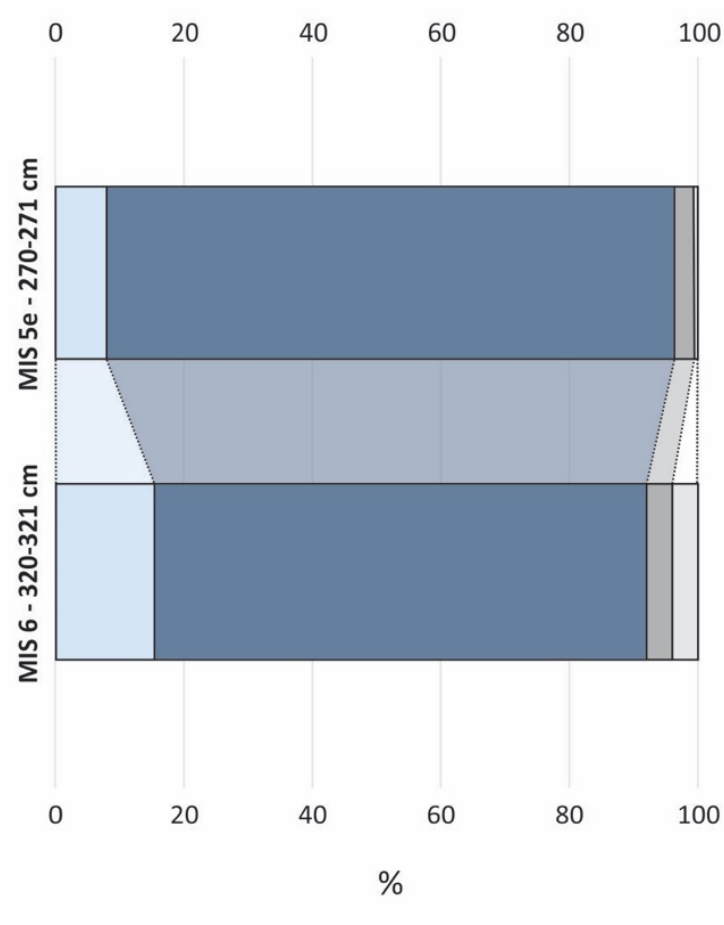

- Sea Ice

- Polar Open Ice Tolerant
TAN1302-97

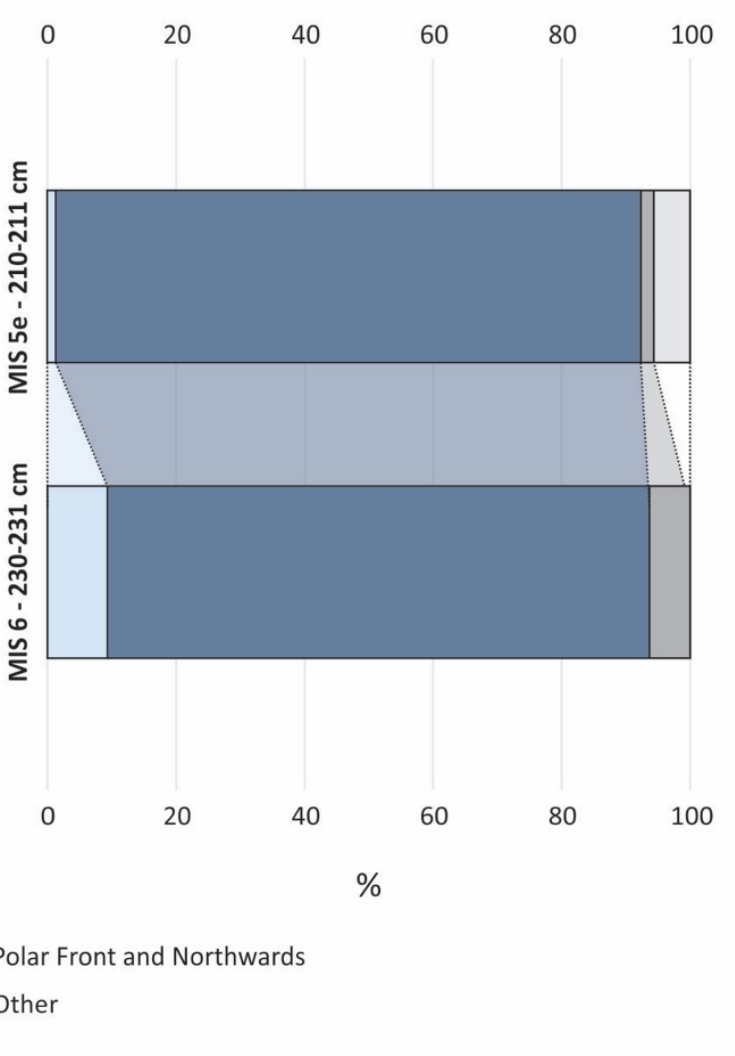

Figure 5.20. Diatom assemblages at MIS 6 and MIS 5e in TAN1302-96 (left) and TAN1302-97 (right). Light blue = Sea Ice group (SI); dark blue = Polar Open Ocean and Seasonal Ice Tolerant group (POOSIT); grey = Polar Front and Northwards group (PFAN); light grey = Other. Note greater percentage of SI diatoms during MIS 6 versus MIS 5e in both cores. 


\section{$\underline{\text { Scanning Electron Microscopy }}$}

SEM imaging revealed coccoliths were present in both cores, but in relatively low abundances even at peak $\mathrm{CaCO}_{3} \%$. No discernible difference in species composition was observed between samples, or between cores, although the most common species present were Gephyrocapsa oceanica and Calcidiscus leptoporus, as well as Gephyrocapsa caribbeanica. The condition of the coccoliths were typically poor, although $C$. leptoporus coccoliths were generally well-preserved (Figure 5.21)
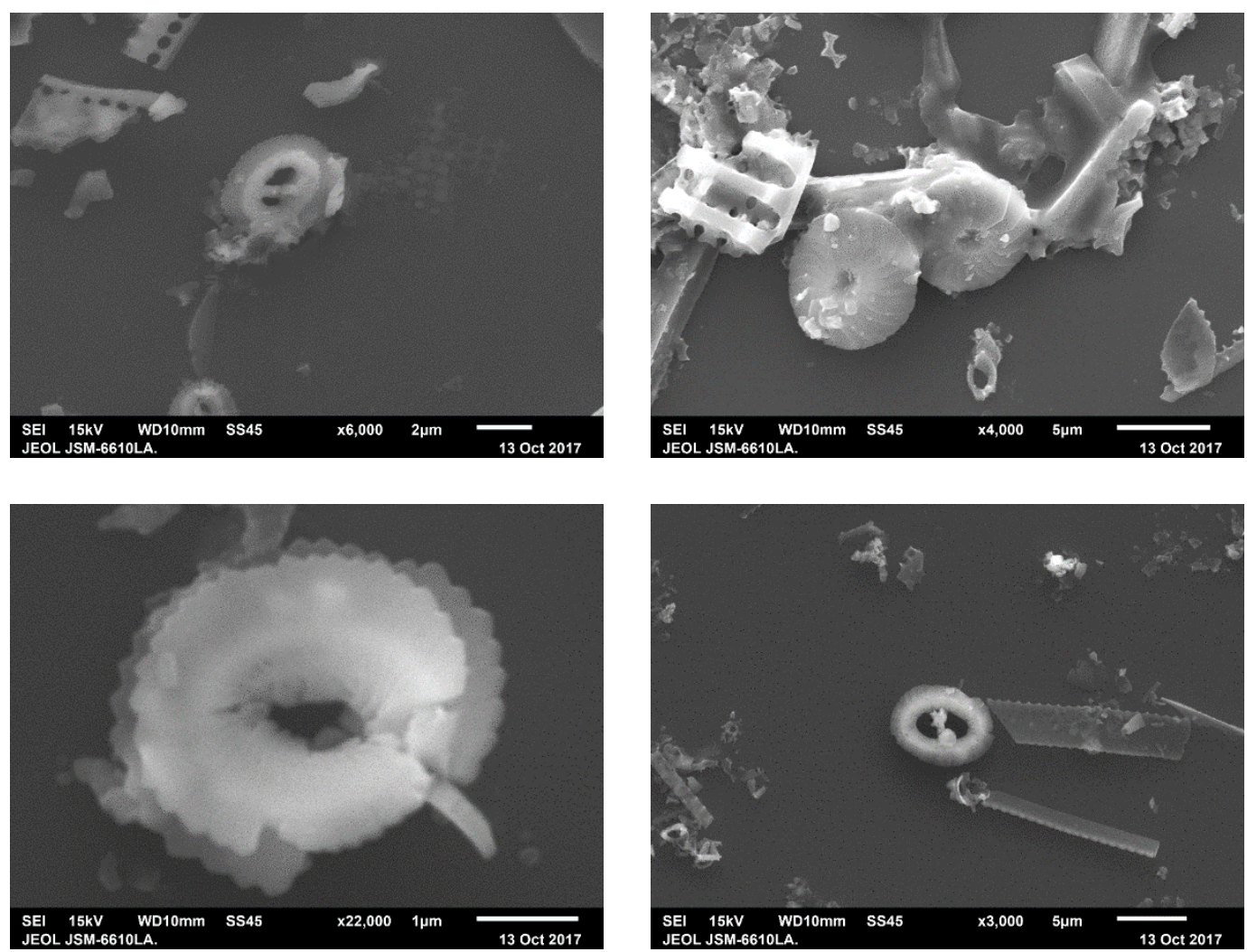

Figure 5.21. A selection of SEM images taken to check the presence of coccolithophores. From top left (clockwise):

G. oceanica, C. leptoporus (centre), G. caribbeanica, and G. oceanica. 


\subsection{Age model}

\subsubsection{Radiocarbon}

Successful radiocarbon dates were used to help constrain the upper section of the cores. OxCal was used to calibrate the dates, and the reservoir age used was $850 \pm 40$ yrs.

Table 5.3. Radiocarbon dates run for TAN1302-96.

\begin{tabular}{|c|c|c|c|c|}
\hline Depth (cm) & ${ }^{14} \mathbf{C}$ (yrs BP) & $\begin{array}{c}\text { Error } \\
(\mathbf{y r s} \text { BP) }\end{array}$ & $\begin{array}{c}\text { Calibrated age } \\
\text { (CalyrBP) }\end{array}$ & $\begin{array}{c}\text { Error } \\
\text { (yrs) }\end{array}$ \\
\hline $20-21$ & 4,130 & 20 & 3,100 & 150 \\
\hline $50-51$ & 7,940 & 30 & 7,570 & 100 \\
\hline $70-71$ & 10,570 & 40 & 10,630 & 150 \\
\hline
\end{tabular}

Table 5.4. Radiocarbon dates run for TAN1302-97.

\begin{tabular}{|c|c|c|c|c|}
\hline Depth (cm) & ${ }^{\mathbf{1 4}} \mathbf{C}(\mathbf{y r s}$ BP) & $\begin{array}{c}\text { Error } \\
(\mathbf{y r s} \text { BP) }\end{array}$ & $\begin{array}{c}\text { Calibrated age } \\
\text { (CalyrBP) }\end{array}$ & $\begin{array}{c}\text { Error } \\
(\mathbf{y r s})\end{array}$ \\
\hline $10-11$ & 5,450 & 30 & 4,810 & 150 \\
\hline $40-41$ & 11,100 & 40 & 11,270 & 160 \\
\hline $80-81$ & $>50,000$ & N/A & - & - \\
\hline
\end{tabular}

$5.6 .2 \delta^{18} O$

Age models for TAN1302-96 and TAN1302-97 were developed using the lineage function in "Analyseries," a commonly used software for analysing time-series data (Paillard et al., 1996). Tie points were selected between the $\delta^{18} \mathrm{O}$ records from $N$. pachyderma in each core to the global benthic $\delta^{18} \mathrm{O}$ stack (Lisiecki and Raymo, 2005), and were constrained using radiocarbon dates in the upper core sections (Table 5.3 and Table 5.4). TAN1302-96 was correlated to the LR04 stack using 9 tie points (Figure 5.22), and 11 tie points were used for TAN1302-97 (Figure 5.23). Tie points were chosen at positions of maximum change in $\delta^{18} \mathrm{O}$, i.e. significant changes in global ice volume (glacial-interglacial transitions). Adjustments were made to the TAN1302-96 age model due to clear timing discrepancies in the upper section of the core, and resulted in the adjustment of two tie points $(110$ and $320 \mathrm{~cm})$ to peak $\delta^{18} \mathrm{O}$ values (Figure 5.22). 
TAN1302-96 goes back to $\sim 160 \mathrm{ka}$ and TAN1302-97 goes back to $\sim 270 \mathrm{ka}$. There is some uncertainty when attempting to correlate the older section of the TAN1302-97 $\delta^{18} \mathrm{O}$ record to the global LR04 stack due to nondescript changes in the record through this lower section of the core. For this reason, other data such as the elemental counts from $\mathrm{XRF}$ was used to assist correlation for the lower $80 \mathrm{~cm}$ of this core where the uncertainty in $\delta^{18} \mathrm{O}$ is greatest.

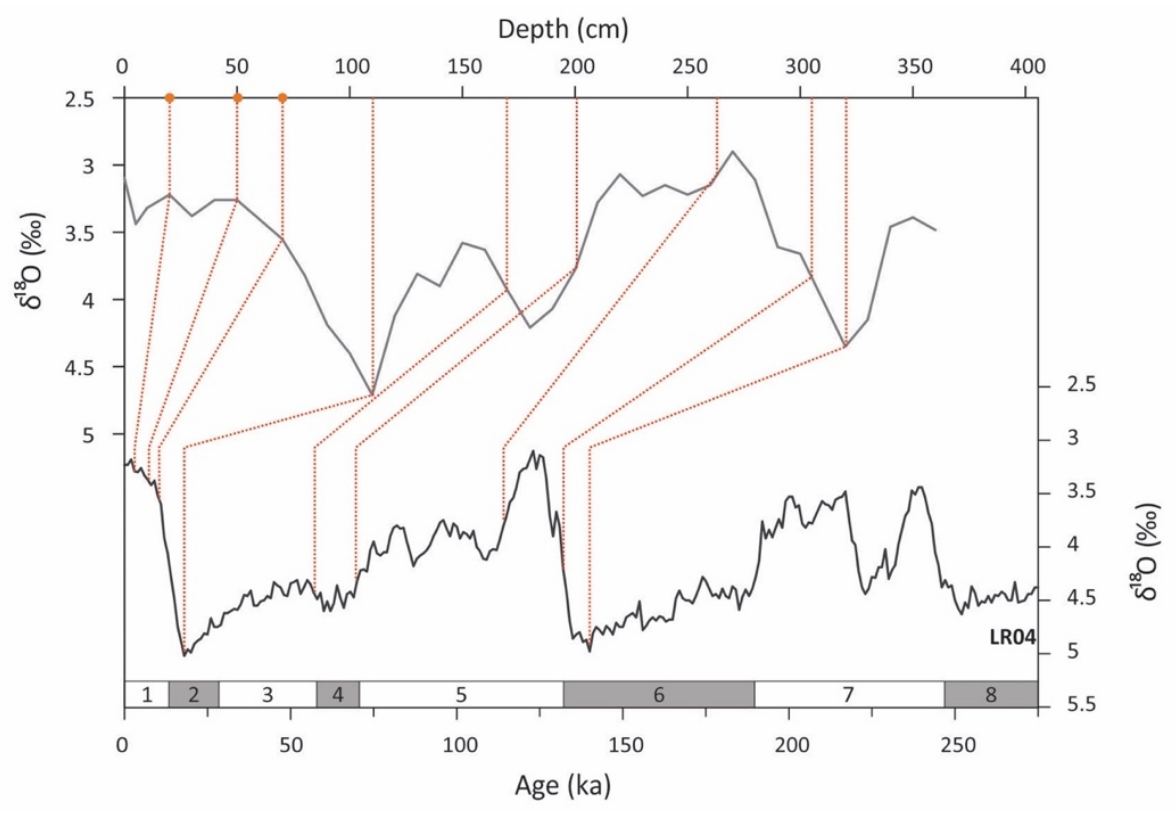

Figure 5.22. Age model for TAN1302-96. Dashed red lines represent tie points between $\delta^{18} \mathrm{O}$ record in TAN96 (grey) and LR04 (black). Orange circles indicate depths of ${ }^{14} \mathrm{C}$ dates. Marine Isotope Stages indicated by bars at the base of the LR04 stack. Shaded bars denote glacial stages.

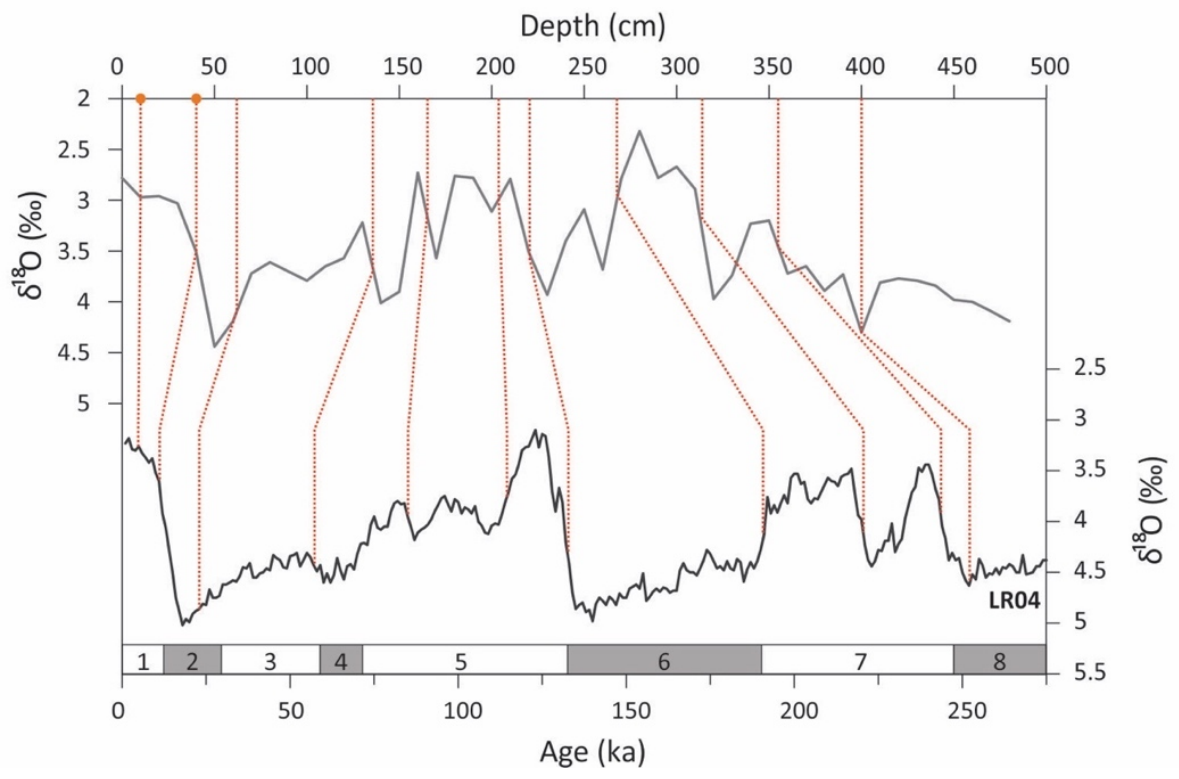

Figure 5.23. Age model for TAN1302-97. Dashed red lines represent tie points between $\delta^{18} \mathrm{O}$ record in TAN97 (grey) and LR04 (black). Orange circles indicate depths of ${ }^{14} \mathrm{C}$ dates. Marine Isotope Stages indicated by bars at the base of the LR04 stack. Shaded bars denote glacial stages. 
MIS 3 and MIS 5 are identifiable in both cores, although the $\delta^{18} \mathrm{O}$ deviation associated with MIS 5e (270 cm in TAN1302-96 and $210 \mathrm{~cm}$ in TAN1302-97) appears to be of a smaller magnitude than expected. This is likely due to sampling resolution, where the peak of MIS 5e has been missed in the 10cm sampling intervals. TAN1302-96 extends back to at least MIS 6, however determining the extent of TAN1302-97 is more difficult, as the signature becomes relatively ambiguous in the lower metre of the core. MIS $7 \mathrm{~d}$ is distinguishable at $320 \mathrm{~cm}$, thus the core dates back to at least the end of MIS 7.

\subsection{Linear Sedimentation Rates and Mass Accumulation Rates}

The age models were used to calculate linear sedimentation rates (LSRs) (Table 5.5), and mass accumulation rates (MARs) for both cores (Figure 5.24 and Figure 5.25).

Table 5.5. Summary of linear sedimentation rates in TAN1302-96 and TAN1302-97.

\begin{tabular}{|c|c|c|c|c|}
\hline Core & $\begin{array}{c}\text { LSR minimum } \\
(\mathbf{c m} / \mathbf{k y r})\end{array}$ & Depth $(\mathbf{c m})$ & $\begin{array}{c}\text { LSR maximum } \\
\mathbf{( c m / k y r})\end{array}$ & Depth $(\mathbf{c m})$ \\
\hline TAN1302-96 & 1.40 & $210-258 \mathrm{~cm}$ & 7.02 & $2-48 \mathrm{~cm}$ \\
\hline TAN1302-97 & 0.82 & $232-260 \mathrm{~cm}$ & 5.36 & $432-480 \mathrm{~cm}$ \\
\hline
\end{tabular}

LSRs are higher in interglacial periods $(\sim 3.37 \mathrm{~cm} / \mathrm{kyr})$ compared to glacials $(\sim 2.74$ $\mathrm{cm} / \mathrm{kyr}$ ) in TAN1302-96 (Figure 5.24). LSRs in TAN1302-97 are marginally lower during glacial periods compared to interglacials ( $\sim 2.38$ and $2.62 \mathrm{~cm} / \mathrm{kyr}$ respectively). $\mathrm{CaCO}_{3}$ MARs are highest in the Holocene in both cores $\left(\sim 6.69\right.$ and $4.49 \mathrm{~g} / \mathrm{cm}^{2} / \mathrm{kyr}$ in -96 and -97 respectively). Additionally, $\mathrm{CaCO}_{3}$ MAR peaks in TAN1302-96 and -97 are observed at MIS 5e, although the magnitude is higher in $-96\left(>0.3 \mathrm{~g} / \mathrm{cm}^{2} / \mathrm{kyr}\right.$ vs $\sim 0.2$ $\mathrm{g} / \mathrm{cm}^{2} / \mathrm{kyr}$ ) (Figure 5.25). LSRs and $\mathrm{CaCO}_{3}$ MARs in MIS 7 - MIS 8 are significantly higher than the rest of the core (LSRs $\sim 2.75$ and $5.36 \mathrm{~cm} / \mathrm{kyr}$, and MARs $\sim 0.20$ and 0.23 $\mathrm{g} / \mathrm{cm}^{2} / \mathrm{kyr}$, respectively), however, this is likely due to the position of tie points. 


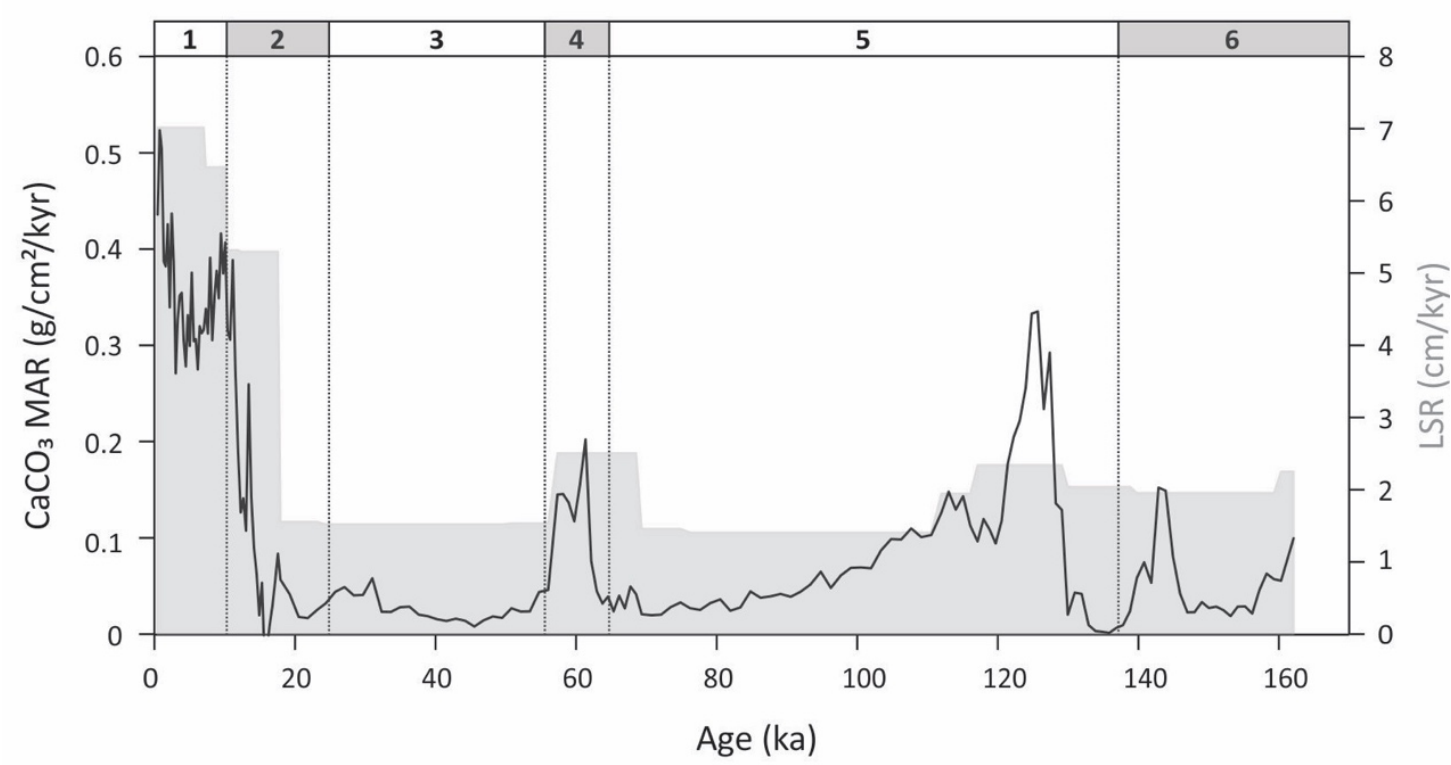

Figure 5.24. $\mathrm{CaCO}_{3} \%$ mass accumulation rates (black) and linear sedimentation rates (grey) throughout TAN1302-96. Marine isotope stages numbered at the top with glacial stages shaded.

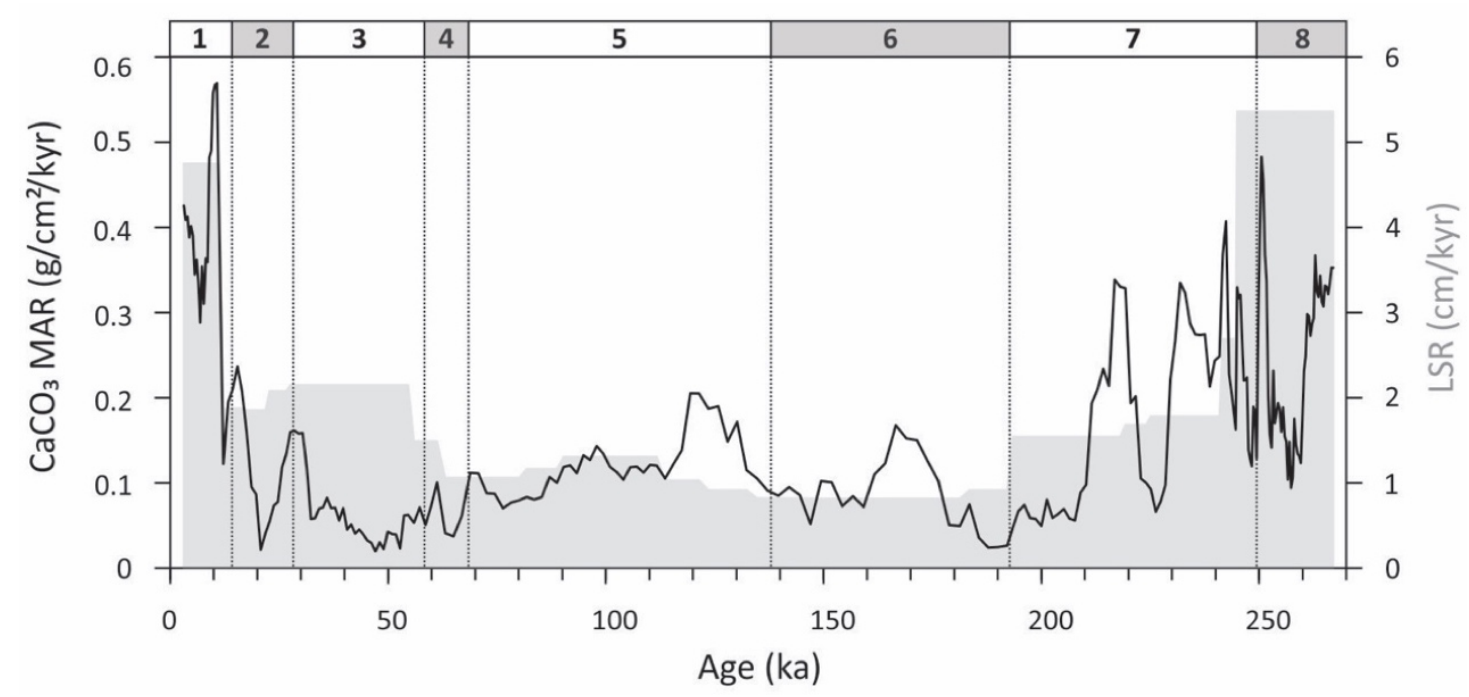

Figure 5.25. $\mathrm{CaCO}_{3} \%$ mass accumulation rates (black) and linear sedimentation rates (grey) throughout TAN1302-97. Marine isotope stages numbered at the top with glacial stages shaded.

\subsection{Total Organic Carbon}

The Total Organic Carbon calculated in both TAN1302-96 and -97 was much higher than expected ( $\sim 8.3 \%$ and $7.2 \%$, respectively). It is likely that the water was not fully removed before combustion, due to the fibrous diatom matrices. For this reason, the TOC results will not be discussed further. 


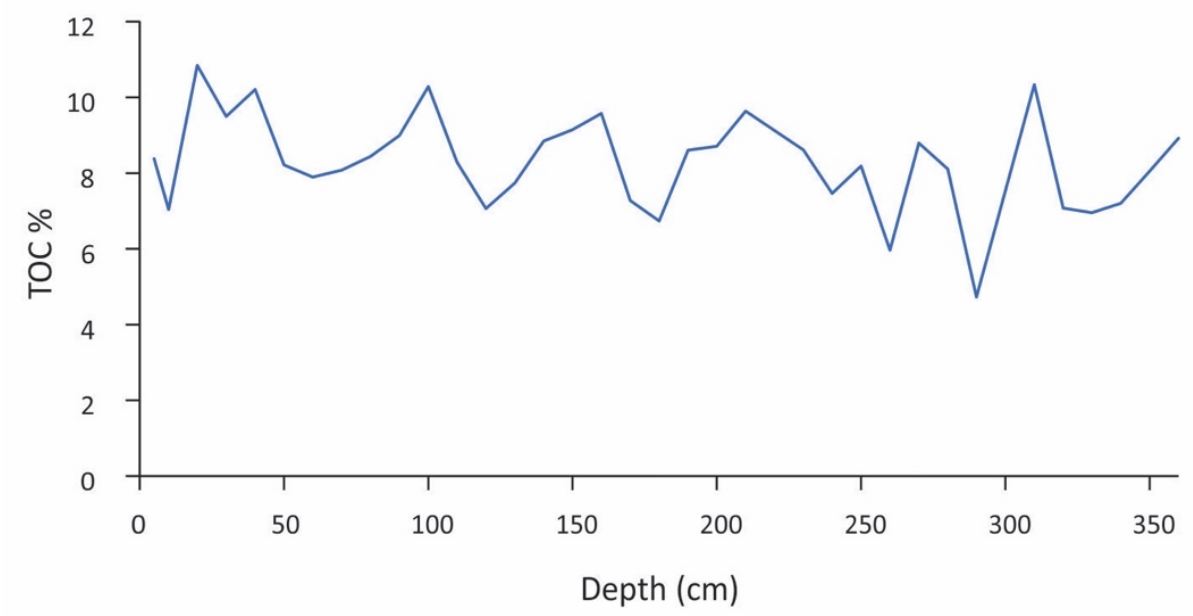

Figure 5.26. Total Organic Carbon (TOC) (\%) in TAN1302-96 at $10 \mathrm{~cm}$ intervals.

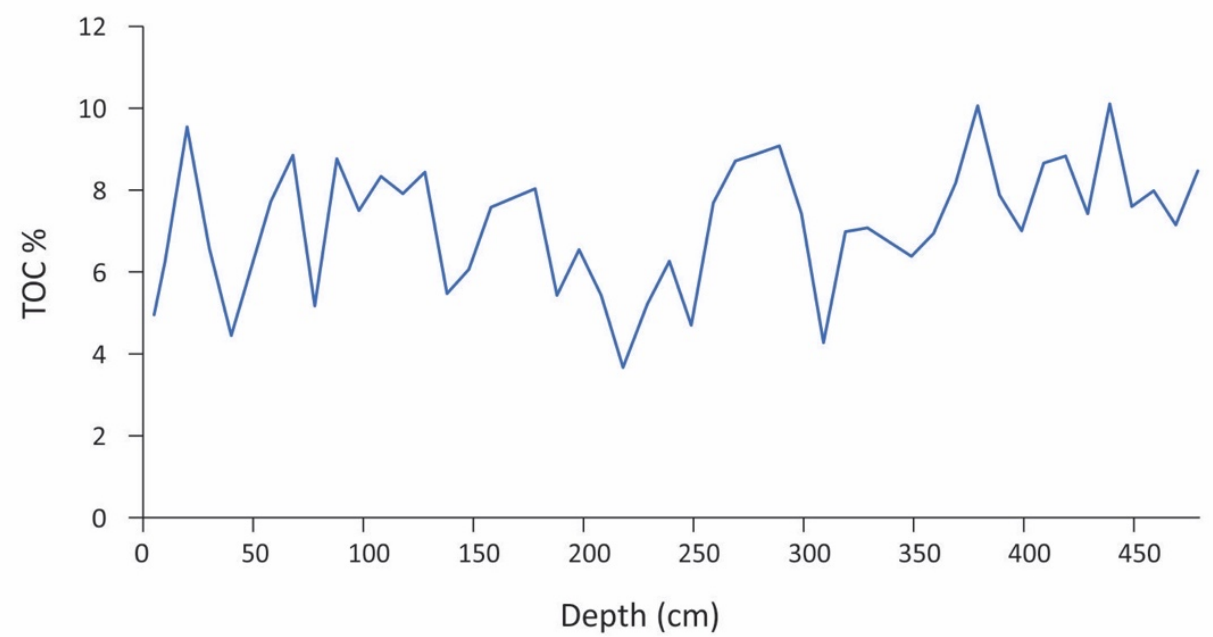

Figure 5.27. Total Organic Carbon (TOC) (\%) in TAN1302-97 at $10 \mathrm{~cm}$ intervals. 


\section{Chapter 6 Discussion}

This section discusses the results presented in Chapter 1, and compares these findings and interpretations with literature pertaining to the Pacific and Atlantic sectors. First, aspects relating to the glacial Southern Ocean are described, including; 1) the relative input of terrigenous material with a strong focus on sediment source, 2) oceanic conditions with regards to SST and WSI extent, and 3) the productivity observed in the PFZ. Next, deglaciation sequences are described, with particular focus on glacial Terminations I (TI) and II (TII). The timing of productivity changes and differences within the PFZ are discussed, and potential reasons for this outlined. Finally, the interglacial Southern Ocean setting is described. Similar conditions will be covered as in the glacial Southern Ocean section, with emphasis on productivity dominance across MIS 3 and MIS 5.

\subsection{The glacial Southern Ocean}

Periods of glacial maxima are identified in $\delta^{18} \mathrm{O}$ records from TAN1302-96 and -97, where Marine Isotope Stages (MIS) 2, 4 and 6 are evident in both cores (Figure 5.6 and Figure 5.7). The northern PFZ core (TAN1302-97) extends back to MIS 8, however the early part of the MIS 8 glaciation is not present in this record. During peak glaciation, viz. MIS 2, 6 and 8, dramatic increases ( $>2$ times) in the concentration of elements associated with terrigenous material (e.g. Fe, Al, Ti, K, Zr, see Table 5.1 and Table 5.2) occur simultaneously with peaks in observed quartz grains and coarse rock fragments $(>180 \mu \mathrm{m})$ counted under the microscope.

Fe is commonly used as a proxy for aeolian dust (Jaccard et al., 2013; Lamy et al., 2014; Croudace and Rothwell, 2015). Data presented in Chapter 5, however, show peaks in Fe occur in tandem with increases in coarse $(>180 \mu \mathrm{m})$ material, indicating that a substantial amount of $\mathrm{Fe}$ is supplied as IRD. The punctuated, periodic timing of greater terrigenous deposition during peak glaciation (Figure 5.8 and Figure 5.9) provides additional evidence for this hypothesis. This signal is consistent with other distal records of iceberg deposition during glacials in the southwest Pacific Ocean (Carter et al., 2002). Likewise, the mineralogy of the coarse material (e.g. quartz) is similar to other records of IRD in the SO (Pudsey, 2000; Carter et al., 2002). 


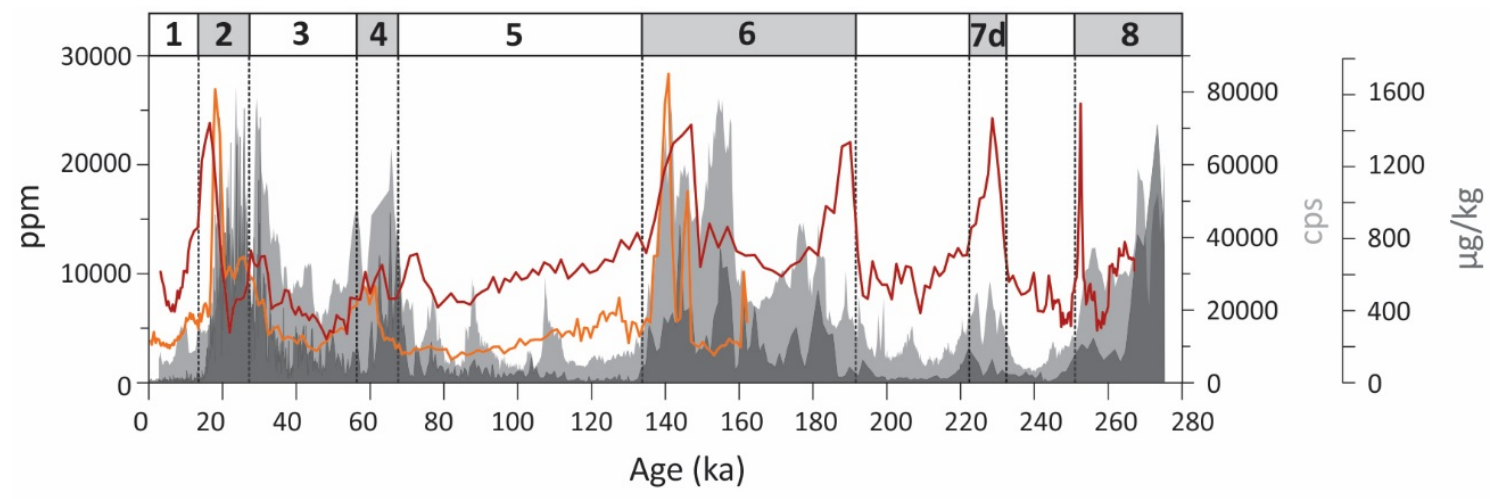

Figure 6.1. Raw Fe concentrations (ppm) from TAN1302-96 (orange) and TAN1302-97 (red). Raw XRF data were used to compare against two dust records; 1) raw Fe counts (cps) in light grey from PS75/93-1, located further east in the South Pacific (Lamy et al., 2014); and 2) dust concentrations $(\mu \mathrm{g} / \mathrm{kg}$ ) in dark grey from EPICA Dome C ice core (Bereiter et al., 2015). Marine Isotope Stages (MIS) numbered along the top with glacial stages shaded.

Although other studies have suggested dust has reached further east in the Pacific, proximal to the PFZ cores (e.g. Lamy et al., 2014), dust accumulation rates in the southwest Pacific sector are among the lowest of any ocean region (Chase et al., 2003). Based on modelled dust distributions, between $0.6-1.2 \mathrm{~g} / \mathrm{m}^{2} / \mathrm{y}$ is estimated to reach the PFZ cores during the Last Glacial Maximum (LGM; Lamy et al., 2014) (Figure 6.2). The influence of such minor concentrations cannot be completely discounted, although this aeolian contribution is considered unlikely to have a significant impact on the Fe concentrations, compared to the IRD source.

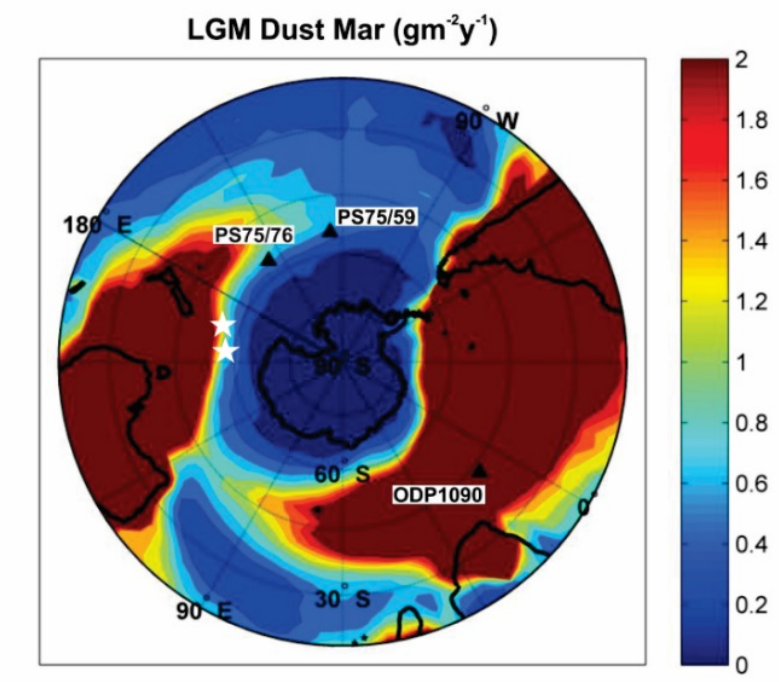

Figure 6.2. Model of dust MAR during the LGM. White stars indicate the location of PFZ cores used in this study. From Lamy et al. (2014). 
Modelled iceberg trajectories suggest the IRD observed in our cores likely originated from the Amery Ice Shelf(Figure 6.3) (Gladstone et al., 2001). The composition of IRD, and the elemental data, are consistent with the geology of the surrounding peninsula; which is largely composed of quartzo-feldspathic and feldspathic gneisses, as well as biotite-rich granites (Manton et al., 1992). Recently revised trajectory models suggest once entrained in the Antarctic Circumpolar Current (ACC), icebergs are transported further east than originally thought, notably so in the south Pacific (Merino et al., 2016). This has important implications for paleoclimate studies focusing on Fe inputs in this sector of the SO, whereby Fe records are commonly interpreted solely in terms of dust (Wolff et al., 2006; Jaccard et al., 2013; Lamy et al., 2014; Martinez-Garcia et al., 2014) but may still contain a significant contribution from IRD.

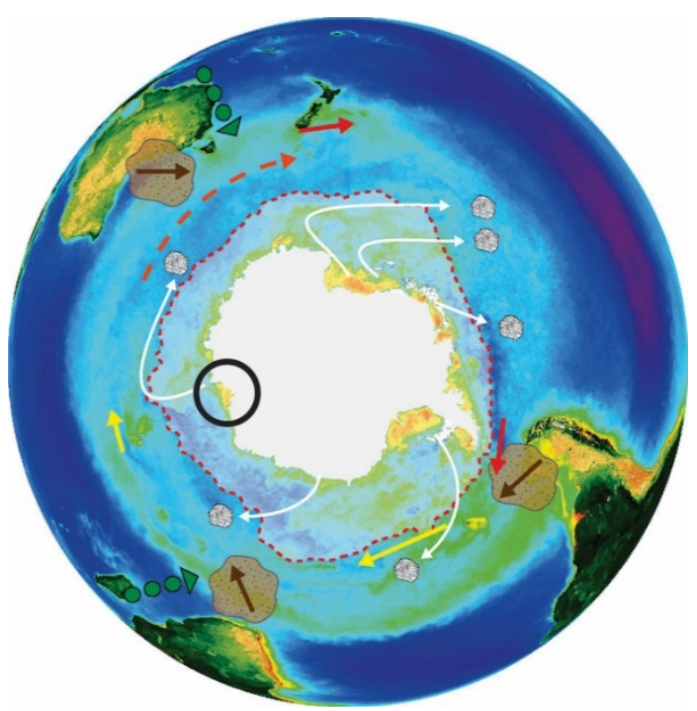

Figure 6.3. Major sources of iron to the Southern Ocean (Boyd and Ellwood, 2010). Dust deposition (brown) and trajectories of icebergs depositing Fe-IRD (white) discussed in this thesis. Location of Amery Ice Sheet circled in black.

Redistribution and deposition of sediment by ocean currents can have large effects on marine sedimentary records, especially in the Southern Ocean, due to strong flows of the ACC (Kohfeld and Harrison, 2001) (see Section 2.1.3). The potential for reworked sedimentation is of specific concern to TAN1302-97, which is located east of Macquarie Ridge. It is possible that some alkaline to sub-alkaline basaltic material arrived to this northern PFZ core via sediment focussing and transport through gaps in the Macquarie Ridge (Conway et al., 2012). This effect could be responsible for the elevated background levels of Fe, Ti, Al, K and Zr, observed in TAN1302-97 compared to -96 (see Appendix A). The composition of Macquarie Ridge is dominantly $\mathrm{SiO}_{2}(>45$ wt. \%) with $<12$ wt. $\% \mathrm{FeO}_{\mathrm{T}}$ (Conway, 2011). Though some sediment reworking is likely, the contribution of 
this to TAN1302-97 is considered insignificant due to the scale of the relative elemental changes observed.

The prevalence of IRD in these records provides some insight into the glacial SO setting. If it is assumed that the amount of terrigenous debris carried by icebergs is constant through time, increased IRD deposition may indicate; 1) increased iceberg discharge from the East Antarctic Ice Sheet (Pudsey, 2000), 2) better survival of icebergs due to the expansion of cooler waters (Carter et al., 2002), 3) increased iceberg dispersal as a result of a more vigorous ACC (Neil et al., 2004), or a combination of all these processes.

The timing of significant peaks in IRD during glacial maximum in the PFZ cores suggests that SSTs in the Pacific SO, particularly during MIS 2 and MIS 6, were cool enough to prevent iceberg melt close to Antarctica, allowing extensive dispersal and survival of icebergs. Conversely, IRD records from sites proximal to the polar continent, in both the Pacific and Atlantic Oceans, show peaks in IRD deposition during deglaciation and interglacials, reflecting deglacial calving and enhanced ice melt due to warmer SSTs (Kanfoush et al., 2000; Carter et al., 2002; Diekmann et al., 2004). With the exception of records proximal to the Antarctic Peninsular and 'iceberg alley', South Atlantic records of IRD are consistent with the PFZ cores in that maximum deposition occurs during glacials, specifically MIS 2 and 6 (Diekmann et al., 2004).

The input of IRD during MIS 4 is significantly lower than in other glacials in both PFZ cores, ( $\sim 10$ grains/gram vs $>25$ grains/gram). This smaller peak has been observed in other IRD records off the Campbell Plateau (Carter et al., 2002). The Fe/Ti record in TAN1302-96 shows a distinct increase in the amount of Fe relative to $\mathrm{Ti}$ in the beginning of MIS 4 (reaching up to 2 times the total glacial-interglacial average $\mathrm{Fe} / \mathrm{Ti} \sim 10$ ). This relative input of $\mathrm{Fe}$ is more consistent with dust records showing $\mathrm{Fe}$ peaks during this time that are similar to the dust input during other glacials (Figure 6.4) (Wolff et al., 2006; Lamy et al., 2014; Martinez-Garcia et al., 2014). 


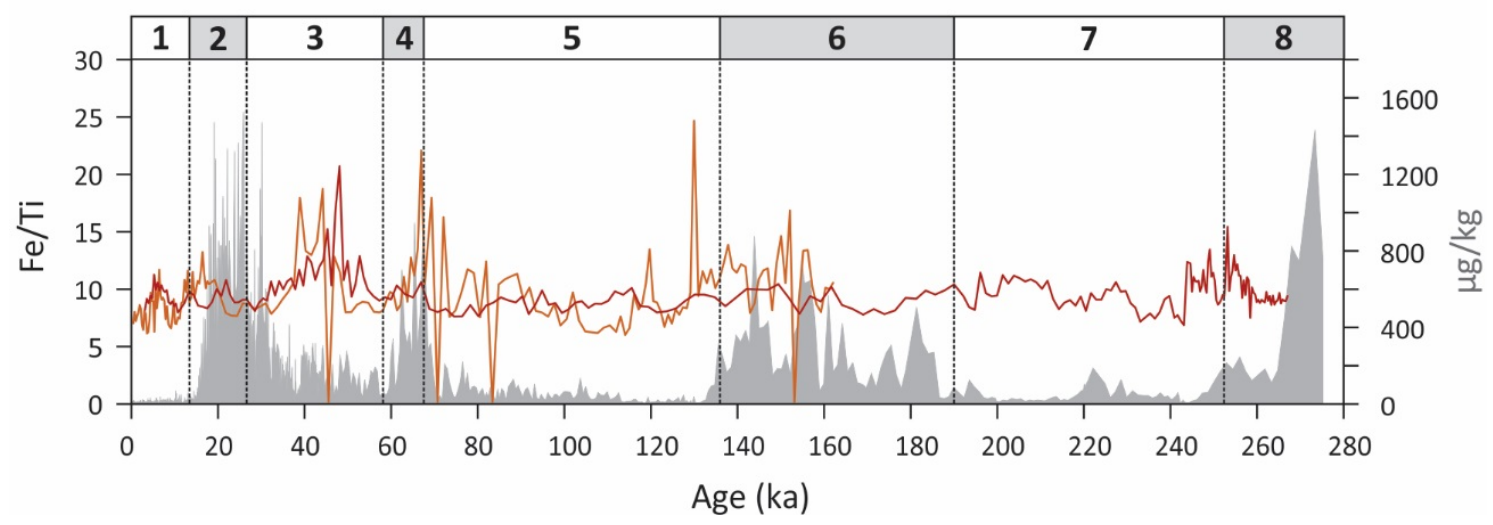

Figure 6.4. Fe/Ti records in TAN1302-96 (orange) and TAN1302-97 (red). Average Fe/Ti = 9.5 in TAN96 and 9.7 in TAN97. Dust concentrations ( $\mu \mathrm{g} / \mathrm{kg}$ ) from EPICA Dome C ice core (grey) from Bereiter et al. (2015).

Global ice volume during MIS 4 was far less compared to other glacials (McCave et al., 2008). Reduced ice volume in MIS 4 could be a consequence of warmer SSTs, where mass ice loss has been associated with ocean warming (Mackintosh et al., 2011). This would likely result in iceberg melt more proximal to Antarctica (Carter et al., 2002), and could account for less IRD reaching the mid-latitudes. Reconstructions of winter sea ice (WSI) cover during MIS 4 for this region of the SO suggest sea ice was absent or at most unconsolidated in the Emerald Basin (Ferry et al., 2015), supporting the idea that SSTs were too warm for substantial amounts of ice to persist this far north of Antarctica. Additionally, the absence of persistent glacial sea ice would allow Fe-borne dust to be deposited at the PFZ. This could explain the higher dust input apparent during MIS 4 (Figure 6.4). Future work should look at SST in these cores during MIS 4 to test this.

Diatom assemblages from MIS 6 and MIS 5 in both TAN cores show a 7-8\% increase in the proportion of sea ice diatoms in the glacial versus the interglacial (Figure 5.20). Additionally, the distinct sea ice diatom F. curta (Armand et al., 2005) is over 4 times more abundant in the MIS 6 sample from TAN1302-96 than in the MIS 5e sample. This could indicate an expansion of sea ice cover during glacials that is consistent with $6-8^{\circ}$ of latitude north from the modern WSI limit in the southwest Pacific, and is congruous with other regions of the SO (Figure 6.5) (Crosta et al., 2004; Gersonde et al., 2005; Carter and Cortese, 2009; Fraser et al., 2009; Benz et al., 2016). Until recently, the extent of sea ice in the Pacific sector was less clear due to the relatively poor regional coverage of paleoecology studies, particularly in the Subantarctic (Gersonde et al., 2005; Kucera et al., 2005). Further detailed diatom assemblage counts on MIS 2, 4 and 8, particularly in 
TAN1302-97, will contribute to improving reconstructions of glacial WSI limits in the Pacific SAZ.

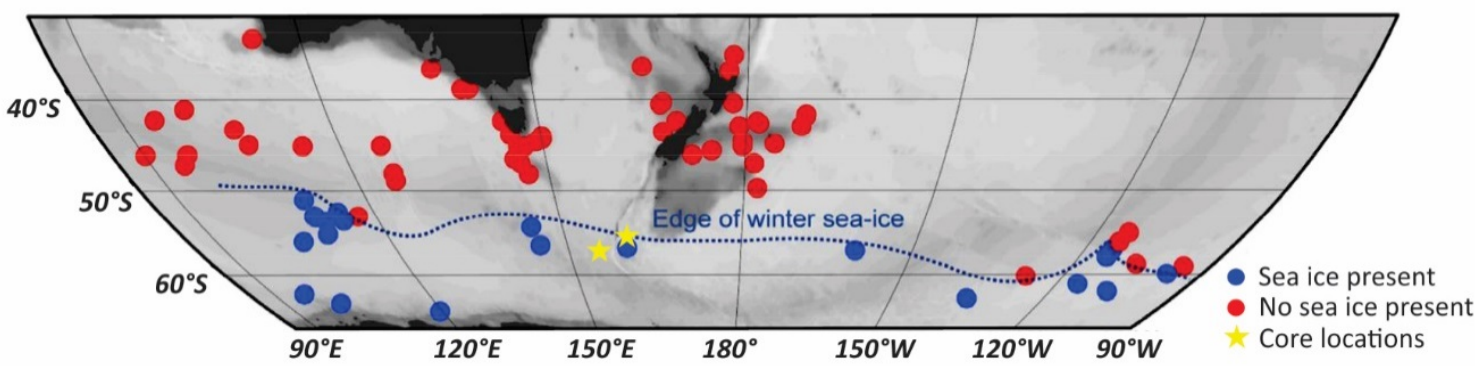

Figure 6.5. Sea ice extent at the LGM. Yellow stars indicate core locations used in this study (TAN1302-96 southern core; TAN1302-97 northern core). From Bostock et al. (2013).

Diatom productivity estimated from $\mathrm{Si} / \mathrm{Fe}$ in TAN1302-96 is on average 2-3 times higher than TAN1302-97 (Figure 6.6), and is highly likely related to the position of these sites relative to the PF. Regardless of observed glacial variability, opal is consistently low (with $\mathrm{Si} / \mathrm{Fe}$ ratios of $\sim 67$ in TAN1302-96 and $\sim 36$ in TAN1302-97) during periods of maximum IRD deposition, i.e. glacial maxima. The coincident timing of peak Fe deposition with decreased biogenic silica suggests that either; 1) the IRD- supplied Fe is not bioavailable and is therefore not being utilised by the diatoms, or 2) the Fe-rich surface waters promoted nitrate consumption relative to silicate (Robinson et al., 2005; Studer et al., 2015). This would reduce silicification and increase the chance of frustule dissolution during sinking to the sea floor, and ultimately reduce the preservation of opal in the sediments.

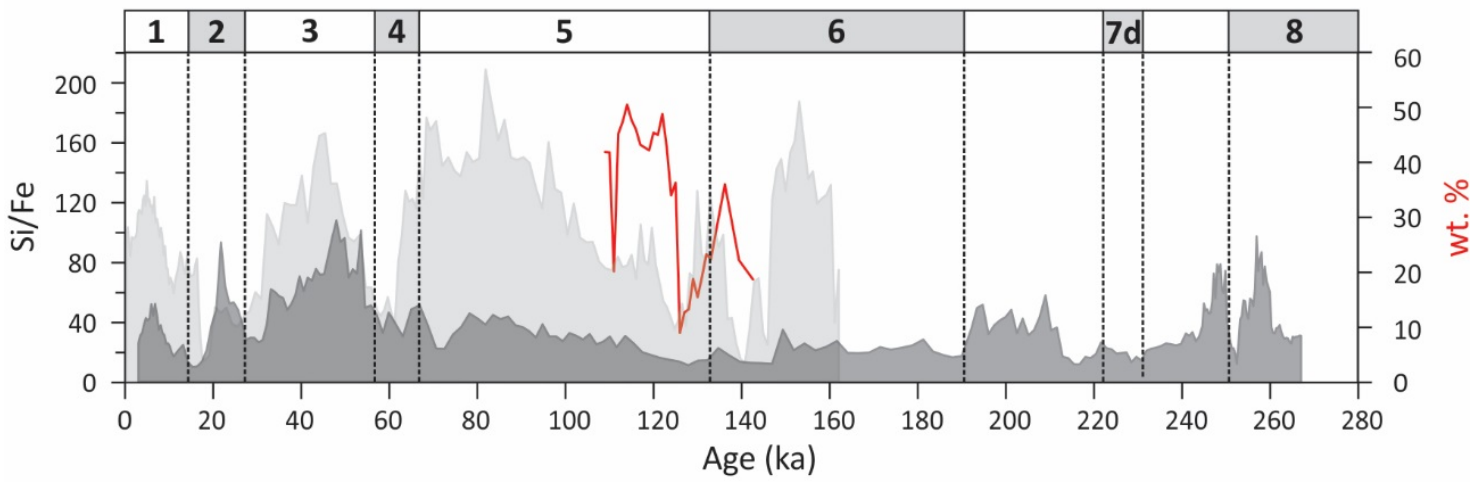

Figure 6.6. Opal productivity of PFZ cores compared to biogenic opal measured in SO136-111 (red) from Sturm (2003). TAN1302-96 opal in light grey and TAN1302-97 in darker grey. Glacial Marine Isotope Stages shaded (top).

Previous research has shown that Fe sourced as nanoparticulate IRD can be bioavailable, and is in fact comparable to concentrations of Fe-borne dust (Raiswell et al., 2008). On this basis, the reduction in opal productivity observed in the TAN cores during glacials is 
interpreted to be associated with reduced opal preservation as a consequence of dissolution.

Evidence of WSI and low $\mathrm{Ba} / \mathrm{Fe}(<0.1)$ presented in this thesis suggests that low opal accumulation could also relate to reduced diatom productivity. Reduced productivity has been attributed to a number of factors, including light or nutrient limitation as a result of sea ice expansion, reduced upwelling, or stratification (e.g. Chase et al., 2003; Hillenbrand and Cortese, 2006; Watson and Naveira Garabato, 2006; Robinson and Sigman, 2008; Sigman et al., 2010; Skinner et al., 2010). Light limitation due to sea ice expansion seems unlikely at the TAN core sites given sea ice is most extensive during winter months when the number of daylight hours are significantly reduced and there is reduced phytoplankton productivity.

The amount of biogenic opal produced in the SO is thought to be limited by the supply of dissolved Si (Anderson et al., 2009). Weakened upwelling as a result of glacial equatorward migration of the westerly winds, or a northward shift of the PF due to increased sea ice, would contribute to low levels of dissolved Si in the PFZ. The efficiency and position of SO upwelling during the LGM and past glacials, however, is heavily debated (Anderson et al., 2002; Skinner et al., 2010). In the southwest Pacific region in particular, strong bathymetric controls are likely to have prevented significant northward migration of the ACC fronts and the associated Circumpolar Deep Water upwelling limb (Neil et al., 2004; Sokolov et al., 2006; Bostock et al., 2015).

Due to poor consensus regarding glacial upwelling conditions, it is difficult to attribute the low diatom productivity to changes in upwelling. Although these theories cannot be ruled out, further geochemical analyses such as $\delta^{15} \mathrm{~N}_{\text {diatoms }}$ and $\delta^{30} \mathrm{Si}_{\text {diatoms }}$ will help to determine if changes in the glacial nutrient utilisation (supply versus demand) are the reasons behind low diatom productivity during glacial periods in these cores. Additionally, ${ }^{231} \mathrm{~Pa} /{ }^{230} \mathrm{Th}$ will help elucidate the true flux of material to the seafloor, to understand the effects of dissolution and potential sediment focussing or erosion on the material in the cores.

Nitrogen isotopes measured on diatoms from cores in the South Pacific sector of the SO (NBP9802-6 and 5) show that there is an increase in $\delta^{15} \mathrm{~N}_{\text {diatoms }}$ associated with a decline in opal flux during the LGM (Robinson and Sigman, 2008). Robinson and Sigman (2008) argue that there was an increase in nitrate utilisation from reduced nutrient supply. Silicon isotopes in diatoms from the Emerald Basin are low during the glacial (Rousseau et al., 
2016), indicating low silica utilisation, reduced demand or plenty of supply. These observations provide further evidence for increased diatom dissolution during glacials, indicating both increased dissolution and reduced productivity are likely impacting low $\mathrm{Si} / \mathrm{Fe}$.

Low diatom productivity in the PFZ cores is consistent with other records of opal south of the PF, both during the LGM and past glacials (Chase et al., 2003; Hillenbrand and Cortese, 2006; Bostock et al., 2013). This is in contrast to opal records north of the PF that document greater diatom productivity during glacials, especially in the Atlantic sector (Charles et al., 1991; Bradtmiller et al., 2009; Hendry and Brzezinski, 2014; Benz et al., 2016). This has been attributed to a northward shift of the opal belt, either as a consequence of increased sea ice, or alternatively, due to increased silica availability in lower latitudes from the excess generated in the higher latitudes, as explained by the "Silicic Acid Leakage Hypothesis" (Brzezinski et al., 2002; Matsumoto et al., 2002). Recent studies, however, show diatom productivity in the equatorial Pacific was generally low during the LGM also (Dubois et al., 2010; Costa et al., 2017). This suggests excess silicic acid was not present at the lower latitudes during this time, and therefore greater opal production north of the PF is more likely to be associated with a northward migration of the PF and opal belt in regions of poor bathymetric constraint, e.g. central South Pacific and South Atlantic basins.

Based on glacial averages, calcium carbonate productivity in TAN1302-97 $(\sim 18 \mathrm{wt} \%)$ is much higher than TAN1302-96 ( $\sim 8$ wt \%). This is almost certainly due to core location as TAN1302-97 sits north of the PF, where calcium carbonate deposition dominates sedimentation (Honjo, 2004). Similar to biogenic silica, calcium carbonate $\%$ in both PFZ cores is generally low during glacials compared to interglacials, i.e. between $5-13 \%$ in TAN1302-96 and between 14-24\% in TAN1302-97 (Figure 6.7). This translates to low $\mathrm{CaCO}_{3}$ accumulation rates (Figure 5.24 and Figure 5.25; $<0.1 \mathrm{~g} / \mathrm{cm}^{2} / \mathrm{kyr}$ and $<0.2$ $\mathrm{g} / \mathrm{cm}^{2} / \mathrm{kyr}$ in -96 and -97 respectively), and could represent; 1) decreased biogenic carbonate productivity during glacials, 2) increased dissolution, or some combination of both. The condition of individual $N$. pachyderma tests from all glacial periods were often fragile, therefore carbonate ion concentrations in the deep waters bathing these cores may have been lower during glacials, enhancing dissolution. 


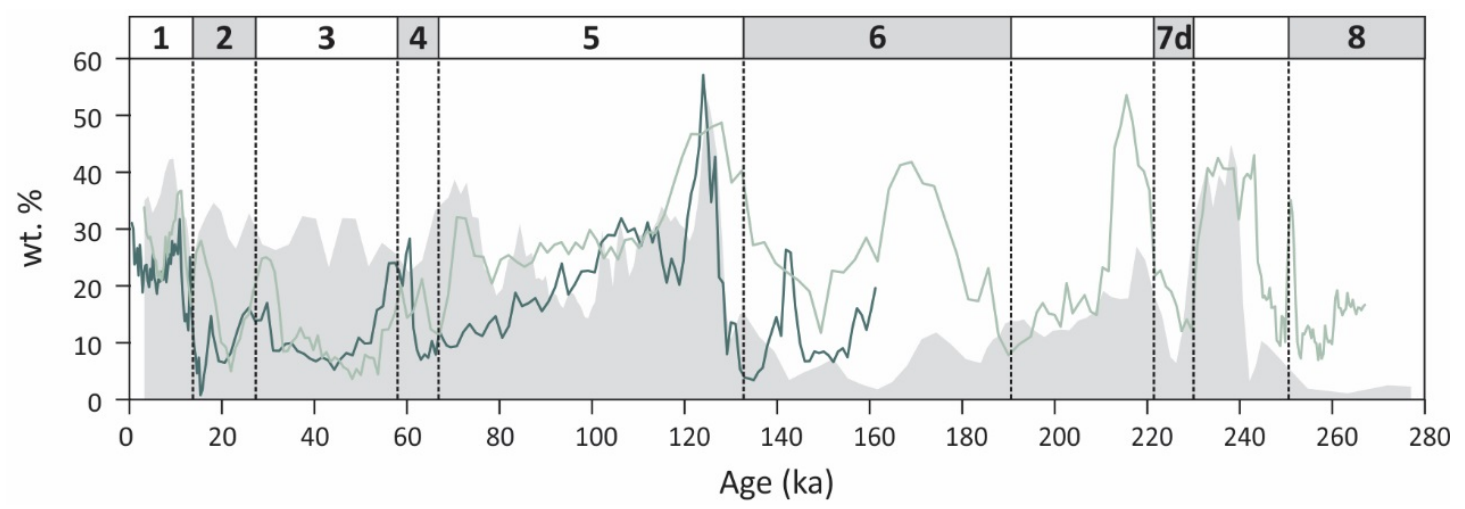

Figure 6.7 Calcium carbonate $\left(\mathrm{CaCO}_{3}\right.$ wt \%) productivity of the $\mathrm{PFZ}$ cores compared to carbonate productivity measured in SO136-111 (grey) from Sturm (2003). TAN1302-96 in dark green, TAN1302-97 in light green.

The present-day lysocline near the Emerald Basin is located at $\sim 3,600 \mathrm{~m}$ water depth (Sturm, 2003), and is thought to have been $>400 \mathrm{~m}$ shallower during glacials though this is strongly contested, where estimations vary considerably throughout the ocean basins (Sturm, 2003; Bostock et al., 2013). The effects of dissolution are more likely to affect the deeper PFZ core (TAN1302-97; 3,544 m) during glacial shoaling of the lysocline, however, this is not clearly reflected in the $\mathrm{CaCO}_{3} \%$ or $\mathrm{CaCO}_{3} \mathrm{MAR}$ records. Sturm (2003) suggested pronounced minima in carbonate concentrations observed in the Emerald Basin (core SO136-111), particularly in MIS 6 and MIS 8, relate to strong carbonate dissolution during glacial periods prior to $150 \mathrm{ka}$. This may represent shallowing of the lysocline during glacials preceding MIS 4 (Sturm, 2003). Calcium carbonate concentrations in TAN1302-97 are on average 2-3 times higher in MIS 6 and MIS 8, respectively, than the proximal Emerald Basin core SO136-111 (Figure 6.7). This could indicate the depth of the lysocline during MIS 6 and MIS 8 is similar to today, or perhaps even deeper. This would explain the higher carbonate concentrations in TAN1302-97 and the lower concentrations observed in the deeper SO136-111 core (3,912 $\mathrm{m})$ in the Emerald Basin.

The abundance of larger $(>250 \mu \mathrm{m}) N$. pachyderma individuals in TAN1302-96 during glacials was much lower than in interglacials, if present at all (see Appendix A). Because the presence of smaller $(>180 \mu \mathrm{m})$ foraminifers did not change dramatically, the ability of tests to reach maturity appears limited. This may be a consequence of limited nutrient supply as a result of reduced upwelling or vertical mixing, either due to a northward displacement of the westerly winds or increased sea ice over the more southern core site. (Toggweiler et al., 2006; Anderson et al., 2009). 
Records in the South Pacific and South Atlantic are in broad agreement with glacial observations of low carbonate accumulation in this thesis (Sturm, 2003; Jaccard et al., 2013; McCave et al., 2014; Lamy et al., 2014). Regardless of this, South Atlantic records in particular are commonly interpreted as preservation records (Jaccard et al., 2013). Although some evidence in this thesis suggests low biogenic carbonate during glacials is influenced by dissolution, low carbonate MARs and low $\mathrm{Ba} / \mathrm{Fe}$ ratios particularly at MIS 2 and MIS 6 glacial maxima, support reduced carbonate productivity during glacials (Figure 6.10). This raises important concerns involving the assumptions made when interpreting paleoproductivity records.

The observed glacial reduction in both productivity modes in this region is likely linked to nutrient availability and effects of dissolution (Figure 6.8). The evidence presented in this thesis is not enough to ascertain the exact mechanisms behind the observed patterns, however, further geochemical analyses will provide clarification.

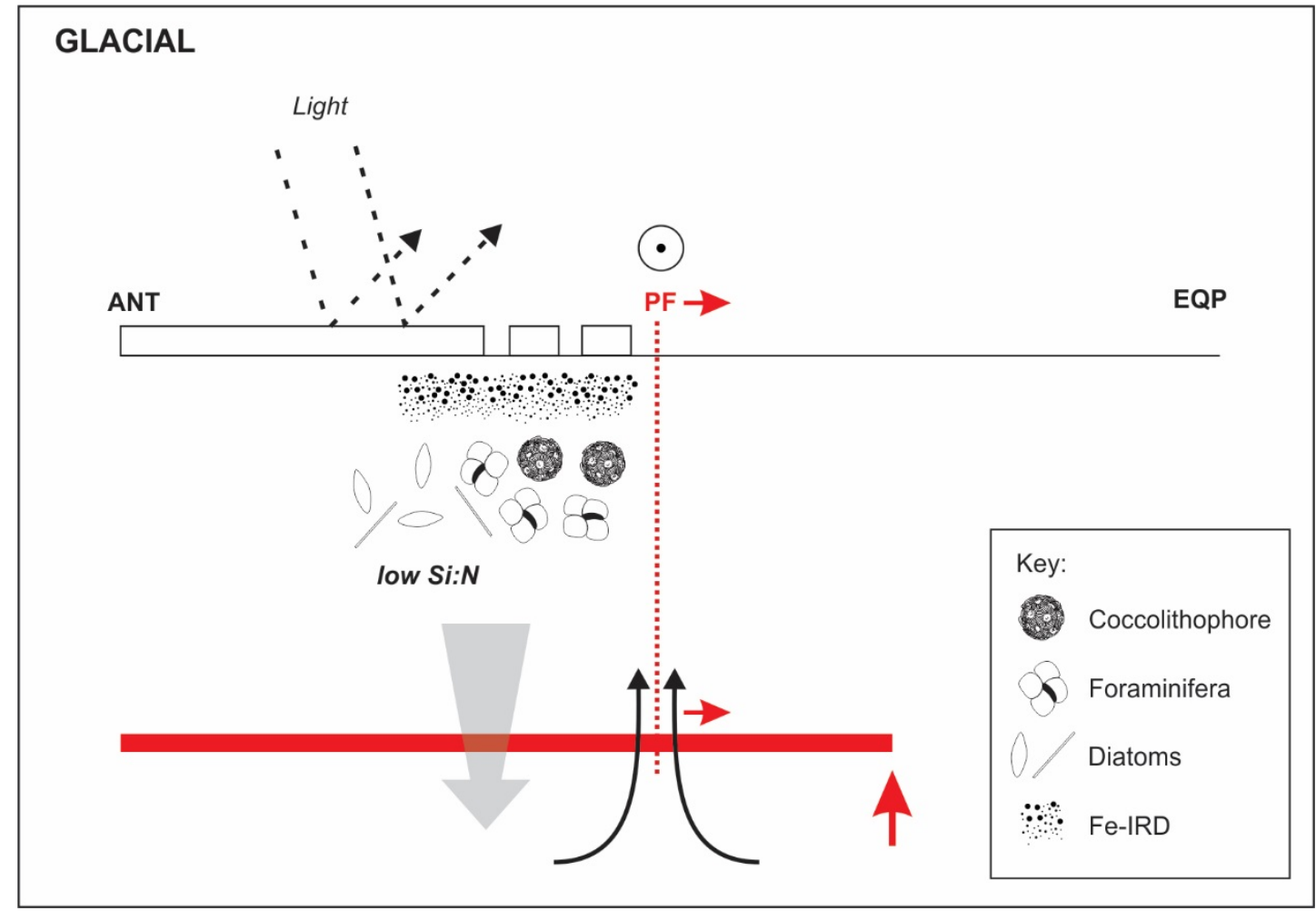

Figure 6.8. Schematic diagram of the glacial Southern Ocean setting. Cooler air and SSTs result in expansion of WSI over the modern PFZ. This forces the PF (red dashed line) and the associated Circumpolar Deep Water upwelling limb (black) slightly northwards, leading to reduced nutrient supply in the region of the modern PFZ. Reduced export production recorded in PFZ cores (grey arrow) due to low nutrient supply, which limits biogenic silica and calcium carbonate productivity. Additionally, increased dissolution from a shallower lysocline (red line) compared to modern, and reduced silicification due to increased Fe that lowers frustule silicification (i.e. low $\mathrm{Si}: \mathrm{N}$ ), results in poor preservation of biogenic carbonate and biogenic silica respectively. Collectively, these processes result in decreased export production during glacials. Small red arrows indicate direction of movement. ANT = Antarctica, EQP = equatorial Pacific. 


\subsection{Deglaciation sequence of events}

The PFZ cores used in this study highlight key differences in productivity that exist north and south of the PF during glacial terminations (Figure 6.9). In the modern ocean, the PF is a key biogeochemical boundary, separating Si-rich waters to the south from carbonate ion-rich waters to the north (Honjo, 2004). South of the PF, diatom productivity in TAN1302-96 increases between 3- and 5-fold during deglaciation after the LGM (opal peak at $\sim 17-13 \mathrm{ka}$ ) and during Termination II (TII) at the MIS 6/5 boundary (136-130 ka), respectively. The initiation of glacial terminations is suggested to require a combination of factors involving; 1) increased Northern Hemisphere summer insolation, 2) extensive Northern Hemisphere ice sheet collapse, 3) a reduction in the Atlantic Meridional Overturning Circulation leading to a southward shift in the Intertropical Convergence Zone, 4) southward shift of the Southern Hemisphere westerly winds over the core of the $\mathrm{ACC}$, and 5) rising Antarctic temperatures and outgassing $\mathrm{CO}_{2}$ from increased upwelling in the Southern Ocean (Anderson et al., 2009; Denton et al., 2010). It has previously been suggested that increased opal flux during the deglaciation was a result of increased upwelling of nutrient rich waters to the surface of the SO (Anderson et al., 2009). Another key consequence following rising Antarctic air temperatures and SSTs post-LGM would be the removal of the IRD Fe source in the South Pacific sector due to iceberg melt. The reduction in Fe would increase the Si:N uptake ratio similar to the modern SO, thereby increasing silicification and enabling better preservation of opal productivity in TAN1302-96.

Interestingly, the timing of the opal peak ( $\sim 15 \mathrm{ka})$ during Termination I (i.e. MIS $2 / 1$ transition; TI) coincides with a distinct increase in the area of individual $F$. kerguelensis valves near the PF in the South Atlantic (PS1654-2; 5.72638889, -50.162500) (Cortese and Gersonde, 2007). This peak in valve area has been associated with proximity to the PF and cooling of surface waters during TI (Cortese and Gersonde, 2007). Although valve areas were not calculated across glacial terminations in detail, valve areas from MIS 6 and MIS 5e in TAN1302-96 did not show a significant size difference (see Appendix A). Further work undertaking high resolution measurements and calculations on $F$. kerguelensis valves across the MIS 2/1 transition is required to test if this SST cooling event recorded in valve area at 12-14 ka is present in the southwest Pacific region. 
Following the peak in opal during TI and TII in TAN1302-96, the productivity mode shifts to one dominated by calcium carbonate (Figure $6.9 \mathrm{~A}$ and $\mathrm{B}$ ). Carbonate concentrations increase from $<5 \%$ to $\sim 20 \%$ across TI, continuing into the Holocene, and are double this $(>40 \%)$ in MIS 5e following TII. The proliferation of diatoms following deglacial initiation provides calcium carbonate zooplankton, e.g. N. pachyderma, with an abundant food source. This could be a reason for the shift from Si-based phytoplankton to grazing foraminifera, however, this seems unlikely given there is a 2-5 ka delay in the biological response. An alternative explanation involves surface nutrient concentrations. Surface waters are heavily depleted in $\mathrm{Si}$ and other nutrients after extensive diatom blooms (Anderson et al., 2009). This leaves the niche open for coccolithophores that have no silicate requirement and do well in nutrient-limited conditions, such as E. huxleyi, and G. oceanica.

These coccolithophore species have previously been found to form blooms during early interglacial phases in the Subantarctic waters of the South Pacific (e.g. Duncan et al., 2016). This calcifying phytoplankton source could encourage high foraminifera abundances which would contribute to the high accumulation of calcium carbonate in the latter half of the glacial terminations. Coccoliths from E. huxleyi were rarely observed compared to coccoliths from other species in the SEM samples from these cores. Given this species accounts for upwards of $50 \%$ of coccolithophore assemblages at the midlatitudes and above (McIntyre and Bé, 1967), it is likely they were present at higher abundances than observed in TAN1302-96 in particular. Future high resolution SEM imaging across glacial terminations will reveal if this is the case.

In theory, heightened diatom productivity should draw down atmospheric $\mathrm{CO}_{2}$ concentrations due to enhanced carbon fixation during photosynthesis (Watson et al., 2000). Perhaps this enhanced productivity could contribute to the Antarctic Cold Reversal, a short-lived cooling event between 12.5-14.5 ka (Ferry et al., 2015). It has been suggested that reversal events such as the Antarctic Cold Reversal are a feature of glacial terminations, hinting that the deglaciation is a two-step process (Carter and Cortese, 2009). The bi-modal productivity pattern observed in the Antarctic SO zone could be a key factor in completing glacial terminations. Subsequent carbonate productivity following the period of enhanced opal production could then contribute to increasing atmospheric $\mathrm{CO}_{2}$ through the carbonate counter pump, completing the glacial termination (Rost and Riebesell, 2004). 
In contrast to TAN1302-96, the productivity pattern following deglaciation in TAN130297 is reversed (Figure 6.9 C \& D). Carbonate concentrations at this site increase from $\sim 15-20 \%$ to $>25$ and $\sim 50 \%$ from LGM and MIS 6 concentrations respectively. Peaks in opal occur 2-5 kyrs later, and could be due to a supply of silicic acid from the lower latitudes developed during coccolithophore and foraminifera blooms south of the PF occurring at the same time. Although reasons for this productivity shift are speculative, this pattern from calcium carbonate dominated productivity to biogenic silica is regional within the southwest Pacific, as it is also recorded during TII in the adjacent Emerald Basin core SO136-111 (Sturm, 2003).

During TI, carbonate productivity is briefly interrupted at $\sim 14 \mathrm{ka}$, coinciding with the Antarctic Cold Reversal. During this time, SO SSTs and Antarctic air temperatures cooled by $2-3^{\circ} \mathrm{C}$ (Barker et al., 2009; Maher et al., 2010), facilitating the expansion of winter sea ice and the northward migration of the ACC fronts (Cortese and Gersonde, 2007; Ferry et al., 2015). A northward shift in the PF would expand the southern Si-rich waters over TAN1302-97, consistent with reduced carbonate productivity and a small peak in opal at this time (Figure $6.9 \mathrm{C}$ ).

The difference in the productivity mode during glacial terminations between TAN130296 and -97 is likely related to the position of the PF. The productivity pattern in TAN1302-97 suggests the PF must have shifted south of its glacial position by at least 16 $\mathrm{ka}$ and $134 \mathrm{ka}$, concurrent with retreating sea ice. This accounts for the growth of carbonate productivity in the Emerald Basin following the resumption in upwelling postglacial conditions (Anderson et al., 2009), and is consistent with other records both in the southwest and northwestern Pacific (Sturm, 2003; Brunelle et al., 2010). The repetition of these patterns across multiple deglaciations, and its presence in other cores elsewhere in the Pacific SO (e.g. SO136-111 and PC13) suggests a common mechanism across the Pacific basin. These consistent patterns coincide with increasing atmospheric $\mathrm{CO}_{2}$, and therefore highlight the potential importance of these productivity shifts in completing glacial-interglacial transitions. 

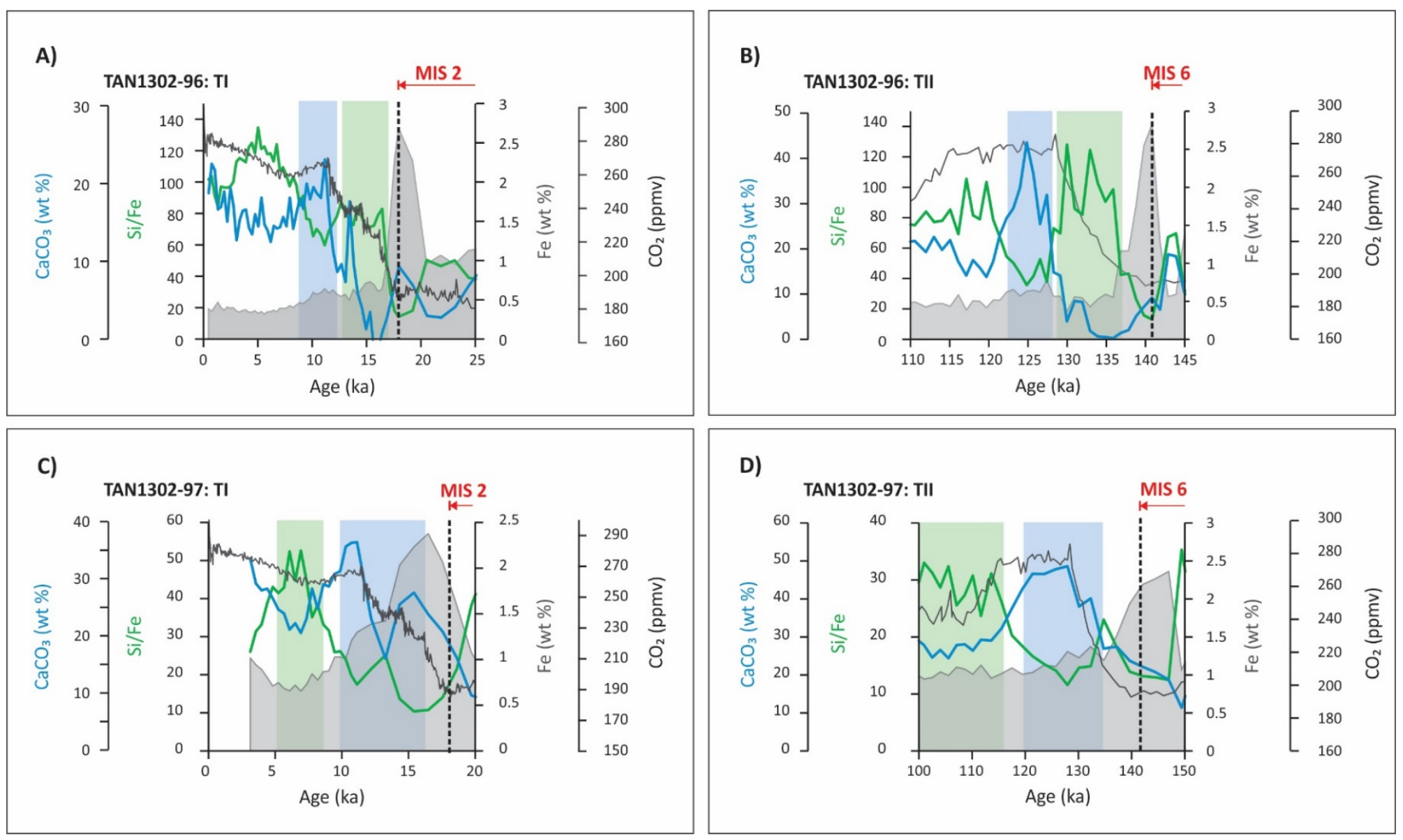

Figure 6.9. Productivity sequence (blue shading = carbonate mode; green shading = opal mode) following glacial maxima (black dashed line). A) TAN1302-96 deglacial transition across MIS 2 - MIS 1, i.e. Termination I (TI); B) TAN1302-96 MIS 6 - MIS 5, i.e. Termination II (TII); C) TAN1302-97 MIS 2 - MIS 1, i.e. TI; D) TAN1302-97 MIS 6 - MIS 5, i.e. TII. Blue $=$ calcium carbonate; green $=$ opal productivity; grey $=\mathrm{Fe}$ input from IRD; black = atmospheric $\mathrm{CO}_{2}$ concentration from EPICA Dome $\mathrm{C}$ ice core $($ Bereiter $e$ al ., 2015). 


\subsection{The interglacial Southern Ocean}

The terrigenous input recorded throughout the interglacials (MIS 1, 3, 5 and 7) in the PFZ cores is extremely low (e.g. IRD concentrations $<4$ grains/gram). The low fluctuations of detrital material observed in these cores is likely to represent the small input from material redistribution along the sea floor (Figure 6.4 and see Appendix A).

Although $88-91 \%$ of the diatoms in the PFZ cores indicate polar open ocean/seasonal sea ice tolerant species dominate this region during MIS 5e, $8 \%$ of the peak interglacial assemblage in TAN1302-96 is comprised of sea ice indicative diatoms (viz. 5\% F. separanda) (Figure 5.20). This could suggest that some degree of sea ice was present in the southern PFZ during MIS 5e. F. separanda, however, has been noted to have a wide temperature range, and therefore may have a relatively poor relationship to sea ice (Armand et al., 2005).

Regardless of this, the species is most abundant (2-5\%) in the Ross Sea and Prydz Bay, (i.e. regions of more prevalent sea ice) which is consistent with the proportion observed in TAN1302-96. It is suggested that global temperatures were up to $3^{\circ} \mathrm{C}$ warmer in MIS 5e than modern (Carter and Cortese, 2009), although regional temperature differences have been observed in the Australian-New Zealand sector of the southwest Pacific (Cortese et al., 2013). Warmer temperatures during MIS 5e may have increased ice sheet instability, a process associated with the 5-9 $\mathrm{m}$ sea level rise during the Last Interglacial, $\sim 129$ - 116 ka (LIG, i.e. MIS 5e) (O’Leary et al., 2013; Dutton et al., 2015). Mass calving events in relation to ocean warming and sea level rise could potentially account for ice reaching the PFZ during the LIG. A peak in IRD ( $\sim 25$ grains/gram) in TAN1302-97 at $\sim 105 \mathrm{ka}$, given age model errors, could correspond to late interglacial collapse of the Antarctic ice sheets (O'Leary et al., 2013). This is supported by IRD records in the South Atlantic PFZ that have been associated with ice sheet instability due to sea level rise in "rapid" interstadials (Kanfoush et al., 2000).

Armand et al. (2005) note $F$. separanda can be heavily silicified, and consequently may survive iceberg dispersal further north relative to other diatoms. This could mean that icebergs were present and relatively common during this time, or that there is a preservation bias. This highlights the need for further diatom assemblage analysis and higher resolution IRD counts on these cores to clarify if sea ice was present, before evaluating potential links to ice sheet instability during the LIG. 


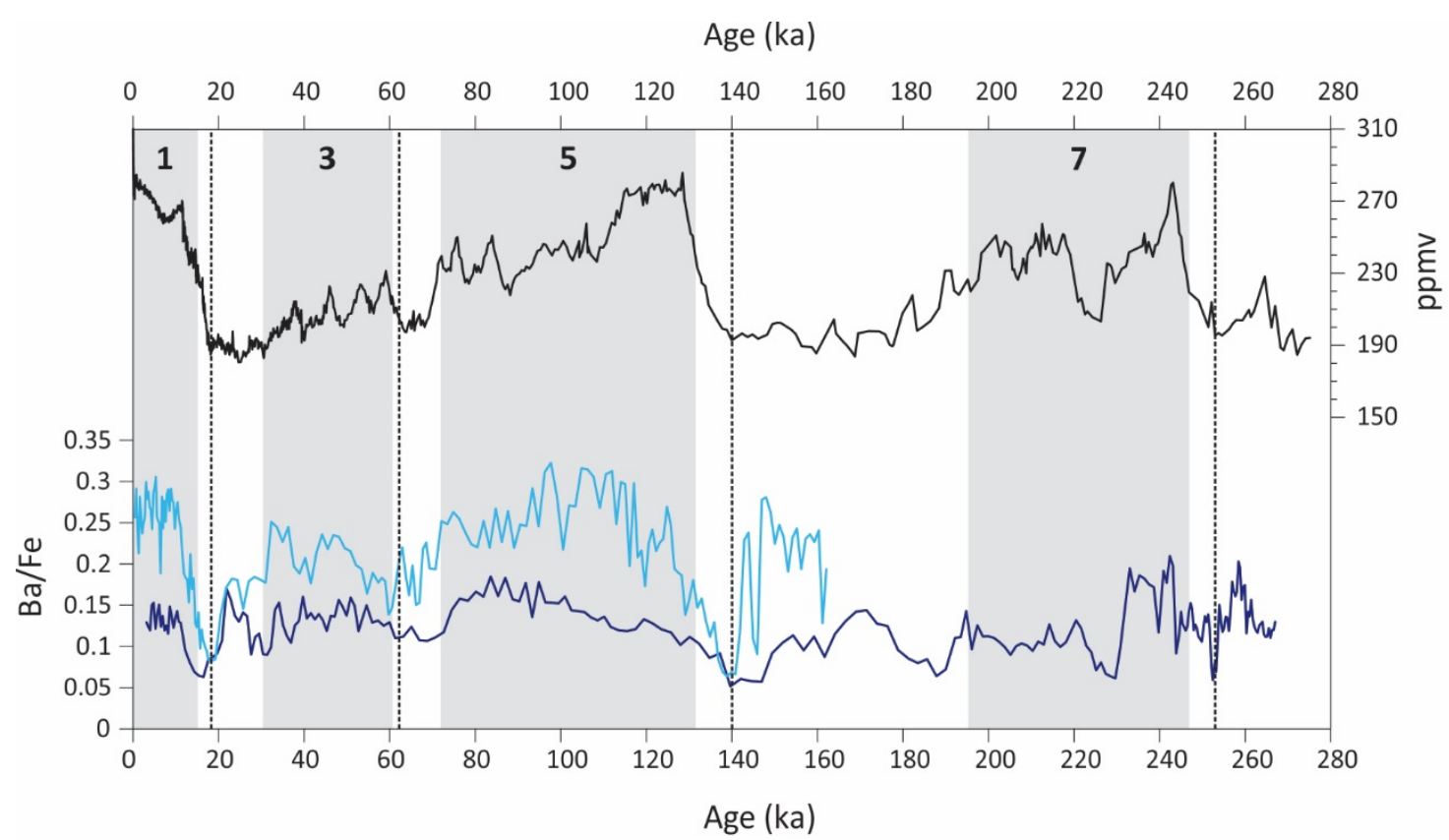

Figure 6.10. Export productivity estimated by Ba/Fe; light blue $=$ TAN1302-96 and dark blue $=$ TAN1302-97, with atmospheric $\mathrm{CO}_{2}$ concentrations from EPICA Dome C in black (Bereiter et al., 2015). Grey bars indicate interglacial periods with glacial maxima highlighted by dashed lines.

In contrast to glacial periods, productivity (both opal and carbonate) is up to 3 times higher during interglacials. Glacial-interglacial productivity differences estimated by $\mathrm{Ba} / \mathrm{Fe}$ are more pronounced in TAN1302-96 (Figure 6.10). This could be related to stronger sea ice influence at this southern core site during glacials and associated weakened upwelling, or glacial-interglacial migrations of the PF. The fronts in this region are heavily constrained by bathymetry (Weaver et al., 1998), therefore significant latitudinal shifts, particularly to the north, are unlikely. Regardless of the observed differences, both interglacial records from TAN1302-96 and -97 highlight the inverse correlation between silicon and calcium carbonate dominated productivity $\left(r^{2}>-0.94\right)$.

Biogenic carbonate productivity is generally high (44-49\%) throughout early MIS 5, whilst diatom productivity is low $(\mathrm{Si} / \mathrm{Fe} \sim 12-36)$, with a clear switch at $\sim 110$ ka (Figure 6.11). These results differ from productivity records in the South Atlantic, which show high opal productivity in MIS 5e (e.g. Hillenbrand and Cortese, 2006; Sigman et al., 2010). Many South Atlantic records also document similar early interglacial carbonate patterns (e.g. ODP 1094, ODP 1090), however, these records are commonly interpreted to reflect preservation changes rather than productivity signals (e.g. Jaccard et al., 2013). Increased $\mathrm{CaCO}_{3}$ MARs in TAN1302-96 and TAN1302-97 during MIS 5e, and a concomitant increase in $\mathrm{Ba} / \mathrm{Fe}$ suggests the carbonate records in these cores reflect enhanced productivity (see sections 5.2 and 5.7). This is consistent with $\mathrm{Ca} / \mathrm{Fe}$ and $\mathrm{Ba} / \mathrm{Fe}$ 
records in the South Atlantic AZ, which show significant increases during peak interglacials (Jaccard et al., 2013), and therefore may represent increased productivity as well as increased preservation.

Along with the elemental proxies, SEM images and foraminifera counts revealed the presence of significantly greater volumes of biological material during MIS 5e in both PFZ cores compared to late MIS 5 and MIS 7c (see section 5.5.3). Presently, high abundances of $N$. pachyderma occur in the zone of maximum chlorophyll abundance, i.e. regions of high primary productivity, where zooplankton can utilize the prolific food source (Kohfeld et al., 1996). Because the abundance of diatoms in MIS 5e is relatively low (Figure 6.6), a different phytoplankton source must be present to account for the abundance of large $N$. pachyderma individuals, and the high carbonate concentration during MIS 5e.

The most common calcifying phytoplankton in the MIS 5e samples were coccolithophore species C. leptoporus and G. oceanica, a prominent bloom former and genetically very similar to E. huxleyi (Rost and Riebesell, 2004; Balch, 2018). The presence of G. oceanica in MIS 5e suggests SSTs in the PFZ were likely warmer than present SSTs $\sim 4-10^{\circ} \mathrm{C}$ ('World Ocean Database', 2005), but by how much remains uncertain. Some research suggests increasing atmospheric $\mathrm{CO}_{2}$ concentrations can increase carbon fixation in photosynthesis, specifically in G. oceanica and E. huxleyi (Rost and Riebesell, 2004), where growth of these species appears carbon-limited at low $\mathrm{CO}_{2}$ concentrations (Krumhardt et al., 2017). Following the rapid increase in atmospheric $\mathrm{CO}_{2}$ from MIS 6 ( $\sim 190$ to $\sim 290$ ppmv, Figure 6.10), G. oceanica could have a competitive advantage over other phytoplankton, such as diatoms, that are less sensitive to $\mathrm{CO}_{2}$ changes (Rost and Riebesell, 2004).

In contrast to G. oceanica, which has no clear silicate requirement, C. leptoporus grows malformed coccoliths under very low silicate concentrations (Durak et al., 2016). This suggests the PFZ waters during early MIS 5e had relatively low-moderate silicate concentrations, given that the C. leptoporus coccoliths found in both PFZ cores were wellformed. This appears to be particularly the case for TAN1302-97, which has up to 4 times less diatom productivity than TAN1302-96 (Figure 6.6). The relatively low-Si waters in the northern PFZ could be due to; 1) a southward shift in the position of the PF closer to the -96 core, 2) weakened upwelling north of the PF, or a combination of both. On the Campbell Plateau (ODP Site 1120) extensive coccolithophore blooms during MIS 5e have been associated with enhanced stratification as a result of reduced windiness and 
circulation (Duncan et al., 2016). Reduced windiness would have a direct effect on the strength of upwelling at the PF. Weakened upwelling and the associated nutrient availability may be a key factor in determining which productivity mode dominates the early interglacials.

Interestingly, the sequential productivity pattern in MIS 5 is reversed in MIS 3, with diatom productivity prevailing throughout the early interglacial $(\sim 50-30 \mathrm{ka})$, followed by peaks in calcium carbonate after $\sim 30 \mathrm{ka}$ (Figure 6.11). In contrast to MIS $5 \mathrm{e}, \mathrm{CO}_{2}$ concentrations are $>60$ ppmv lower in MIS 3 (Bereiter et al., 2015). This could mean calcifying phytoplankton such as G. oceanica do not have the same competitive advantage that may have existed in MIS 5e, leaving the niche open for diatoms. Alternatively, there was enough upwelling of silicate to the surface waters to give diatoms a competitive advantage.

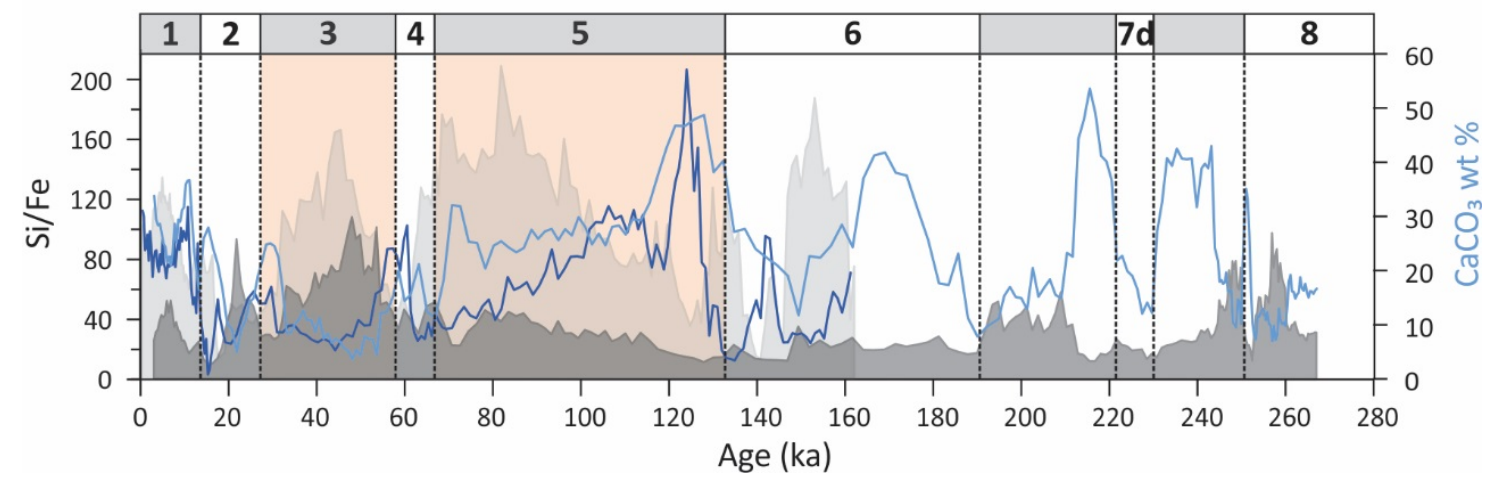

Figure 6.11. Composite productivity record in the PFZ cores. Biogenic silica $=$ light grey shaded (TAN96) and dark grey shaded (TAN97). Calcium carbonate $=$ dark blue line (TAN96) and light blue line (TAN97). MIS 3 and MIS 5 highlighted.

Although lower $\mathrm{CO}_{2}$ could be a contributing factor to this opal productivity, perhaps the most compelling explanation involves the silicate and nitrate concentration in the ocean. During glacials, increased Fe input as IRD led to reduced Si-utilisation due to higher consumption of nitrate (Robinson and Sigman, 2008), thereby increasing the chance of frustule dissolution during sinking to the sea floor (Figure 6.8). Conversely, in MIS 3, the low Fe input at this time, as estimated by low IRD and low terrigenous deposition relative to biological input (i.e. $\mathrm{Fe} / \mathrm{Ca} \sim 0.1$ ), would have promoted Si-utilisation relative to nitrate. This is thought to increase silicification and thus preservation of the diatoms (Figure 6.12). Principal Component Analysis (PCA) revealed the silicon concentrations during MIS 3 have a different affinity to other elements relative to the rest of the core, especially in TAN1302-97. This may represent the increased preservation in addition to enhanced 
productivity during this time, and is consistent with equatorial Pacific records that document this apparent preservation event (Kienast et al., 2006; Dubois et al., 2010).

The peak in opal productivity during MIS 3 is not typically well defined in the SAZ or $\mathrm{AZ}$ in the SO, where opal flux is strongly correlated to dust flux in the South Atlantic in particular (e.g. PS2498-1) (Charles et al., 1991; Diekmann and Kuhn, 2002; Anderson et al., 2014). The southwest Pacific PFZ records from this study expand the results of the equatorial Pacific, and suggest this event is largely related to the lack of Fe across the Pacific in contrast to the South Atlantic.

While increased $\mathrm{CO}_{2}$ may have enhanced coccolithophore productivity in the LIG, very high levels of $\mathrm{CO}_{2}$ show detrimental effects to growth, evolutionary plasticity, fitness and calcification (Riebesell et al., 2000; Jin and Gao, 2015). Therefore under current rising $\mathrm{CO}_{2}$ concentrations, it is unlikely that carbonate productivity will show the same response in the future as in the LIG (Jin and Gao, 2015). Additionally, modern observations show a southward shift in the westerly winds over the last several decades, in conjunction with strengthening of the bathymetrically constrained ACC fronts, and upwelling in the South Pacific (Fernandez et al., 2013). These differences will likely have a large influence over which productivity mode thrives in the future.

Both competitive advantages and nutrient availability appear to dictate the productivity that dominates during interglacials. Key differences in interglacial productivity and inferred circulation changes have been highlighted in the southwest Pacific PFZ in this thesis. Understanding these differences and what causes them will be extremely beneficial for anticipating the response of the oceans in the future, in regards to biological, chemical and physical changes. 


\section{INTERGLACIAL}

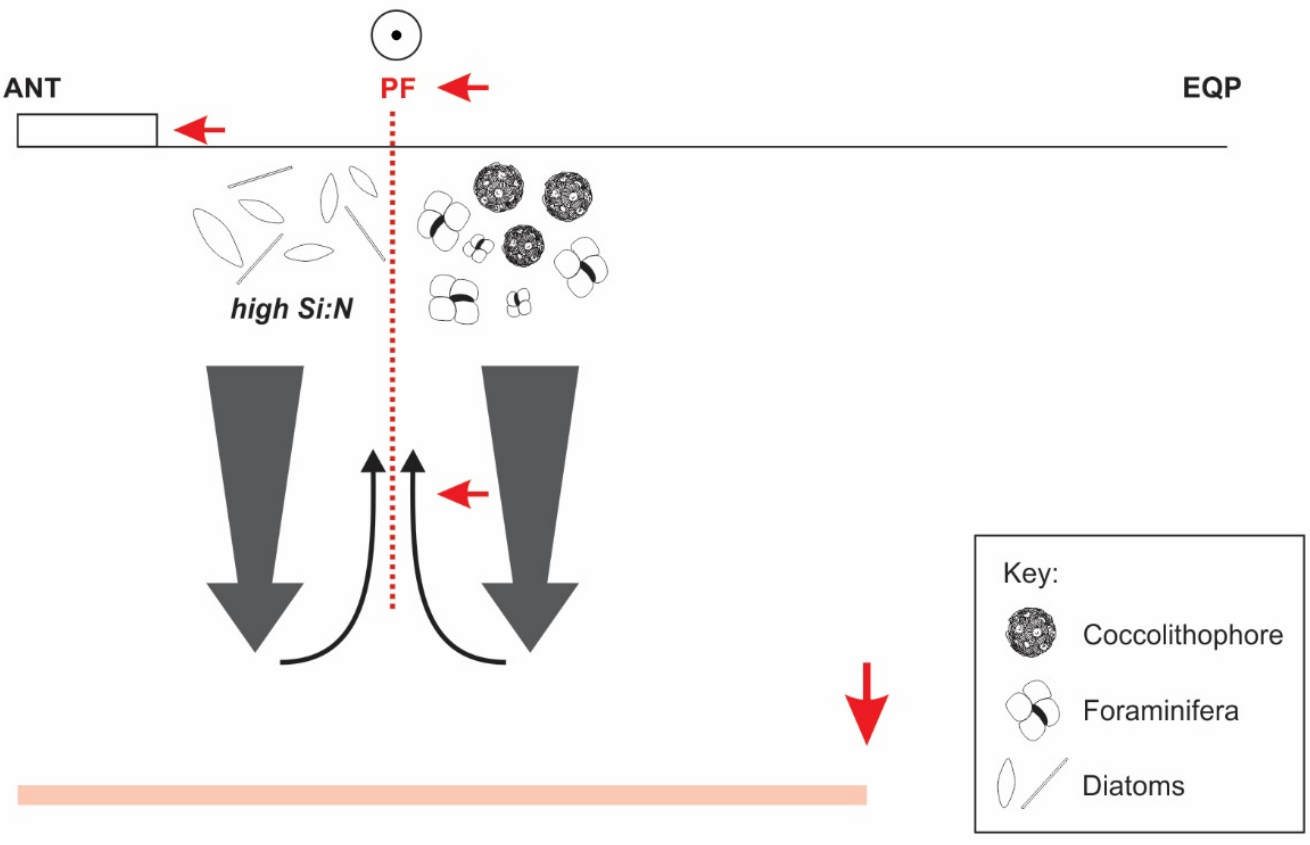

Figure 6.12. Schematic diagram of the interglacial Southern Ocean setting. Modern PFZ: PF separates $\mathrm{CaCO}_{3}-$ dominated sedimentation in the north from Si-dominated sedimentation in the south. Following glacial terminations, air temperatures and SSTs warm, resulting in the retreat of glacial sea ice, and the subsequent poleward migration of the PF (red dashed line) and the Circumpolar Deep Water upwelling limb (black lines). High calcium carbonate productivity in the early interglacial potentially due to; 1) competitive advantage during rapid $\mathrm{CO}_{2}$ increase, 2) low/moderate Si concentrations, or 3) southward migration of the PF to its southern-most position. High biogenic silica productivity during late interglacials could be due to; 1) lowered $\mathrm{CO}_{2}$ concentrations, 2) sufficient dissolved Si supply or 3) expansion of Si-rich waters following a northward shift in the position of the PF. Better preservation of productivity due to a deeper lysocline (red line) and increased silicification (high Si:N) as a result of low Fe input. Small red arrows indicate the direction of early interglacial movement. Dark grey arrows indicate increased export production recorded in the PFZ records, as a result of both increased productivity and decreased dissolution. ANT = Antarctica, EQP = equatorial Pacific. 


\section{Chapter 7 Conclusions and future work}

The main purpose of this thesis was to investigate potential processes responsible for productivity changes in the southwest Pacific PFZ over glacial-interglacial timescales. Two gravity cores from the PFZ were analysed using a combination of geochemical, sedimentological and biological methods to reconstruct glacial-interglacial changes in terrigenous input and paleoproductivity. Using well-established proxies, together with $\delta^{18} \mathrm{O}$ stratigraphy and ${ }^{14} \mathrm{C}$ chronology, a series of conclusions were reached:

- IRD likely came from the Amery Ice Sheet, and travelled to the southwest Pacific due to cooler SSTs. The co-occurrence of peak IRD and peak iron concentrations suggests a substantial contribution of $\mathrm{Fe}$ is from IRD.

- Sea ice reached the northern PFZ $\left(\sim 57^{\circ} \mathrm{S}\right)$ during glacials, apart from MIS 4. Low concentrations of IRD suggests SSTs were slightly warmer in MIS 4 than other glacials, thus icebergs did not survive to the PFZ.

- Glacial periods are characterised by low productivity and increased dissolution, potentially due to reduced upwelling of nutrients, shoaling of the lysocline, and increased Fe deposition. Increased glacial sea ice cover could have forced the PF slightly northwards, moving the Circumpolar Deep Water upwelling limb and the belt of increased opal and calcite accumulation equatorward. The addition of $\mathrm{Fe}$ sourced from IRD during glacial maxima could increase the uptake of nitrate relative to silicate, resulting in reduced silicification and increasing the chance of frustule dissolution during sinking to the sea floor.

- Glacial terminations TI and TII are characterised by a sequence of key productivity changes that influence atmospheric $\mathrm{CO}_{2}$ concentrations. North of the $\mathrm{PF}$, calcium carbonate productivity dominates the early termination for $\sim 5 \mathrm{kyr}$ after peak glaciation, followed by biogenic silica. South of the PF, biogenic silica productivity dominates the early termination, followed by calcium carbonate production after 2-5 kyr. The difference in the leading productivity mode following peak glaciation is likely due to position relative to the PF.

- Early interglacial productivity is characterised by enhanced calcium carbonate productivity, followed by diatom productivity during the later interglacial. This 
could be due to coccolithophore species present having a competitive advantage over diatoms during periods of higher $\mathrm{CO}_{2}$ concentrations. Alternatively, this could be due to relatively low-Si waters as a consequence of reduced upwelling, a southward migration of the PF, or a combination of both.

\section{Future work}

This research highlights the need for future work to resolve some of the uncertainties regarding oceanographic interpretations made. Some recommendations include:

- Further detailed diatom assemblage analysis. This will better constrain winter sea ice extent in the PFZ during other glacial periods, i.e. MIS 2, 4 and 8, particularly in TAN1302-97. Additionally, assemblages could be grouped differently to obtain different oceanographic information, such as SST and surface stratification. This would clarify some of the interpretations made regarding upwelling and SST in this thesis.

- Geochemical analyses such as $\delta^{15} \mathrm{~N}_{\text {diatoms }}$ and $\delta^{30} \mathrm{Si}_{\text {diatoms. This }}$ will help to determine if changes in the glacial nutrient utilisation (supply versus demand) are the reasons behind low diatom productivity during glacial periods in these cores. Additionally, ${ }^{231} \mathrm{~Pa} /{ }^{230} \mathrm{Th}$ will help elucidate the true flux of material to the seafloor, to understand the effects of dissolution and potential focussing or erosion on the sediments in the cores.

- Further work undertaking high resolution measurements and calculations on $F$. kerguelensis valves across the MIS 2 - MIS 1 transition in the TAN cores used in this study, and in neighbouring PFZ cores. This would reveal if the signal observed in the South Atlantic is a basin-wide phenomenon.

- Higher-resolution IRD measurements on the TAN cores used in this study. This would clarify if large-scale ice-sheet instability during periods of rapid sea level rise are documented in the PFZ IRD records. 


\section{Chapter 8 References}

Agnihotri, R., Altabet, M. A., Herbert, T. D. and Tierney, J. E. (2008) 'Subdecadally resolved paleoceanography of the Peru margin during the last two millennia', Geochemistry, Geophysics, Geosystems, 9(5), p. n/a-n/a. doi: 10.1029/2007GC001744.

Anderson, R. F., Ali, S., Bradtmiller, L. I., Nielsen, S. H. H., Fleisher, M. Q., Anderson, B. E. and Burckle, L. H. (2009) 'Wind-Driven Upwelling in the Southern Ocean and the Deglacial Rise in Atmospheric CO2', Science. American Association for the Advancement of Science, 323(5920), pp. 1443-1448. doi: 10.1126/science.1167441.

Anderson, R. F., Barker, S., Fleisher, M., Gersonde, R., Goldstein, S. L., Kuhn, G., Mortyn, P. G., Pahnke, K. and Sachs, J. P. (2014) 'Biological response to millennial variability of dust and nutrient supply in the Subantarctic South Atlantic Ocean', Philosophical Transactions of the Royal Society A: Mathematical, Physical and Engineering Sciences, 372(2019), pp. 20130054-20130054. doi: 10.1098/rsta.2013.0054.

Anderson, R. F., Chase, Z., Fleisher, M. Q. and Sachs, J. (2002) 'The Southern Ocean's biological pump during the Last Glacial Maximum', Deep-Sea Research II, 49, pp. 19091938. Available at: https://ac.els-cdn.com/S0967064502000188/1-s2.0S0967064502000188-main.pdf?_tid=5c4c6454-c4f0-11e7-8526-

00000aacb35e\&acdnat $=1510192408 \_2 b 40 f 54 f 983571$ c606c0ff2bd601a660 (Accessed: 9 November 2017).

Armand, L. K., Crosta, X., Romero, O. and Pichon, J. J. (2005) 'The biogeography of major diatom taxa in Southern Ocean sediments: 1. Sea ice related species', Palaeogeography, Palaeoclimatology, Palaeoecology, 223(1-2), pp. 93-126. doi: 10.1016/j.palaeo.2005.02.015.

Balch, W. M. (2018) 'The Ecology, Biogeochemistry, and Optical Properties of Coccolithophores', Annual Review of Marine Science. Annual Reviews, 10(1), pp. 7198. doi: 10.1146/annurev-marine-121916-063319.

Balch, W. M., Bates, N. R., Lam, P. J., Twining, B. S., Rosengard, S. Z., Bowler, B. C., Drapeau, D. T., Garley, R., Lubelczyk, L. C., Mitchell, C. and Rauschenberg, S. (2016) 
'Factors regulating the Great Calcite Belt in the Southern Ocean and its biogeochemical significanc', AGU Publications, pp. 1124-1144. doi: 10.1002/2016GB005414.Received. Balch, W. M., Drapeau, D. T., Bowler, B. C., Lyczskowski, E., Booth, E. S. and Alley, D. (2011) 'The contribution of coccolithophores to the optical and inorganic carbon budgets during the Southern Ocean Gas Exchange Experiment: New evidence in support of the Great Calcite Belt hypothesis', Journal of Geophysical Research: Oceans, 116(8), pp. 1-14. doi: 10.1029/2011JC006941.

Barker, S., Diz, P., Vautravers, M. J., Pike, J., Knorr, G., Hall, I. R. and Broecker, W. S. (2009) 'Interhemispheric Atlantic seesaw response during the last deglaciation', Nature. Nature Publishing Group, 457(7233), pp. 1097-1102. doi: 10.1038/nature07770.

Belkin, I. M. and Gordon, A. L. (1996) 'Southern Ocean fronts from the Greenwich meridian to Tasmania', Journal of Geophysical Research: Oceans, 101(C2), pp. 36753696. doi: 10.1029/95JC02750.

Bendif, E. M. and Young, J. (2014) 'On the Ultrastructure of Gephyrocapsa oceanica (Haptophyta) Life Stages', Cryptogamie, Algologie, 35(4), pp. 379-388. doi: 10.7872/crya.v35.iss4.2014.379.

Benz, V., Esper, O., Gersonde, R., Lamy, F. and Tiedemann, R. (2016) 'Last Glacial Maximum sea surface temperature and sea-ice extent in the Pacific sector of the Southern Ocean', Quaternary Science Reviews, 146, pp. 216-237. doi: 10.1016/j.quascirev.2016.06.006.

Bereiter, B., Eggleston, S., Schmitt, J., Nehrbass-Ahles, C., Stocker, T. F., Fischer, H., Kipfstuhl, S. and Chappellaz, J. (2015) 'Revision of the EPICA Dome C CO2 record from 800 to 600-kyr before present', Geophysical Research Letters, 42(2), pp. 542-549. doi: 10.1002/2014GL061957.

Borcard, D., Gillet, F. and Legendre, P. (2011) 'Spatial analysis of ecological data' In Numerical ecology with $R$ (pp. 227-292). Springer, New York, NY.

Bostock, H. C., Barrows, T. T., Carter, L., Chase, Z., Cortese, G., Dunbar, G. B., Ellwood, M., Hayward, B., Howard, W., Neil, H. L., Noble, T. L., Mackintosh, A., Moss, P. T., Moy, A. D., White, D., Williams, M. J. M. and Armand, L. K. (2013) 'A review of the Australian-New Zealand sector of the Southern Ocean over the last 30 ka (AusINTIMATE project)', Quaternary Science Reviews, 74, pp. 35-57. doi: 10.1016/j.quascirev.2012.07.018. 
Bostock, H. C., Hayward, B. W., Neil, H. L., Sabaa, A. T. and Scott, G. H. (2015) 'Changes in the position of the Subtropical Front south of New Zealand since the last glacial period', Paleoceanography, 30(7), pp. 824-844. doi: 10.1002/2014PA002652.

Boyd, P.W. and Ellwood, M.J., (2010). The biogeochemical cycle of iron in the ocean. Nature Geoscience, 3(10), p.675.

Boyd, P., Laroche, J., Gall, M., Frew, R., Mckay, R. M. L. (1999) 'Role of iron, light, and silicate in controlling algal biomass in subantarctic waters SE of New Zealand', Journal of Geophysical Research: Oceans, 104(C6), pp. 395-408. doi: 10.1029/1999JC900009.

Boyd, P. W., Jickells, T., Law, C. S., Blain, S., Boyle, E. A., Buesseler, K. O., Coale, K. H., Cullen, J. J., de Baar, H. J. W., Follows, M., Harvey, M., Lancelot, C., Levasseur, M., Owens, N. P. J., Pollard, R., Rivkin, R. B., Sarmiento, J., ... Watson, A. J. (2007) 'Mesoscale Iron Enrichment Experiments 1993-2005: Synthesis and Future Directions', Science. American Association for the Advancement of Science, 315(5812), pp. 612-617. doi: $10.1126 /$ science. 1131669 .

Boyd, P. W., Watson, A. J., Law, C. S., Abraham, E. R., Trull, R., Murdoch, R., Bakker, D. C. E., Bowle, A. R., Buesseler, K. O., Chang, H., Charette, M., Croot, P., Downing, K., Frew, R., Gall, M., Hadfield, M., Hall, J., ... Zeldis, J. (2000) 'A mesoscale phytoplankton bloom in the polar Southern Ocean stimulated by iron fertilization', Nature, 407(12), pp. 695-702.

Bradtmiller, L. I., Anderson, R. F., Fleisher, M. Q. and Burckle, L. H. (2009) 'Comparing glacial and Holocene opal fluxes in the Pacific sector of the Southern Ocean', Paleoceanography. Wiley-Blackwell, 24(2), p. n/a-n/a. doi: 10.1029/2008PA001693.

Broecker, W.S., (1982). Glacial to interglacial changes in ocean chemistry. Progress in Oceanography, 11(2), pp.151-197.

Brummer, G. J. A. and van Eijden, A. J. M. (1992) “"Blue-ocean” paleoproductivity estimates from pelagic carbonate mass accumulation rates', Marine Micropaleontology. Elsevier, 19(1-2), pp. 99-117. doi: 10.1016/0377-8398(92)90023-D.

Brunelle, B. G., Sigman, D. M., Jaccard, S. L., Keigwin, L. D., Plessen, B., Schettler, G., Cook, M. S. and Haug, G. H. (2010) 'Glacial/interglacial changes in nutrient supply and stratification in the western subarctic North Pacific since the penultimate glacial maximum', Quaternary Science Reviews, 29(19-20), pp. 2579-2590. doi: 
10.1016/j.quascirev.2010.03.010.

Brzezinski, M. A., Pride, C. J., Franck, V. M., Sigman, D. M., Sarmiento, J. L., Matsumoto, K., Gruber, N., Rau, G. H. and Coale, K. H. (2002) 'A switch from $\operatorname{Si}(\mathrm{OH})$ 4 to $\mathrm{NO}_{3}{ }^{-}$depletion in the glacial Southern Ocean', Geophysical Research Letters. Wiley-Blackwell, 29(12), p. 1564. doi: 10.1029/2001GL014349.

Burckle, L. H. and Cirilli, J. (1987) 'Origin of diatom ooze belt in the Southern Ocean; Implications for late Quaternary paleoceanography'. Micropaleontology. Available at: https://gsw.silverchair-

cdn.com/gsw/Content_public/Journal/micropal/33/1/scimport_gsmicropal_33_1_c4bba 2ef-cbd6-49c9-a4145649b4a8cd75/4/82.pdf?Expires $=1516325672 \&$ Signature $=$ TrFNWhEiBAqyL7BzqOct0a6n6QLQtqYhKVIPW-3m1rnJqrzN8cZgBTIA95ONPMCuTWpSaEPq3hPIwBnVK. Carter, L., Carter, R. M., McCave, I. N. and Gamble, J. (1996) 'Regional sediment recycling in the abyssal Southwest Pacific Ocean', Geology, 24(8), pp. 735-738. doi: 10.1130/0091-7613(1996)024<0735:RSRITA>2.3.CO;2.

Carter, L. and Cortese, G. (2009) 'Change in the Southern Ocean: Responding to Antarctica', PAGES News@BULLET, 17(1). Available at: https://www.victoria.ac.nz/antarctic/pdf/Carter-Cortese-Pages2009.pdf (Accessed: 3 October 2017).

Carter, L., Neil, H. L. and Northcote, L. (2002) 'Late quaternary ice-rafting events in the SW Pacific Ocean, off eastern New Zealand', Marine Geology, 191(1-2), pp. 19-35. doi: 10.1016/S0025-3227(02)00509-1.

Charles, C. D., Froelich, P. N., Zibello, M. A., Mortlock, R. A. and Morley, J. J. (1991) 'Biogenic opal in Southern Ocean sediments over the last 450,000 years: Implications for surface water chemistry and circulation', Paleoceanography, 6(6), pp. 697-728. doi: 10.1029/91PA02477.

Chase, Z., Anderson, R. F., Fleisher, M. Q. and Kubik, P. W. (2003) 'Accumulation of biogenic and lithogenic material in the Pacific sector of the Southern Ocean during the past 40,000 years', Deep-Sea Research Part II: Topical Studies in Oceanography. Pergamon, 50(3-4), pp. 799-832. doi: 10.1016/S0967-0645(02)00595-7.

Chisholm, S.W. (2000). 'Oceanography: stirring times in the Southern Ocean.' Nature, 407(6805), p.685. 
Clarke, G., Kernan, M., Marchetto, A., Sorvari, S. and Catalan, J., (2005). Using diatoms to assess geographical patterns of change in high-altitude European lakes from preindustrial times to the present day. Aquatic Sciences, 67(3), pp.224-236.

Conan, S. M. H., Ivanova, E. M. and Brummer, G.-J. J. A. (2002) 'Quantifying carbonate dissolution and calibration of foraminiferal dissolution indices in the Somali Basin', Marine Geology, 182(3-4), pp. 325-349. doi: 10.1016/S0025-3227(01)00238-9.

Conway, C. E. (2011) 'The volcano - tectonic evolution of the Macquarie Ridge Complex , Australia - Pacific plate boundary south of New Zealand'. Available at: http://hdl.handle.net/10063/2122.

Conway, C. E., Bostock, H. C., Baker, J. A., Wysoczanski, R. J. and Verdier, A. L. (2012) 'Evolution of Macquarie Ridge Complex seamounts: Implications for volcanic and tectonic processes at the Australia-Pacific plate boundary south of New Zealand', Marine Geology, 295-298, pp. 34-50. doi: 10.1016/j.margeo.2011.11.009.

Cortese, G., Dunbar, G. B., Carter, L., Scott, G., Bostock, H., Bowen, M., Crundwell, M., Hayward, B. W., Howard, W., Martínez, J. I., Moy, A., Neil, H., Sabaa, A. and Sturm, A. (2013) 'Southwest Pacific Ocean response to a warmer world: Insights from Marine Isotope Stage 5e', Paleoceanography, 28(3), pp. 585-598. doi: 10.1002/palo.20052.

Cortese, G. and Gersonde, R. (2007) 'Morphometric variability in the diatom Fragilariopsis kerguelensis: Implications for Southern Ocean paleoceanography', Earth and Planetary Science Letters. Elsevier, 257(3-4), pp. 526-544. doi: 10.1016/j.epsl.2007.03.021.

Cortese, G., Gersonde, R., Maschner, K. and Medley, P. (2012) 'Glacial-interglacial size variability in the diatom Fragilariopsis kerguelensis: Possible iron/dust controls?', Paleoceanography, 27(1), pp. 1-14. doi: 10.1029/2011PA002187.

Costa, K. M., Jacobel, A. W., McManus, J. F., Anderson, R. F., Winckler, G. and Thiagarajan, N. (2017) 'Productivity patterns in the equatorial Pacific over the last 30,000 years', Global Biogeochemical Cycles, 31(5), pp. 850-865. doi: 10.1002/2016GB005579.

Crosta, X., Romero, O., Armand, L. K., Pichon, J.-J. and Armand, L. K. (2005) 'The biogeography of major diatom taxa in Southern Ocean sediments: 2. Open ocean related species', Palaeogeography, Palaeoclimatology, Palaeoecology, 223, pp. 66-92. doi: 10.1016/j.palaeo.2005.03.028. 
Crosta, X., Sturm, A., Armand, L. and Pichon, J.-J. (2004) 'Late Quaternary sea ice history in the Indian sector of the Southern Ocean as recorded by diatom assemblages', Marine Micropaleontology, 50(3-4), pp. 209-223. doi: 10.1016/S0377-8398(03)000720 .

Croudace, I. W. and Rothwell, R. G. (2015) Micro-XRF Studies of Sediment Cores: Applications of a non-destructive tool for the environmental sciences (Developments in Paleoenvironmental Research), Tracking Environmental Change Using Lake Sediments. Volume 2: Physical and Geochemical Methods. doi: 10.1007/978-94-017-9849-5.

Crundwell, M., Scott, G., Naish, T. and Carter, L. (2008) 'Glacial-interglacial ocean climate variability from planktonic foraminifera during the Mid-Pleistocene transition in the temperate Southwest Pacific, ODP Site 1123', Palaeogeography, Palaeoclimatology, Palaeoecology, 260(1-2), pp. 202-229. doi: 10.1016/j.palaeo.2007.08.023.

DeMaster, D. J. (1981) 'The supply and accumulation of silica in the marine environment' Geochimica et Cosmochimica acta, 45(10), pp.1715-1732.

Denton, G. H., Anderson, R. F., Toggweiler, J. R., Edwards, R. L., Schaefer, J. M. and Putnam, A. E. (2010) 'The last glacial termination.', Science (New York, N.Y.). American Association for the Advancement of Science, 328(5986), pp. 1652-6. doi: 10.1126/science. 1184119.

Deppeler, S. L. and Davidson, A. T. (2017) 'Southern Ocean Phytoplankton in a Changing Climate', Frontiers in Marine Science. Frontiers, 4, p. 40. doi: 10.3389/fmars.2017.00040.

Dickson, A. J., Leng, M. J., Maslin, M. A. and Röhl, U. (2010) 'Oceanic, atmospheric and ice-sheet forcing of South East Atlantic Ocean productivity and South African monsoon intensity during MIS-12 to 10', Quaternary Science Reviews. Pergamon, 29(27-28), pp. 3936-3947. doi: 10.1016/J.QUASCIREV.2010.09.014.

Dieckmann, G. S., Spindler, M., Lange, M. A., Ackley, S. F. and Eicken, H. (1991) 'Antarctic sea ice; a habitat for the foraminifer Neogloboquadrina pachyderma', The Journal of Foraminiferal Research, 21(2), pp. 182-189. doi: 10.2113/gsjfr.21.2.182.

Diekmann, B., Fütterer, D., Grobe, H., Hillenbrand, C.-D., Kuhn, G., Michels, K., Petschick, R. and Pirrung, M. (2004) 'Terrigenous sediment supply in the polar to temperate South Atlantic: Land-ocean links of environmental changes during the late Quaternary', The South Atlantic in the ..., pp. 375-399. doi: 10.1007/978-3-642-18917- 
$3 \_18$.

Diekmann, B. and Kuhn, G. (2002) 'Sedimentary record of the mid-Pleistocene climate transition in the southeastern South Atlantic (ODP Site 1090)', Palaeogeography, Palaeoclimatology, Palaeoecology, 182(3-4), pp. 241-258. doi: 10.1016/S00310182(01)00498-9.

Dubois, N., Kienast, M., Kienast, S., Calvert, S. E., Franois, R. and Anderson, R. F. (2010) 'Sedimentary opal records in the eastern equatorial Pacific: It is not all about leakage', Global Biogeochemical Cycles, 24(4), p. n/a-n/a. doi: 10.1029/2010GB003821.

Duncan, B., Carter, L., Dunbar, G., Bostock, H., Neil, H., Scott, G., Hayward, B. W. and Sabaa, A. (2016) 'Interglacial/glacial changes in coccolith-rich deposition in the SW Pacific Ocean: An analogue for a warmer world?', Global and Planetary Change. Elsevier B.V., 144, pp. 252-262. doi: 10.1016/j.gloplacha.2016.08.001.

Durak, G. M., Taylor, A. R., Walker, C. E., Probert, I., de Vargas, C., Audic, S., Schroeder, D., Brownlee, C. and Wheeler, G. L. (2016) 'A role for diatom-like silicon transporters in calcifying coccolithophores', Nature Communications, 7, p. 10543. doi: 10.1038/ncomms 10543 .

Dutton, A., Carlson, A. E., Long, A. J., Milne, G. A., Clark, P. U., DeConto, R., Horton, B. P., Rahmstorf, S. and Raymo, M. E. (2015) 'Sea-level rise due to polar ice-sheet mass loss during past warm periods', Science, 349(6244). doi: 10.1126/science.aaa4019.

Fernandez, D., Bowen, M. and Carter, L. (2013) 'Do winds control the confluence of subtropical and subantarctic surface waters east of New Zealand ?', 15(April), p. 6444

Ferry, A. J., Crosta, X., Quilty, P. G., Fink, D., Howard, W. and Armand, L. K. (2015) 'First records of winter sea ice concentration in the southwest Pacific sector of the Southern Ocean', Paleoceanography, 30(11), pp. 1525-1539. doi: 10.1002/2014PA002764.

Fraser, C. I., Nikula, R., Spencer, H. G. and Waters, J. M. (2009) 'Kelp genes reveal effects of subantarctic sea ice during the Last Glacial Maximum', Proceedings of the National Academy of Sciences, 106(9), pp. 3249-3253. doi: 10.1073/pnas.0810635106.

Fung, I. Y., Meyn, S. K., Tegen, I., Doney, S. C., John, J. G. and Bishop, J. K. B. (2000) 'Iron supply and demand in the upper ocean', Global Biogeochemical Cycles, 14(1), pp. 281-295. doi: 10.1029/1999GB900059. 
Gersonde, R., Crosta, X., Abelmann, A. and Armand, L. (2005) 'Sea-surface temperature and sea ice distribution of the Southern Ocean at the EPILOG Last Glacial Maximum A circum-Antarctic view based on siliceous microfossil records', Quaternary Science Reviews, 24(7-9 SPEC. ISS.), pp. 869-896. doi: 10.1016/j.quascirev.2004.07.015.

Gersonde, R. and Zielinski, U. (2000) 'The reconstruction of late Quaternary Antarctic sea-ice distribution - the use of diatoms as a proxy for sea-ice', Palaeogeography, Palaeoclimatology, Palaeoecology. Elsevier, 162(3-4), pp. 263-286. doi: 10.1016/S0031-0182(00)00131-0.

Gladstone, R. M., Bigg, G. R. and Nicholls, K. W. (2001) 'Iceberg trajectory modeling and meltwater injection in the Southern Ocean', Journal of Geophysical Research: Oceans, 106(C9), pp. 19903-19915. doi: 10.1029/2000JC000347.

Gottschalk, J., Skinner, L. C., Lippold, J., Vogel, H., Frank, N., Jaccard, S. L. and Waelbroeck, C. (2016) 'Biological and physical controls in the Southern Ocean on past millennial-scale atmospheric CO2changes', Nature Communications, 7 . doi: 10.1038/ncomms11539.

Hasle, G.R. and Fryxell, G.A., (1970). Diatoms: cleaning and mounting for light and electron microscopy. Transactions of the American Microscopical Society, pp.469-474.

Hemleben, C., Spindler, M. and Anderson, O. R. (1989) Modern Planktonic Foraminifera. Springer New York. doi: 10.1007/978-1-4612-3544-6.

Hendry, K. R. and Brzezinski, M. A. (2014) 'Using silicon isotopes to understand the role of the Southern Ocean in modern and ancient biogeochemistry and climate', Quaternary Science Reviews. Elsevier Ltd, 89, pp. 13-26. doi: 10.1016/j.quascirev.2014.01.019.

Hilbrecht, H. (1997) 'Morphologic gradation and ecology in Neogloboquadrina pachyderma and N. dutertrei (planktic foraminifera) from core top sediments', Marine Micropaleontology. Elsevier, 31(1-2), pp. 31-43. doi: 10.1016/S0377-8398(96)00054-0.

Hillenbrand, C. D. and Cortese, G. (2006) 'Polar stratification: A critical view from the Southern Ocean', Palaeogeography, Palaeoclimatology, Palaeoecology, 242(3-4), pp. 240-252. doi: 10.1016/j.palaeo.2006.06.001.

Honjo, S. (2004) 'Particle export and the biological pump in the Southern Ocean', Antarctic Science. Cambridge University Press, 16(4), pp. 501-516. doi: $10.1017 / \mathrm{S} 0954102004002287$. 
Jaccard, S. L., Hayes, C. T., Martínez-García, A., Hodell, D. A., Anderson, R. F., Sigman, D. M. and Haug, G. H. (2013) 'Two modes of change in Southern Ocean productivity over the past million years.', Science (New York, N.Y.). American Association for the Advancement of Science, 339(6126), pp. 1419-23. doi: 10.1126/science.1227545.

Jin, P. and Gao, K. (2015) 'Reduced resilience of a globally distributed coccolithophore to ocean acidification: Confirmed up to 2000 generations', Marine pollution bulletin, 103(1), pp.101-108. doi: 10.1016/j.marpolbul.2015.12.039.

Jonkers, L., Van Heuven, S., Zahn, R. and Peeters, F. J. C. (2013) 'Seasonal patterns of shell flux, $\delta^{18} \mathrm{O}$ and $\delta^{13} \mathrm{C}$ of small and large N. pachyderma (s) and G. bulloides in the subpolar North Atlantic', Paleoceanography, 28(1), pp. 164-174. doi: 10.1002/palo.20018.

Kanfoush, S. L., Hodell, D. A., Charles, C. D., Guilderson, T. P., Mortyn, P. G. and Ninnemann, U. S. (2000) 'Millennial-scale instability of the Antartic ice sheet during the last glaciation', Science, 288, pp. 1815-1818.

Kienast, S. S., Kienast, M., Jaccard, S., Calvert, S. E. and François, R. (2006) 'Testing the silica leakage hypothesis with sedimentary opal records from the eastern equatorial Pacific over the last 150 kyrs', Geophysical Research Letters, 33(15), pp. 2-5. doi: 10.1029/2006GL026651.

Kohfeld, K. E., Fairbanks, R. G., Smith, S. L. and Walsh, I. D. (1996) 'Neogloboquadrina pachyderma (sinistral coiling) as paleoceanographic tracers in polar oceans: Evidence from Northeast Water Polynya plankton tows, sediment traps, and surface sediments.' Paleoceanography, 11(6), pp.679-699.

Kohfeld, K. E. and Harrison, S. P. (2001) 'DIRTMAP: The geological record of dust', Earth-Science Reviews. Elsevier, 54(1-3), pp. 81-114. doi: 10.1016/S00128252(01)00042-3.

Krumhardt, K. M., Lovenduski, N. S., Iglesias-Rodriguez, M. D. and Kleypas, J. A. (2017) 'Coccolithophore growth and calcification in a changing ocean', Progress in Oceanography. Pergamon, pp. 276-295. doi: 10.1016/j.pocean.2017.10.007.

Kucera, M., Weinelt, M., Kiefer, T., Pflaumann, U., Hayes, A., Weinelt, M., Chen, M. Te, Mix, A. C., Barrows, T. T., Cortijo, E., Duprat, J., Juggins, S. and Waelbroeck, C. (2005) 'Reconstruction of sea-surface temperatures from assemblages of planktonic foraminifera: Multi-technique approach based on geographically constrained calibration 
data sets and its application to glacial Atlantic and Pacific Oceans', Quaternary Science Reviews. Pergamon, 24(7-9 SPEC. ISS.), pp. 951-998. doi: 10.1016/j.quascirev.2004.07.014.

Lamy, F., Gersonde, R., Winckler, G., Esper, O., Jaeschke, A., Kuhn, G., Ullermann, J., Martinez-Garcia, A., Lambert, F. and Kilian, R. (2014) 'Increased dust deposition in the Pacific Southern Ocean during glacial periods.', Science (New York, N.Y.). American Association for the Advancement of Science, 343(6169), pp. 403-7. doi: 10.1126/science. 1245424 .

Lisiecki, L. E. and Raymo, M. E. (2005) 'A Pliocene-Pleistocene stack of 57 globally distributed benthic $\delta 18$ O records', Paleoceanography, 20(1), p. n/a-n/a. doi: 10.1029/2004PA001071.

Mackensen, A. (2004) 'Changing Southern Ocean palaeocirculation and effects on global climate', Antarctic Science. Cambridge University Press, pp. 369-386. doi: 10.1017/S0954102004002202.

MacKintosh, A., Golledge, N., Domack, E., Dunbar, R., Leventer, A., White, D., Pollard, D., Deconto, R., Fink, D., Zwartz, D., Gore, D. and Lavoie, C. (2011) 'Retreat of the East Antarctic ice sheet during the last glacial termination', Nature Geoscience. Nature Publishing Group, 4(3), pp. 195-202. doi: 10.1038/ngeo1061.

Maher, B. A., Prospero, J. M., Mackie, D., Gaiero, D., Hesse, P. P. and Balkanski, Y. (2010) 'Global connections between aeolian dust, climate and ocean biogeochemistry at the present day and at the last glacial maximum', Earth-Science Reviews, 99(1-2), pp. 61-97. doi: 10.1016/j.earscirev.2009.12.001.

Manton, W. I., Grew, E. S., Hofmann, J. and Sheraton, J. W. (1992) 'Granitic rocks ofJetty Peninsula, Amery Ice Shelf, East Antarctica', Recent Progress in Antarctic Earth Science:edited by Y.Yoshida et al., pp. 179-189.

Marshall, G. J. (2003) 'Trends in the Southern Annular Mode from observations and reanalyses', Journal of Climate, 16(24), pp. 4134-4143. doi: 10.1175/15200442(2003)016<4134:TITSAM>2.0.CO;2.

Martin, J. H. (1990) 'Glacial-interglacial CO 2 change: The Iron Hypothesis', Paleoceanography, 5(1), pp. 1-13. doi: 10.1029/PA005i001p00001.

Martinez-Garcia, A., Sigman, D. M., Ren, H., Anderson, R. F., Straub, M., Hodell, D. A., 
Jaccard, S. L., Eglinton, T. I. and Haug, G. H. (2014) 'Iron Fertilization of the Subantarctic Ocean During the Last Ice Age', Science, 343(6177), pp. 1347-1350. doi: $10.1126 /$ science. 1246848 .

Matsumoto, K., Sarmiento, J. L. and Brzezinski, M. A. (2002) 'Silicic acid leakage from the Southern Ocean: A possible explanation for glacial atmospheric p CO 2', Global Biogeochemical Cycles, 16(3), pp. 5-1-5-23. doi: 10.1029/2001GB001442.

McCave, I. N., Carter, L. and Hall, I. R. (2008) 'Glacial-interglacial changes in water mass structure and flow in the SW Pacific Ocean', Quaternary Science Reviews. Pergamon, 27(19-20), pp. 1886-1908. doi: 10.1016/J.QUASCIREV.2008.07.010.

McCave, I. N., Crowhurst, S. J., Kuhn, G., Hillenbrand, C.-D. and Meredith, M. P. (2014) 'Minimal change in Antarctic Circumpolar Current flow speed between the last glacial and Holocene', Nature Geoscience, 7(2), pp. 113-116. doi: 10.1038/ngeo2037.

McIntyre, A. and Bé, A. W. H. (1967) 'Modern coccolithophoridae of the atlantic ocean-I. Placoliths and cyrtoliths', Deep Sea Research and Oceanographic Abstracts. Elsevier, 14(5), pp. 561-597. doi: 10.1016/0011-7471(67)90065-4.

McKay, R., Naish, T., Carter, L., Riesselman, C., Dunbar, R., Sjunneskog, C., Winter, D., Sangiorgi, F., Warren, C., Pagani, M., Schouten, S., Willmott, V., Levy, R., DeConto, R. and Powell, R. D. (2012) 'Antarctic and Southern Ocean influences on Late Pliocene global cooling', Proceedings of the National Academy of Sciences, 109(17), pp. 64236428. doi: 10.1073/pnas.1112248109.

Merino, N., Le Sommer, J., Durand, G., Jourdain, N. C., Madec, G., Mathiot, P. and Tournadre, J. (2016) 'Antarctic icebergs melt over the Southern Ocean : Climatology and impact on sea ice', Ocean Modelling. Elsevier, pp. 99-110. doi: 10.1016/j.ocemod.2016.05.001.

Minas, H. and Minas, M. (1992) 'Net community production in high nutrient-low chlorophyll waters of the tropical and antarctic oceans - grazing vs iron hypothesis', Oceanologica Acta, 15(2), pp. 145-162.

Mitchell, B. G., Brody, E. A., Holm-Hansen, O., McClain, C. and Bishop, J. (1991) 'Light limitation of phytoplankton biomass and macronutrient utilization in the Southern Ocean', Limnology and Oceanography, 36(8), pp. 1662-1677. doi: 10.4319/1o.1991.36.8.1662. 
Mortlock, R. A. and Froelich, P. N. (1989) 'A simple method for the rapid determination of biogenic opal in pelagic marine sediments' Deep Sea Research Part A. Oceanographic Research Papers, 36(9), pp.1415-1426.

Neil, H. L., Carter, L. and Morris, M. Y. (2004) 'Thermal isolation of Campbell Plateau, New Zealand, by the Antarctic Circumpolar Current over the past 130 kyr', Paleoceanography, 19(4), pp. 1-17. doi: 10.1029/2003PA000975.

O’Leary, M. J., Hearty, P. J., Thompson, W. G., Raymo, M. E., Mitrovica, J. X. and Webster, J. M. (2013) 'Ice sheet collapse following a prolonged period of stable sea level during the last interglacial', Nature Geoscience, 6. doi: 10.1038/NGEO1890.

Orsi, A. H., Whitworth, T. and Nowlin, N. D. J. (1995) 'On the meridional extent and frontsof the Antartic Circumpolar Current', Deep-Sea Research I, 42(5), pp. 641-673. Available at: https://ac.els-cdn.com/096706379500021W/1-s2.0-096706379500021Wmain.pdf? tid=ed53eaec-feef-11e7-be9f00000aab0f27\&acdnat=1516569389_c9f964ce58d0375c006667a966f25db2 (Accessed: 22 January 2018).

Paillard, Didier \& Labeyrie, Laurent \& Yiou, P. (1996). Macintosh Program performs time-series analysis. Eos, Transactions American Geophysical Union 77, (39) 379-379. $10.1029 / 96 \mathrm{EO} 00259$.

Phillips, H. E. and Rintoul, S. R. (2002) 'A Mean Synoptic View of the Subantarctic Front South of Australia', Journal of Physical Oceanography, 32(5), pp. 1536-1553. doi: 10.1175/1520-0485(2002)032<1536:AMSVOT>2.0.CO;2.

Pichon, J., Labracherie, M., Labeyrie, L. and Duprat, J. (1987) 'TRANSFER FUNCTIONS BETWEEN DIATOM ASSEMBLAGES AND SURFACE HYDROLOGY IN THE SOUTHERN OCEAN', Elsevier Science Publishers B.V, 61, pp. 79-95. Available at: https://ac.els-cdn.com/0031018287900411/1-s2.00031018287900411-main.pdf?_tid=1f0638a8-fa52-11e7-9b6600000aab0f27\&acdnat=1516061807_d043a84539fd76b46572504b2cfaaaa0 (Accessed: 16 January 2018).

Prasanna, K., Ghosh, P., Bhattacharya, S. K., Mohan, K. and Anilkumar, N. (2016) 'Isotopic disequilibrium in Globigerina bulloides and carbon isotope response to productivity increase in Southern Ocean', Nature Publishing Group. doi: $10.1038 /$ srep21533. 
Pudsey, C. . (2000) 'Sedimentation on the continental rise west of the Antarctic Peninsula over the last three glacial cycles', Marine Geology. Elsevier, 167(3-4), pp. 313-338. doi: 10.1016/S0025-3227(00)00039-6.

Raiswell, R., Benning, L. G., Tranter, M. and Tulaczyk, S. (2008) 'Bioavailable iron in the Southern Ocean: the significance of the iceberg conveyor belt', Geochemical Transactions. Nature Publishing Group, 9(1), p. 7. doi: 10.1186/1467-4866-9-7.

Rhodes, L. L., Peake, B. M., Lincoln MacKenzie, A., Marwick, S. and Lincoln Mackenzie, A. (1995) 'Coccolithophores Gephyrocapsa oceanica and Emiliania huxleyi (Prymnesiophyceae $=$ Haptophyceae) in New Zealand's coastal waters: Characteristics of blooms and growth in laboratory culture', New Zealand Journal of Marine and Freshwater Research, 293(29), pp. 345-357. doi: 10.1080/00288330.1995.9516669doi.org/10.1080/00288330.1995.9516669.

Riebesell, U., Zondervan, I., Rost, B., Tortell, P. D., Zeebe, R. E. and Morel, F. M. M. (2000) 'Reduced calcification of marine plankton in response to increased atmospheric $\mathrm{CO}_{2}$ ', Nature. Nature Publishing Group, 407(6802), pp. 364-367. doi: $10.1038 / 35030078$.

Rintoul, S. R., Sokolov, S., Williams, M. J. M., Peña Molino, B., Rosenberg, M. and Bindoff, N. L. (2014) 'Antarctic Circumpolar Current transport and barotropic transition at Macquarie Ridge', Geophysical Research Letters, 41(20), pp. 7254-7261. doi: 10.1002/2014GL061880.

Rintoul, S. R., Speer, K., Sparrow, M., Meredith, M., Hofmann, E., Fahrbach, E., Summerhayes, C., Worby, A., England, M., Bellerby, R. G. J., Speich, S., Costa, D., Hall, J., Hindell, M., Hosie, G., Stansfield, K., Fukamachi, Y., ... Gladyshev, S. (2010) 'Southern Ocean Observing System (SOOS): Rationale and strategy for sustained observations of the Southern Ocean', Proceedings of OceanObs'09: Sustained Ocean Observations and Information for Society (Vol. 2), (1). doi: 10.5270/OceanObs09.cwp.74.

Robinson, R. S. and Sigman, D. M. (2008) 'Nitrogen isotopic evidence for a poleward decrease in surface nitrate within the ice age Antarctic', Quaternary Science Reviews, 27(9-10), pp. 1076-1090. doi: 10.1016/j.quascirev.2008.02.005.

Robinson, R. S., Sigman, D. M., DiFiore, P. J., Rohde, M. M., Mashiotta, T. A. and Lea, D. W. (2005) 'Diatom-bound 15N/14N: New support for enhanced nutrient consumption 
in the ice age subantarctic', Paleoceanography, 20(3), pp. 1-14. doi: 10.1029/2004PA001114.

Romero, O. E., Armand, L. K., Crosta, X. and Pichon, J. J. (2005) 'The biogeography of major diatom taxa in Southern Ocean surface sediments: 3. Tropical/Subtropical species', Palaeogeography, Palaeoclimatology, Palaeoecology, 223(1-2), pp. 49-65. doi: 10.1016/j.palaeo.2005.03.027.

Rost, B. and Riebesell, U. (2004) 'Coccolithophores and the biological pump: Responses to environmental changes', Coccolithophores: From Molecular Processes to Global Impact, pp. 99-125. doi: 10.1007/978-3-662-06278-4_5.

Rousseau, J., Ellwood, M.J., Bostock, H. and Neil, H., (2016). Estimates of late Quaternary mode and intermediate water silicic acid concentration in the Pacific Southern Ocean. Earth and Planetary Science Letters, 439, pp.101-108

Schlitzer, R., (2014) Ocean Data View, http://odv.awi.de, 2014.

Schneider, R. R., Müller, P. J. and Wefer, G. (1994) 'Late Quaternary paleoproductivity changes off the Congo deduced from stable carbon isotopes of planktonic foraminifera', Palaeogeography, Palaeoclimatology, Palaeoecology. Elsevier, 110(3-4), pp. 255-274. doi: 10.1016/0031-0182(94)90087-6.

Shukla, S. K., Crosta, X., Cortese, G. and Nayak, G. N. (2013) 'Climate mediated size variability of diatom Fragilariopsis kerguelensis in the Southern Ocean' Quaternary Science Reviews, 69, pp.49-58.

Sigman, D. M. and Boyle, E. A. (2000) 'Glacial/interglacial variations in atmospheric carbon dioxide', Nature. Nature Publishing Group, 407(6806), pp. 859-869. doi: $10.1038 / 35038000$.

Sigman, D. M., Hain, M. P. and Haug, G. H. (2010) 'The polar ocean and glacial cycles in atmospheric CO2 concentration', Nature, pp. 47-55. doi: 10.1038/nature09149.

Skinner, L. C., Fallon, S., Waelbroeck, C., Michel, E. and Barker, S. (2010) 'Ventilation of the deep Southern Ocean and deglacial CO2 rise.', Science (New York, N.Y.). American Association for the Advancement of Science, 328(5982), pp. 1147-51. doi: 10.1126/science. 1183627 . 
Smith, H. E. K., Poulton, A. J., Garley, R., Hopkins, J., Lubelczyk, L. C., Drapeau, D. T., Rauschenberg, S., Twining, B. S., Bates, N. R. and Balch, W. M. (2017) 'The influence of environmental variability on the biogeography of coccolithophores and diatoms in the Great Calcite Belt', Biogeosciences, 14(21), pp. 4905-4925. doi: 10.5194/bg-14-49052017.

Sokolov, S. and Rintoul, S. R. (2007) 'Multiple Jets of the Antarctic Circumpolar Current South of Australia*', Journal of Physical Oceanography, 37(5), pp. 1394-1412. doi: 10.1175/JPO3111.1.

Sokolov, S. and Rintoul, S. R. (2009) 'Circumpolar structure and distribution of the antarctic circumpolar current fronts: 1. Mean circumpolar paths', Journal of Geophysical Research: Oceans, 114(11). doi: 10.1029/2008JC005108.

Sokolov, S., Rintoul, S. R. and Wienecke, B. (2006) 'Tracking the Polar Front south of New Zealand using penguin dive data', Deep-Sea Research Part I: Oceanographic Research Papers, 53(4), pp. 591-607. doi: 10.1016/j.dsr.2005.12.012.

Spindler, M. (1996) 'ON THE SALINITY TOLERANCE OF THE PLANKTONIC FORAMINIFER NEOGLOBOQUADRINA PACHYDERMA FROM ANTARCTIC SEA ICE (17th Symposium on ...', Polar Biology, 9, pp. 85-91. Available at: http://citeseerx.ist.psu.edu/viewdoc/download?doi=10.1.1.599.8961\&rep=rep1\&type $=$ p df (Accessed: 13 January 2018).

Spindler, M. and Dieckmann, G. S. (1986) 'Distribution and abundance of the planktic foraminifer Neogloboquadrina pachyderma in sea ice of the Weddell Sea (Antarctica)', Polar Biology. Springer-Verlag, 5(3), pp. 185-191. doi: 10.1007/BF00441699.

Stephens, B. B. and Keeling, R. F. (2000) 'The influence of Antarctic sea ice on glacialinterglacial CO2 variations', Nature, 404(6774), pp. 171-174. doi: 10.1038/35004556.

Studer, A. S., Sigman, D. M., Martínez-García, A., Benz, V., Winckler, G., Kuhn, G., Esper, O., Lamy, F., Jaccard, S. L., Wacker, L., Oleynik, S., Gersonde, R. and Haug, G. H. (2015) 'Antarctic Zone nutrient conditions during the last two glacial cycles', Paleoceanography, 30(7), pp. 845-862. doi: 10.1002/2014PA002745.

Sturm, A. (2003) Dissertation: Changes in ocean circulation and carbonate chemistry in the Australian sector of the Southern Ocean during the last 500,000 years. Available at: http://oceanrep.geomar.de/1614/1/641_Sturm_2004_ChangesInOceanCirculationAnd_ Hschri_pubid5837.pdf(Accessed: 2 March 2018). 
Tang, Z., Shi, X., Zhang, X., Chen, Z., Chen, M. Te, Wang, X., Wang, H., Liu, H., Lohmann, G., Li, P., Ge, S. and Huang, Y. (2016) 'Deglacial biogenic opal peaks revealing enhanced Southern Ocean upwelling during the last 513 ka', Quaternary International. Elsevier Ltd, 425, pp. 445-452. doi: 10.1016/j.quaint.2016.09.020.

Toggweiler, J. R., Russell, J. L. and Carson, S. R. (2006) 'Midlatitude westerlies, atmospheric $\mathrm{CO} 2$, and climate change during the ice ages', Paleoceanography, 21(2). doi: 10.1029/2005PA001154.

Tolderlund, D. S. and Bé, A. W. H. (1971) Seasonal distribution of planktonic foraminifera in the western North Atlantic, Micropaleontology.

Tréguer, P., Nelson, D. M., Van Bennekom, A. J., Demaster, D. J., Leynaert, A. and Quéguiner, B. (1995) 'The silica balance in the world ocean: a reestimate.', Science (New York, N.Y.). American Association for the Advancement of Science, 268(5209), pp. 3759. doi: $10.1126 /$ science. 268.5209 .375 .

Varne, R., Brown, A.V. and Falloon, T., (2000). Macquarie Island: Its geology, structural history, and the timing and tectonic setting of its N-MORB to E-MORB magmatism.Special Papers-Geological society of America, pp.301-320. Varne, R., Brown, A.V. and Falloon, T., 2000. Macquarie Island: Its geology, structural history, and the timing and tectonic setting of its N-MORB to E-MORB magmatism.Special PapersGeological society of America, pp.301-320.

Watson, A. J., Bakker, D. C., Ridgwell, A. J., Boyd, P. W. and Law, C. S. (2000) 'Effect of iron supply on Southern Ocean $\mathrm{CO} 2$ uptake and implications for glacial atmospheric CO2.', Nature. Springer Cambridge Univ. Press, 407(October), pp. 730-733. doi: $10.1038 / 35037561$.

Watson, A. J. and Naveira Garabato, A. C. (2006) 'The role of Southern Ocean mixing and upwelling in glacial-interglacial atmospheric CO2change', Tellus, Series B: Chemical and Physical Meteorology, 58(1), pp. 73-87. doi: 10.1111/j.16000889.2005.00167.x.

Weaver, P. P. E., Carter, L. and Neil, H. L. (1998) 'Response of surface water masses and circulation to late Quaternary climate change east of New Zealand', Paleoceanography and Paleoclimatology, 13(1), pp. 70-83. doi: 10.1029/97PA02982.

Wells, P. and Okada, H. (1997) 'Response of nannoplankton to major changes in seasurface temperature and movements of hydrological fronts over Site DSDP 594 (south 
Chatham Rise, southeastern New Zealand), during the last 130 kyr', Marine Micropaleontology, 32(3-4), pp. 341-363. doi: 10.1016/S0377-8398(97)00025-X.

Wilks, J. V., Rigual-Hernández, A. S., Trull, T. W., Bray, S. G., Flores, J. A. and Armand, L. K. (2017) 'Biogeochemical flux and phytoplankton succession: A year-long sediment trap record in the Australian sector of the Subantarctic Zone', Deep-Sea Research Part I: Oceanographic Research Papers. Elsevier Ltd, 121(September 2016), pp. 143-159. doi: 10.1016/j.dsr.2017.01.001.

Wolff, E. W., Fischer, H., Fundel, F., Ruth, U., Twarloh, B., Littot, G. C., Mulvaney, R., Röthlisberger, R., De Angelis, M., Boutron, C. F., Hansson, M., Jonsell, U., Hutterli, M. A., Lambert, F., Kaufmann, P., Stauffer, B., Stocker, T. F., ... Gaspari, V. (2006) 'Southern Ocean sea-ice extent, productivity and iron flux over the past eight glacial cycles', Nature, 440(7083), pp. 491-496. doi: 10.1038/nature04614.

'World Ocean Database' (2005) Administrator, p. 164. doi: Available from http://www.nodc.noaa.gov/OC5/indprod.html. 


\section{Appendix A}

A1) $\mathrm{TAN} 1302-96 \mathrm{CaCO}_{3}$ content (wt \%) vs $\mathrm{Ca}$ concentration acquired from XRF

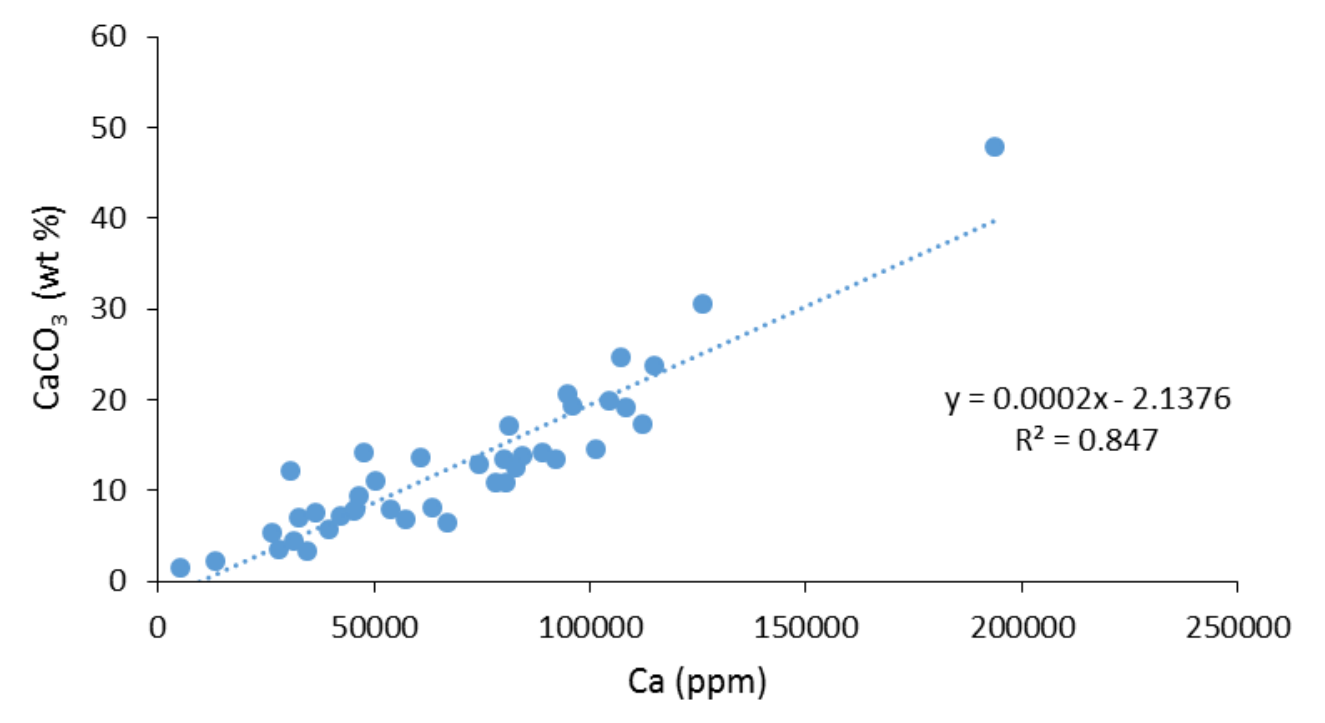

A2) $\mathrm{TAN} 1302-97 \mathrm{CaCO}_{3}$ content (wt \%) vs $\mathrm{Ca}$ concentrations acquired from $\mathrm{XRF}$

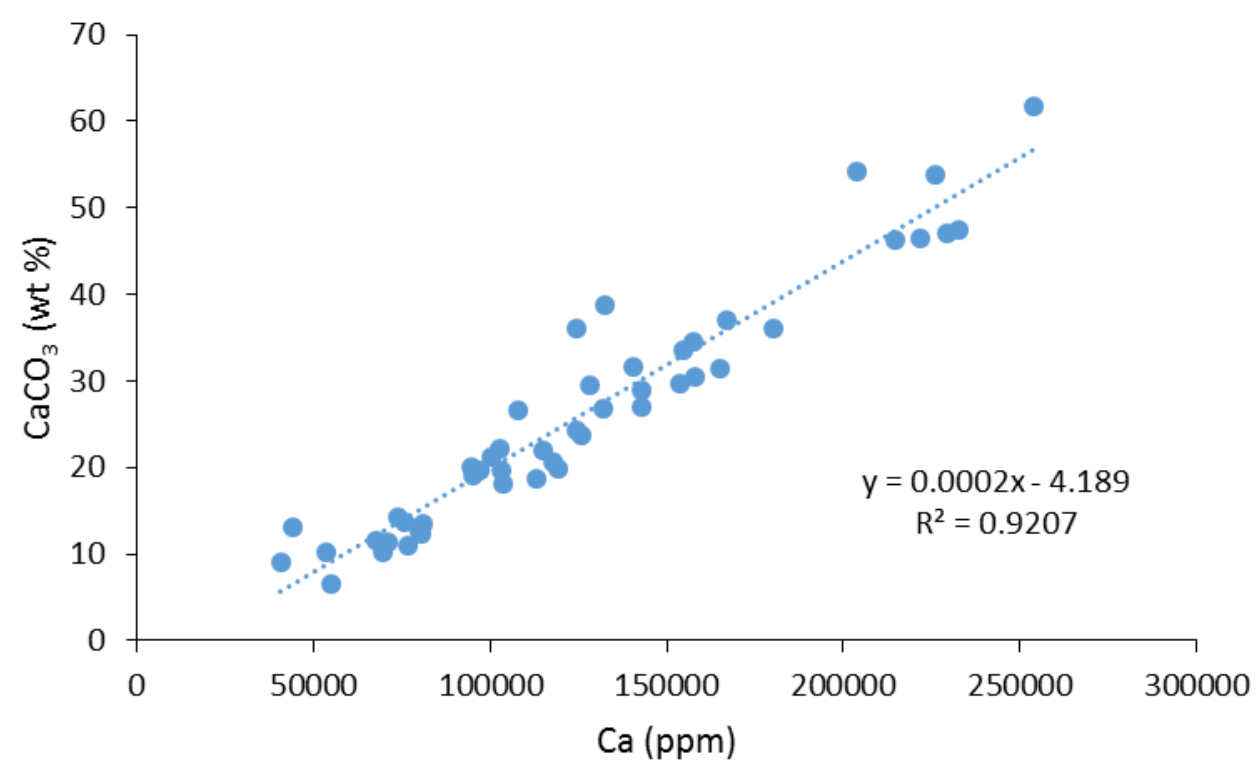


A3) Series of plots showing combined opal dataset for TAN1302-96 (blue) and TAN1302-97 (orange) against biogenic silica proxies, i.e. $\mathrm{Si}, \mathrm{Si} / \mathrm{Ti}$ and $\mathrm{Si} / \mathrm{Fe}$.
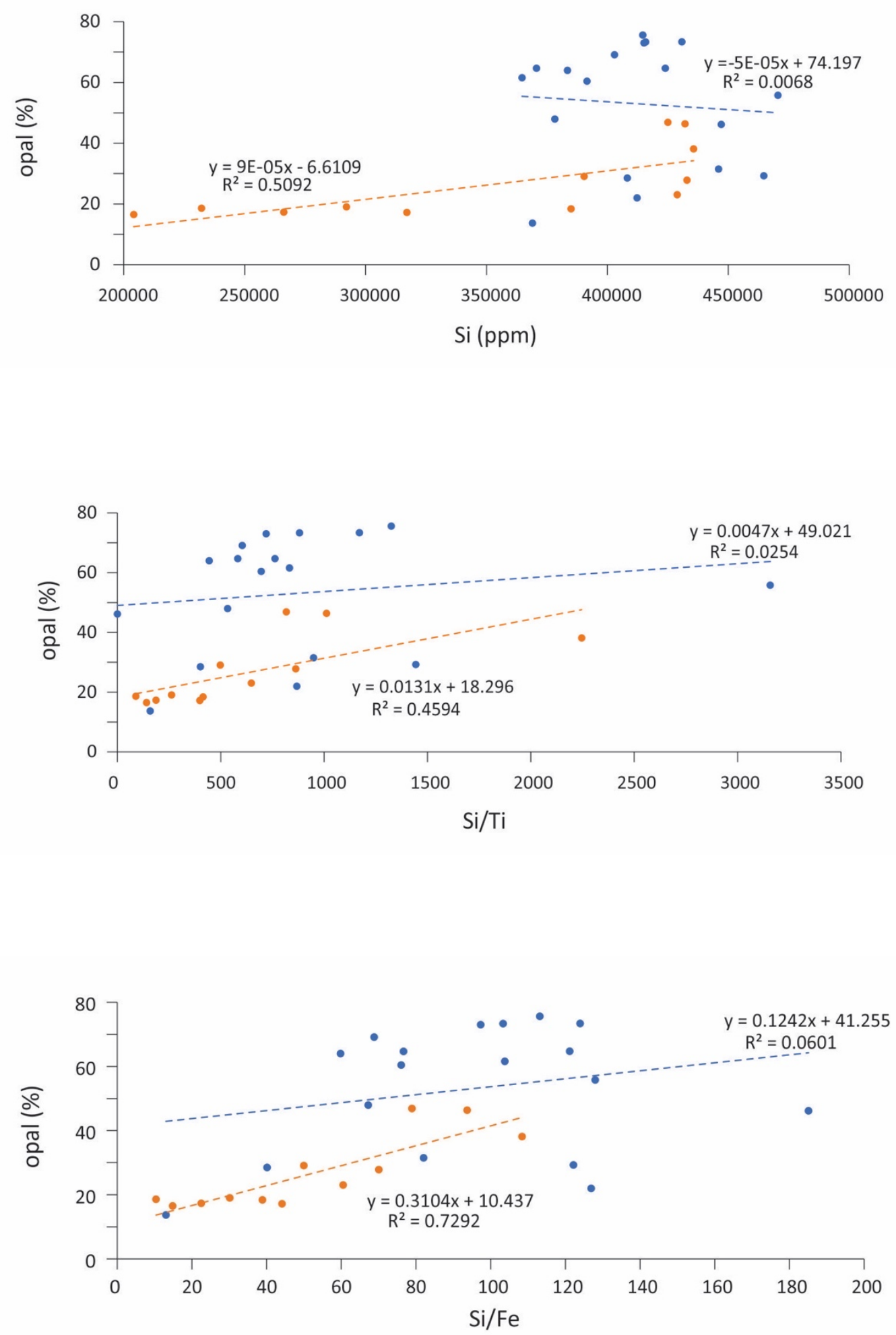
A4) Non-linear relationships between opal content vs $\mathrm{Si} / \mathrm{Fe}$ (bottom). Correlation coefficients improved in TAN1302-96 opal data from Tasmania (blue) and TAN1302-97 (orange) compared to linear relationships. Correlation between Dalhousie University opal data and Si/Fe in TAN1302-96 (blue with black outline) does not improve with non-linear regression.

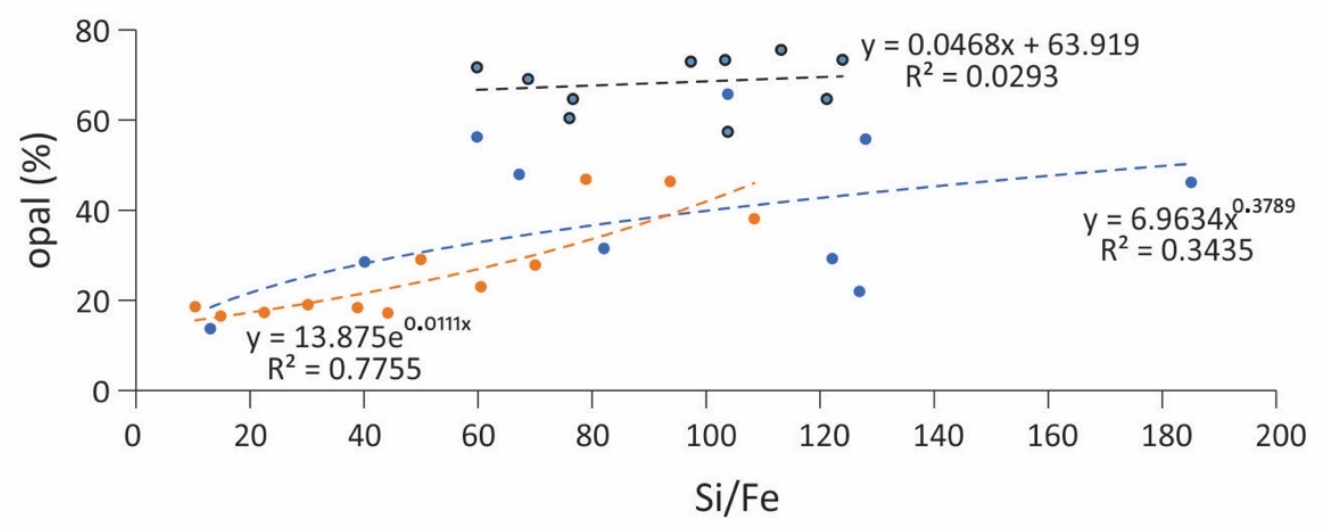

A5) Cross correlation between opal \% and the water content (\%) of TAN1302-96 (blue) and TAN1302-97. TAN1302-96 opal data from Dalhousie University outlined in black.

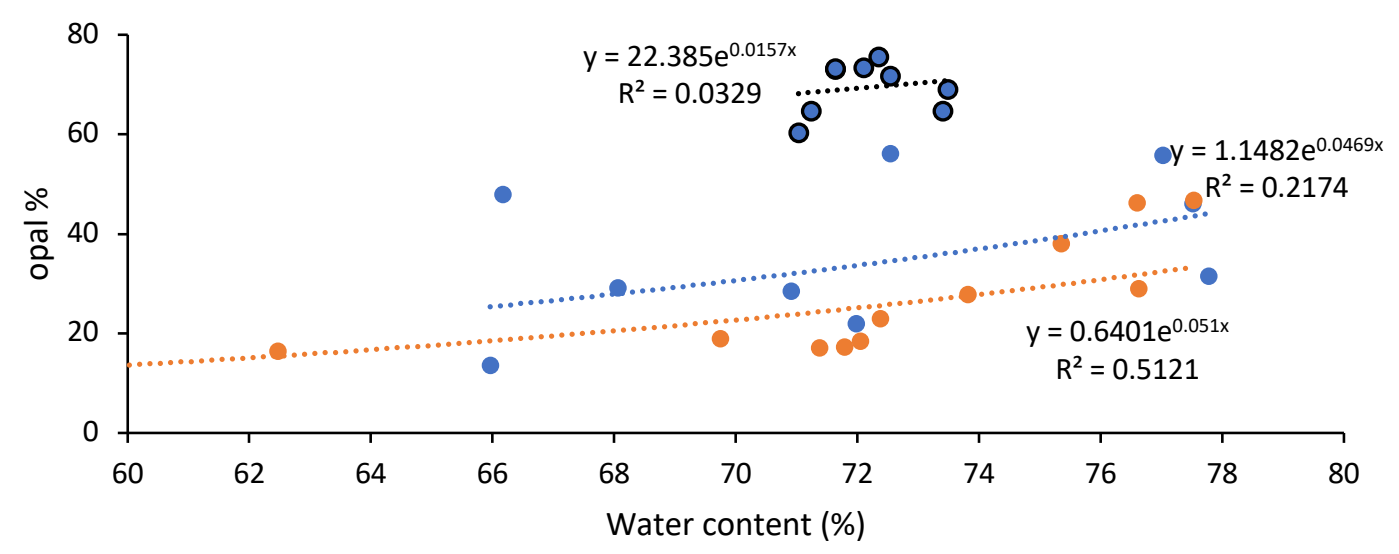


A6) TAN1302-96 $\delta^{18} \mathrm{O}$ record with the number of large $(>250 \mu \mathrm{m}) N$. pachyderma picked

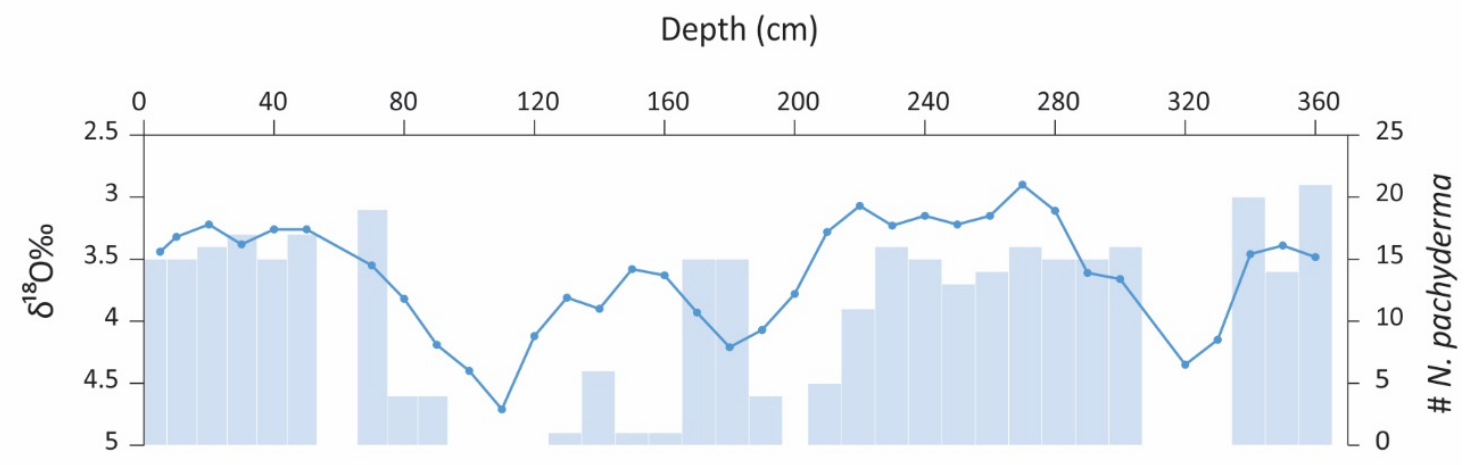

A7) TAN1302-97 $\delta^{18} \mathrm{O}$ record with the number of large $(>250 \mu \mathrm{m}) N$. pachyderma picked

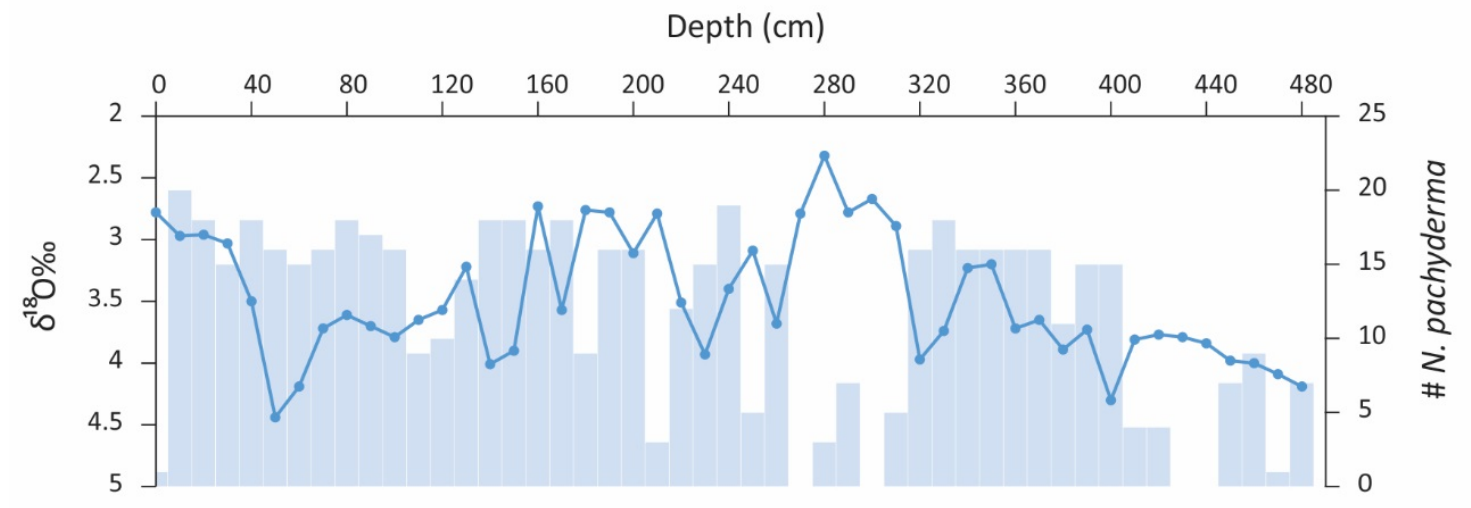

A8) Valve area comparison between MIS 5e $(270 \mathrm{~cm})$ and MIS $6(320 \mathrm{~cm})$ in TAN130296

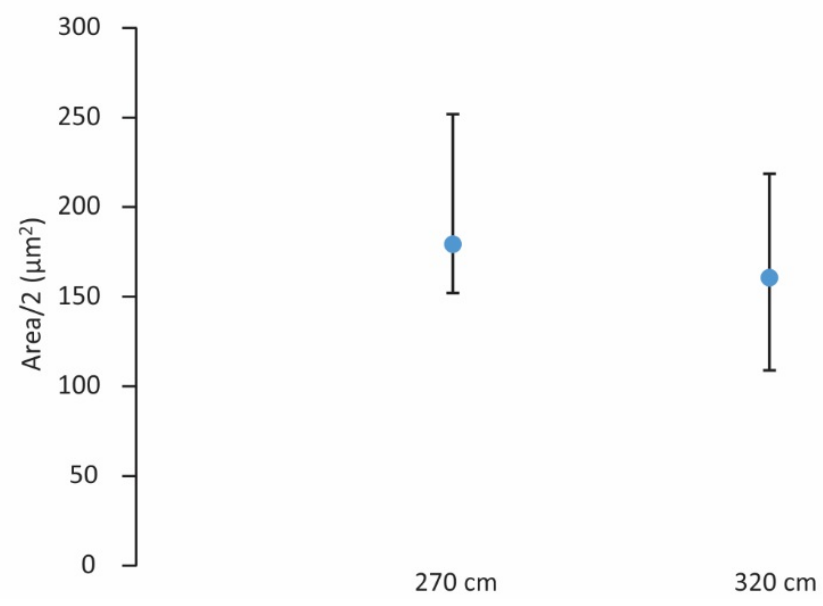


A9) Valve area comparison between MIS 5e $(210 \mathrm{~cm})$ and MIS 6 (230 cm) in TAN130297

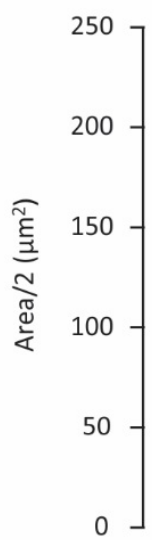

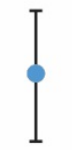

$210 \mathrm{~cm}$

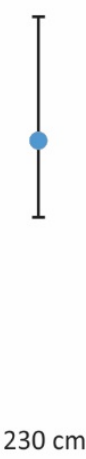

$230 \mathrm{~cm}$ 
A10) Elemental profiles in TAN1302-96 obtained via XRF scanning. Elements shown are associated with terrigenous input

TAN1302-96
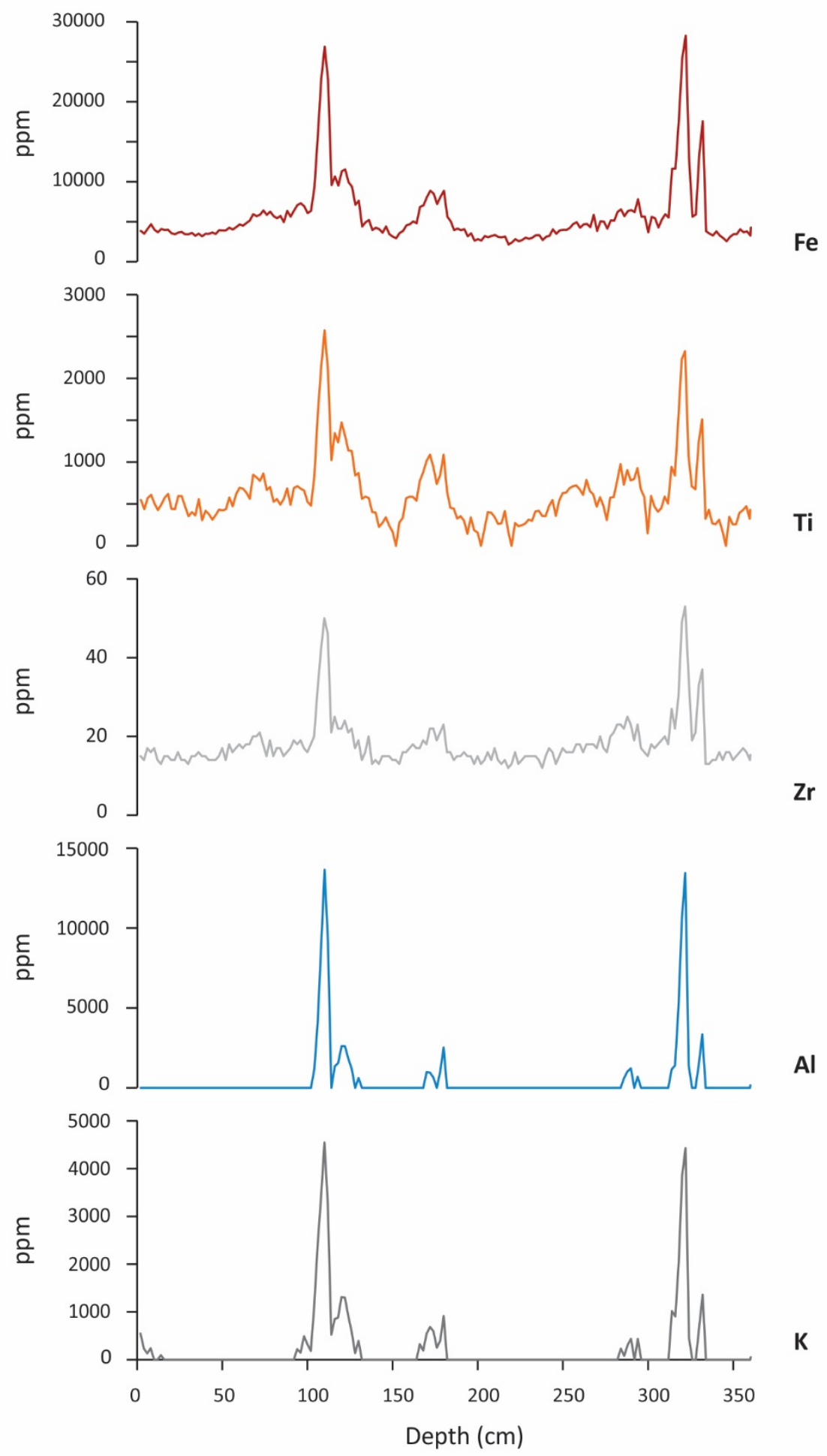
A11) Elemental profiles in TAN1302-97 obtained via XRF scanning. Elements shown are associated with terrigenous input

\section{TAN1302-97}
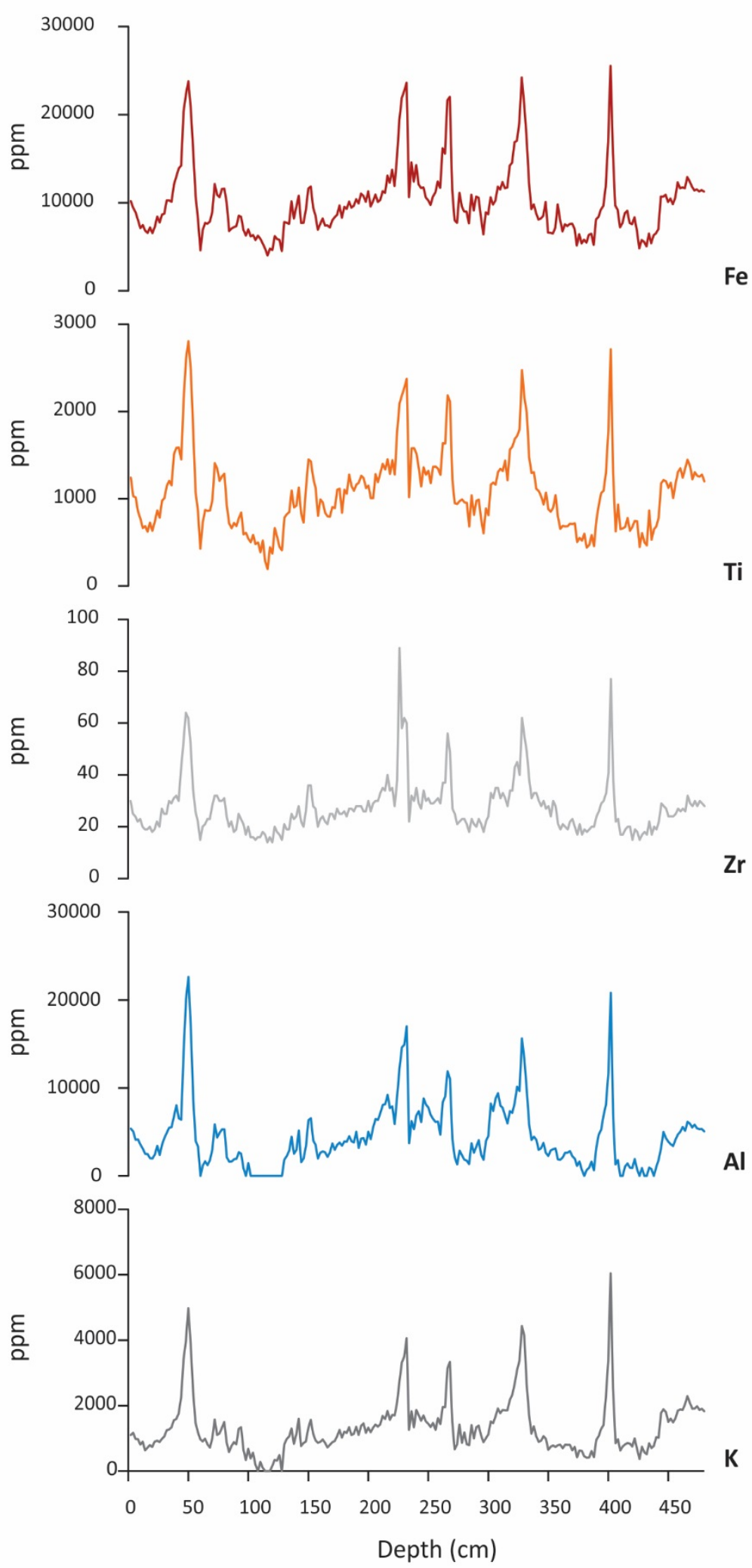


\section{Appendix B}

B1) Code used in OxCal to calibrate radiocarbon dates

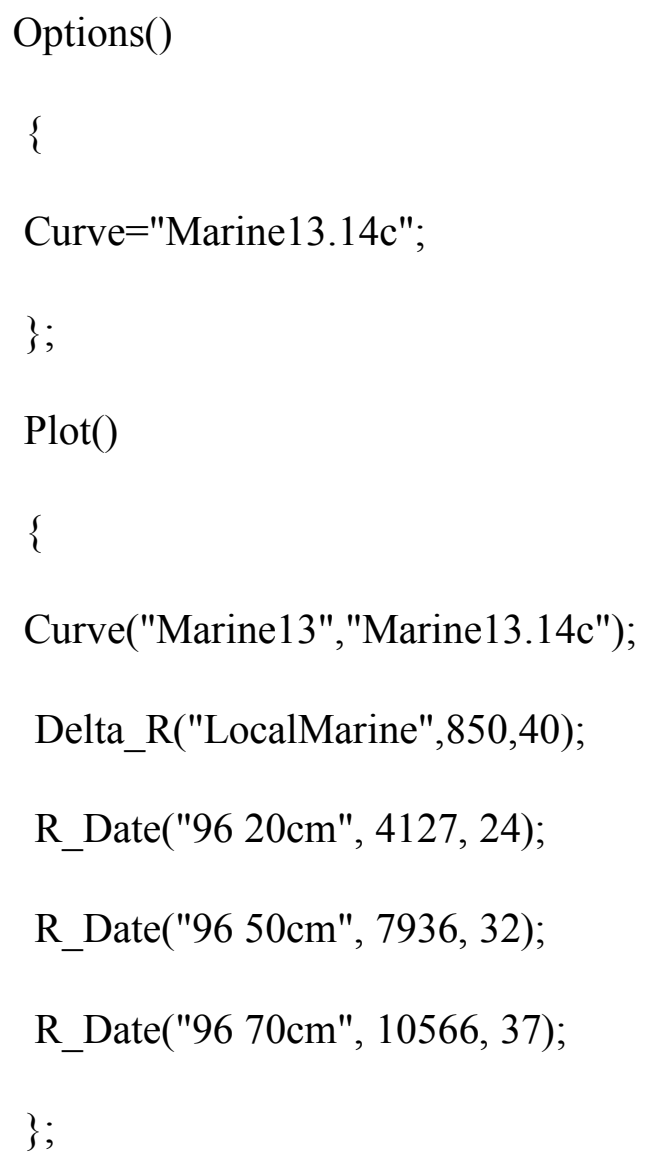

\section{Appendix C}

See CD 